\title{
Development of a Reduced Four-Component (Toluene/n-Heptane/iso- Octane/Ethanol) Gasoline Surrogate Model
}

\author{
Yang Li ${ }^{*}, 1$, Adamu Alfazazi ${ }^{1,2}$, Balaji Mohan ${ }^{1}$, Efstathios Alexandros Tingas ${ }^{1}$, Jihad Badra ${ }^{3}$, Hong G. Im ${ }^{1}$, S. Mani \\ Sarathy ${ }^{*}, 1$ \\ ${ }^{1}$ King Abdullah University of Science and Technology, Clean Combustion Research Center, Thuwal, Saudi Arabia \\ ${ }^{2}$ Department of Chemical Engineering, University of Jeddah, Jeddah 21589, Saudi Arabia \\ ${ }^{3}$ Fuel Technology Division, R\&DC, Saudi Aramco, Dhahran, Saudi Arabia
}

\begin{abstract}
The prospect of blending gasoline fuel with ethanol is being investigated as a potential way to improve the knock residence of the base gasoline. However, one of the drawbacks is a lack of proper understanding of the reason for the non-linear response of blending ethanol and gasoline. This nonlinearity could be better understood by an improved knowledge of the interactions of these fuel components at a molecular level. This study proposed a highly reduced four-component (toluene/nheptane/iso-octane/ethanol) gasoline surrogate model containing 59 species and 270 reactions. The model was reduced using the direct relation graph with expert knowledge (DRG-X) [1,2] and isomer lumping method. The computational singular perturbation (CSP) analysis were performed to reduce the potential stiffness issues by accordingly adjusting the Arrhenius coefficients of the proper reactions. The model has been comprehensively validated against wide range of ignition delay times (IDT) and flame speed (FS) measurement data as well as compared against two representative literature models from Liu et al. [3] and Wang et al. [4]. Overall, good agreements were observed between model predictions and experimental data across the entire research octane number (RON), equivalence ratio, pressure and temperature range. In addition, the model has also been coupled with the computational fluid dynamic (CFD) models to simulate the experimental data of constant volume reacting spray of a low-octane gasoline (Haltermann straight-run naphtha), and in-cylinder pressures and temperatures of a high-octane gasoline (Haltermann Gasoline) combustion in a heavy duty compression ignition engine. The coupled model can qualitatively predict the experimentally obtained data with an improved performance for PRF, TPRF, and TPRF-ethanol surrogates.
\end{abstract}

\footnotetext{
*Corresponding author: yang.li@kaust.edu.sa, mani.sarathy@kaust.edu.sa
} 


\section{Introduction}

Recent review papers by Kalghatgi et al. [5, 6] emphasized the essential role of the internal combustion engines (ICEs) in transportation sector in the foreseeable future. The use of gasoline fuels in spark ignition (SI) and compression ignition (CI) engines [7] can be improved by following a systematic fuel design approach linking combustion fundamentals with computational engineering and design. From a combustion perspective, one of the main challenges is to co-optimize engine and fuel to achieve both high efficiency and low emissions. Commercial fuels like gasoline, diesel, aviation kerosene etc. are complex mixtures of hundreds to thousands of hydrocarbons and oxygenated chemical species; therefore, simple and reliable surrogate mixtures are required to represent the corresponding commercial fuels for the further experimental or computational studies coupled with practical engines. The simplest and most widely used gasoline surrogates are Primary Reference Fuel (PRF) and Toluene Primary Reference Fuel (TPRF) surrogates, which are binary mixtures of isooctane and n-heptane, and ternary mixtures of PRF plus toluene. Sarathy et al. [7] reviewed the gasoline surrogate formulation approaches and the experimental and chemical kinetic studies on the relevant surrogates. Among these approaches, Kalghatgi et al. $[8,9]$ developed a method to define the composition of a TPRF by matching both research octane number (RON) and motor octane number (MON) of a target gasoline. Ahmed et al. [10] presented a computational method for formulating multicomponent surrogates by matching the fuel properties such as hydrogen/carbon $(\mathrm{H} / \mathrm{C})$ ratio, density, distillation characteristics, carbon types, RON etc. Jameel et al. [11] demonstrated a novel approach for surrogate formulation by emulating the functional groups of target gasoline fuels, while minimizing the number of surrogate species.

Nowadays, the use of oxygenated gasolines, such as blending oxygenates, methyl tertiary-butyl ether (MTBE), ethyl tert-butyl ether (ETBE), and ethanol added to regular gasoline, has grown significantly, as an attempt to improve the anti-knock quality [12] and to reduce the lifecycle (well-towheel) $\mathrm{CO}_{2}$ emission [13]. Lee et al. [14] performed the experimental and kinetic modelling studies of the auto-ignition behavior of two oxygenated certification gasolines: Haltermann $(\mathrm{RON}=91)$ and Coryton $(\mathrm{RON}=97.5)$. In this study, a quaternary surrogate (iso-octane, n-heptane, toluene and 
ethanol) was formulated to simulate the experimental results using detailed chemical kinetic model, and it was proved to be a promising surrogate which can reproduce the IDT of both fuels, especially for Coryton gasoline which has a high octane sensitivity ( $\mathrm{S}=\mathrm{RON}-\mathrm{MON})$.

A comprehensive literature review has been done regarding the reduced gasoline surrogate models published since 2000, they have been summarized in Table S1 in the Supplementary Material. The type of surrogates varies from the simplest two-component (iso-octane/n-heptane) PRF, threecomponent (toluene/iso-octane/n-heptane) TPRF, and additional multi-component surrogates. The size of model varies from dozens of species and hundreds to thousands of reactions. These models were validated against different targets including ignition delay times (IDT), flame speeds (FS), speciation profiles measured from flow reactors and premixed flames under different conditions.

Most recently, Sarathy et al. [15] presented a skeletal TPRF model with 76 species and 401 reactions, which was developed using the direct relation graph with expert knowledge (DRG-X) [1,2] and isomer lumping method. Building on this model, the present study aims to develop a four-component (toluene/n-heptane/iso-octane/ethanol) - TPRF-Ethanol gasoline surrogate model with even fewer number of species and reactions for use in more computationally demanding multi-dimensional CFD model. This model has been systematically validated against a wide range of IDT and FS measurement data available in literature. In addition, the developed kinetic model was then implemented in CFD simulations of a low-octane gasoline combustion in both constant volume reactor and heavy duty compression ignition engine. All the simulation results were compared against the results by Liu et al. [3] and Wang et al. [4].

\section{Computational Methods}

\section{Model reduction approach}

In our previous study [15], a three component TPRF kinetic model with 80 species and 414 reactions (including NOx) is developed and fully validated. Here, the goal is to develop a fourcomponent TPRF-E model with a smaller number of species and reactions for multi-dimensional CFD 
applications. Targeted conditions include low, intermediate and high-temperature chemistry regimes that are encountered in engine combustion.

First, a skeletal ethanol sub-mechanism was added to the recently developed TPRF model in [15], which was generated manually, which includes three more species: $\mathrm{C}_{2} \mathrm{H}_{5} \mathrm{OH}, \mathrm{SC}_{2} \mathrm{H}_{4} \mathrm{OH}$ and $\mathrm{CH}_{3} \mathrm{CHO}$, and the relevant high temperature reaction classes ( $\mathrm{H}$-atom abstraction and radical beta-scission). Combined, the detailed TPRF + ethanol mechanism consists of 83 species, which was further reduced to 59 species using a second round of DRG-X reduction [2].

As reported in [15], decoupling approach is based on the assumption that heat release, flame speeds, extinction and emissions of unburnt $\mathrm{HC}, \mathrm{CO} \& \mathrm{NOx}$ strongly depend on the chemistry of $\mathrm{H}_{2} / \mathrm{CO} / \mathrm{C}_{1}$ and that of small radicals. These properties could be predicted by inclusion of detailed $\mathrm{H}_{2} / \mathrm{CO} / \mathrm{C}_{1}$ mechanism and reduced $\mathrm{C}_{2}-\mathrm{C}_{3}$ mechanism. In DRG-X, it is assumed that some species are weakly coupled to others, so they have little contributions to the reaction pathways and thus can be eliminated [2, 16-18]. A list of starting species is first developed, and then all species that are irrelevant to the species are removed based on a user-specified error threshold. Additional conditions of interest, such as the equivalence ratios, temperature and pressure are specified. In this study, targeted conditions for reduction include: high/low temperature $(600-1300 \mathrm{~K})$, high pressure $(5-50 \mathrm{~atm})$; lean to reach equivalence ratio and the error for heat release is specified as 0.5 .

\section{Stiffness analysis with computational singular perturbation}

The development procedure of the introduced reduced model included a stiffness analysis. The main goal of this step was to reduce as much as possible the model's stiffness by accordingly adjusting the Arrhenius coefficients of the proper reactions, i.e., the reactions contributing to the generation of the fastest chemical timescales. This tuning procedure is of paramount importance, since the fastest chemical timescales are those that control the necessary time step in explicit solvers of computational fluid dynamics (CFD) codes. As a result, the faster the chemical timescales, the more expensive the simulation's computational cost. Despite its high significance, this procedure is not commonly 
practiced in the community as of today. To our knowledge, this is the first study to formally follow the procedure during the development of a reduced chemical kinetics model.

The analysis was performed in the general framework of the computational singular perturbation (CSP) approach [1, 19], an algorithmic method of asymptotic analysis which has been successfully employed in the context of reacting flows for model reduction [20-23], for the identification of the key processes and species in auto-igniting systems [24-33] and flames [34-36] and for the characterization of the flame topology in the context of DNS $[37,38]$.

According to the CSP theory, the system of the species $\mathrm{N}$ and energy governing equations is transformed into a new form by means of the CSP basis vectors, which in the current study are approximated by the right eigenvectors of the Jacobian $J$ of the chemical source term $[1,19]$. In the CSP form, the system is decomposed into $N+1$ CSP modes. Each of the CSP modes is described by two quantities: (i) a timescale, which sets the timeframe of the action of that mode and (ii) an amplitude, which signifies the impact of that mode to the system's slow evolution. The timescale of the $i$-th mode can be approximated by the inverse norm of the related $i$-th eigenvalue, i.e., $\tau_{i}=\frac{1}{\left|\lambda_{i}\right|}[1,19]$. The positive and negative real parts of the eigenvalues represents explosive and dissipative nature of the process, respectively. By definition, fast timescales relate to eigenvalues with large norms. The timescale participation index (TPI) is an algorithmic tool which identifies the chemical reactions that contribute to the generation of each timescale/eigenvalue [24-33]. In the current study, the TPI tool has been used in order to identify the reactions that contribute to the generation of the system's fastest chemical timescales. Considering the large dynamic range of the system's eigenvalues, their logarithmic scale is employed as follows:

$$
\Lambda_{i}=\operatorname{sign}\left(\lambda_{i}\right) \cdot \log _{10}\left|\lambda_{i}\right|
$$

The stiffness analysis was performed after the completion of the reduction process using DRG and the isomer lumping methods. The produced reduced model was employed in zero-dimensional (0D) autoignition simulations in a wide range of initial conditions. In particular, the following conditions 
were tested for various fuel blends of toluene/iso-octane/n-heptane/ethanol: $700 K<T(0)<1,500 K$, $10 \mathrm{~atm}<p(0)<50 \mathrm{~atm}, 0.6<\varphi<1.5$. Each one of the 0D simulations was analyzed through the CSP approach, in that, all system's eigenvalues were generated and the TPI tool was used in order to identify the reactions generating the eigenvalues with the largest norms. The analysis revealed that the set of the reactions generating the fastest timescales remained the same, regardless the different initial conditions.

\section{Spray combustion simulations}

The spray experiments were conducted in an optically accessible constant volume chamber at Michigan Technological University (MTU) [39, 40]. The chamber is a pre-burn type which uses a mixture of acetylene and hydrogen in an appropriate composition with oxygen and nitrogen for preburn. The fuel injection is timed during the cool-down phase of the pre-burn when an exact ambient condition was reached. Further details of the experimental facilities can be found in Zhang et al. [39] and Meng et al. [40]. The injector nozzle used was a single hole of outlet diameter $176 \mu \mathrm{m}$ with kfactor of 1.8 and discharge coefficient of 0.94 at $\mathrm{Re}=12000$.

The spray combustion simulations were performed using commercial finite volume based CFD code CONVERGE ${ }^{\mathrm{TM}}$. The spray break-up was modeled using the modified Kelvin-Helmholtz and Rayleigh-Taylor (KH-RT) model without an ad-hoc break-up length. In addition, blob injection atomization model, NTC droplet collision model, Post collision outcome model, and Frossling evaporation models were used. For turbulence modeling, Renormalization group (RNG) k- $\varepsilon$ model was used. Further details of the models used can be found in Mohan et al. [41] and Pei et al [42]. The fuel liquid properties used in the simulations were generated using Aspen HYSYS. These properties have been extensively validated in the previous studies.

The computational domain is a cube of side $100 \mathrm{~mm}$. The mesh was generated during runtime by the CFD code. The base grid size of $2 \mathrm{~mm}$ is used along with a level 4 fixed embedding of injector type and adaptive mesh refinement (AMR) of level 4 was employed for velocity, temperature, and fuel 
species fields. Figure 1 shows the base mesh, fixed embedding, and AMR generated by the CFD code at $0.5 \mathrm{~ms}$ After the Start Of Injection (ASOI).

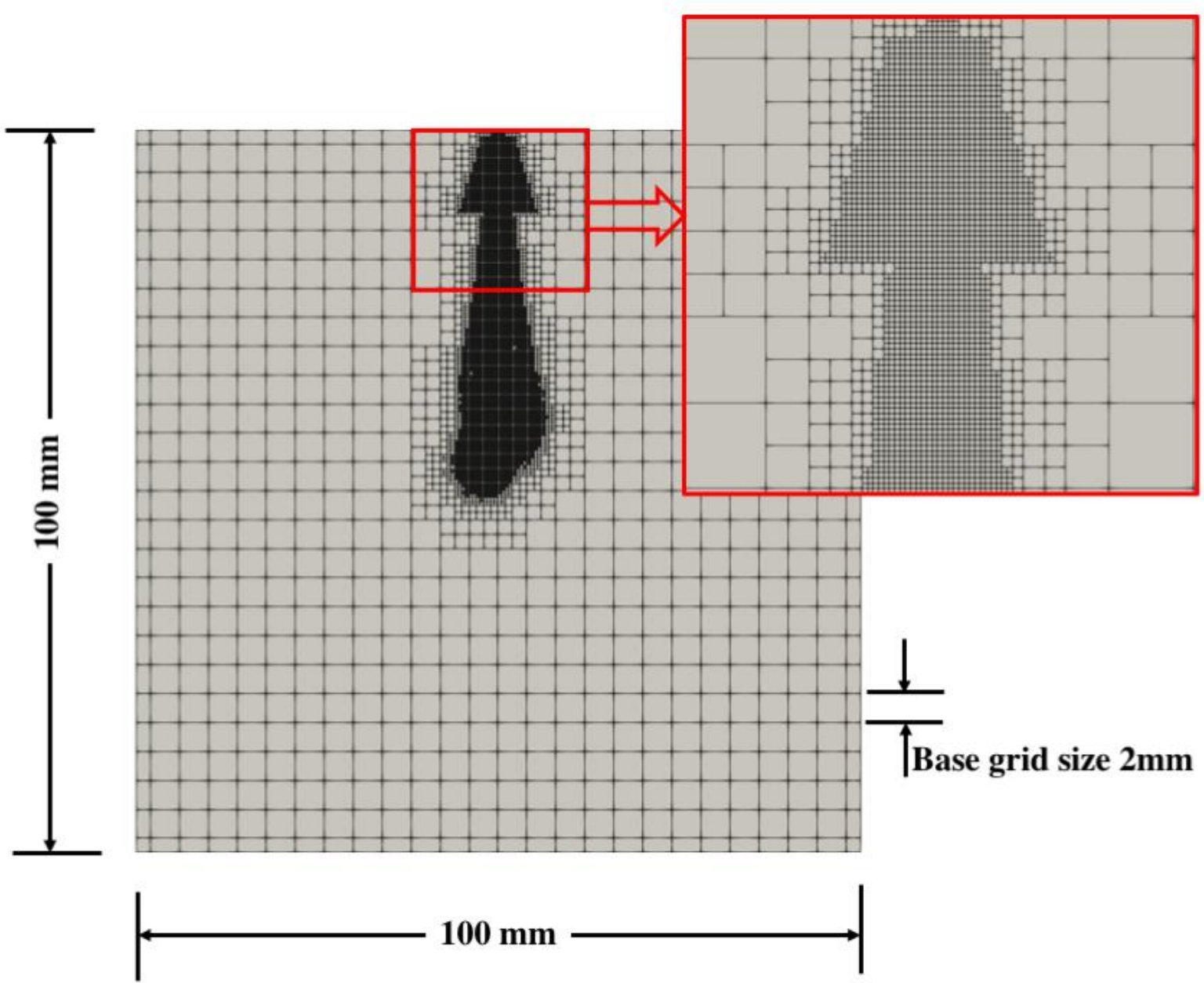

Figure 1. Grid generated by CONVERGE ${ }^{\mathrm{TM}}$ at $0.5 \mathrm{~ms}$ ASOI

\section{Engine combustion simulations}

A single cylinder 4 valve engine with a $16: 1$ volumetric compression ratio $(\mathrm{CR})$ is used in this investigation. Table 1 shows the details of the engine specifications and more details about the engine can be found in [43, 44]. A new set of CR 16 piston was designed and used here to accommodate the PPC combustion strategy using a commercial gasoline with research octane number (RON) of 91. The fuel used in this study is the CARB LEV III E10 certification gasoline and some of its properties are listed in Table 2. A low-load operating point is used here for model validation. The low-load point details are listed in Table 3. This point was chosen because the combustion mode at these operating 
conditions is governed by sequential autoignitions of the partially premixed fuel/air in-cylinder mixtures and this poses a challenge of the robustness of chemical kinetic models.

Table 1 Single cylinder engine specifications.

\begin{tabular}{|l|l|}
\hline Cylinders & 1 \\
\hline Number of Valves & 4 \\
\hline Displacement (L) & 0.55 \\
\hline Bore (mm) & 86 \\
\hline Stroke (mm) & 94.6 \\
\hline Connecting Rod (mm) & 148 \\
\hline CR & $14.5: 1$ \\
\hline Fuel Injector & Centrally mounted, multi-hole GDI \\
\hline Spray angle ( $\left.{ }^{\circ}\right)$ & 130 \\
\hline Number of nozzles & 10 \\
\hline Nozzle diameter (mm) & 0.165 \\
\hline
\end{tabular}

Table 2 Properties of the RON91 gasoline.

\begin{tabular}{|l|l|}
\hline RON & 91 \\
\hline MON & 83.4 \\
\hline S & 7.6 \\
\hline H/C & 1.97 \\
\hline Lower heating value (MJ/kg) & 41.9 \\
\hline Oxygenates (vol.\%) & 8.2 \\
\hline Paraffins (vol.\%) & 13.4 \\
\hline Iso-paraffins (vol.\%) & 33.7 \\
\hline Olefins (vol.\%) & 6.8 \\
\hline Naphthenes (vol.\%) & 15.2 \\
\hline Aromatics (vol.\%) & 22.7 \\
\hline
\end{tabular}




\begin{tabular}{|l|l|}
\hline $\operatorname{IBP}\left({ }^{\circ} \mathrm{C}\right)$ & 41.1 \\
\hline $\mathrm{T} 10\left({ }^{\circ} \mathrm{C}\right)$ & 58.9 \\
\hline $\mathrm{T} 50\left({ }^{\circ} \mathrm{C}\right)$ & 101.6 \\
\hline $\mathrm{T} 90\left({ }^{\circ} \mathrm{C}\right)$ & 158.3 \\
\hline FBP $\left({ }^{\circ} \mathrm{C}\right)$ & 176.1 \\
\hline
\end{tabular}

Table 3 Engine operating and boundary conditions.

\begin{tabular}{|l|l|}
\hline IMEP (bar) & 6 \\
\hline RMP & 1500 \\
\hline Intake pressure (bar) & 1.5 \\
\hline Intake Temperature (K) & 331 \\
\hline SOI (CAD aTDC) & -40 \\
\hline Injection pressure (bar) & 51 \\
\hline Fuel temperature (K) & 363 \\
\hline Exhaust gas recirculation (EGR) (\%) & 0 \\
\hline Fuel mass (mg/cycle) & 16.49 \\
\hline Spray angle $\left(^{\circ}\right)$ & 130 \\
\hline Plume angle $\left({ }^{\circ}\right)$ & 15 \\
\hline Number of nozzles & 10 \\
\hline Nozzle diameter $(\mathrm{mm})$ & 0.142 \\
\hline
\end{tabular}

CONVERGE v2.4 [45] was used to perform the CFD simulations in this work. CONVERGE is a general purpose CFD code to solve multi-dimensional reacting flows with stationary and moving boundaries. More detailed descriptions of the models can be found in [45]. The RANS-based turbulent renormalization group (RNG) k- $\varepsilon$ model was utilized throughout the simulations. A Lagrangian spray model based on the blob injection model of Reitz and Diwakar [46] was used, wherein computational parcels of liquid with a characteristic size equal to the effective nozzle diameter were introduced into the computational domain. The spray breakup models were implemented based on the recommendations from the constant volume chamber simulations [43, 44]. More details about the 
spray models and the validations against engine combustion network (ECN4) spray G [47] can be found in $[43,44]$.

\section{Results and discussions}

\subsection{Stiffness analysis}

Figure 2 displays a typical example of the system's temporal evolution of the fastest timescales (grey circles) along with temperature (red-dashed line) against time scaled with the ignition delay time, for $30 \%$ iso-octane/30\%n-heptane/20\%toluene/20\%ethanol/air, $T(0)=800 \mathrm{~K}, p(0)=20 \mathrm{~atm}, \varphi=$ 0.6. It is shown that after ignition $\Lambda_{1}<-15$, corresponding to a timescale faster than 1 femtosecond (fs), which can be considered a non-physical value. In addition, there is a large gap between $\Lambda_{2}$ and $\Lambda_{3}$ for the most part of the process, suggesting that a potential decrease of that gap would decrease significantly the computational cost in integration solvers of explicit type. Thus, the first two fastest timescales $\left(\Lambda_{1}\right.$ and $\left.\Lambda_{2}\right)$ were investigated further and the reactions shown in Table 4 were identified by the TPI tool to contribute the most to the large norms of $\Lambda_{1}$ and $\Lambda_{2}$. As a result, the Arrhenius coefficients of those reactions were gradually revised (decreased) in an iterative fashion so that the gap between $\Lambda_{2}$ and $\Lambda_{3}$ was minimized and the large norm of $\Lambda_{1}$ after ignition was significantly decreased as shown by the green signs in Figure 2, with a sufficiently small impact to the model's accuracy at all operating conditions. It is noted that in the original version of the mechanism, no Arrhenius coefficients were provided for $38 \mathrm{~b}$ and its rate constant was calculated based on the respective forward and equilibrium constants while after the revision, Arrhenius coefficients were explicitly provided. Figure

2 shows that as a result of this refining procedure, the norm of fastest eigenvalue (i.e, $\left.\Lambda_{1}\right)$ was decreased by approximately two orders of magnitude in the cold region and roughly three orders of magnitude in the hot region, after ignition. 


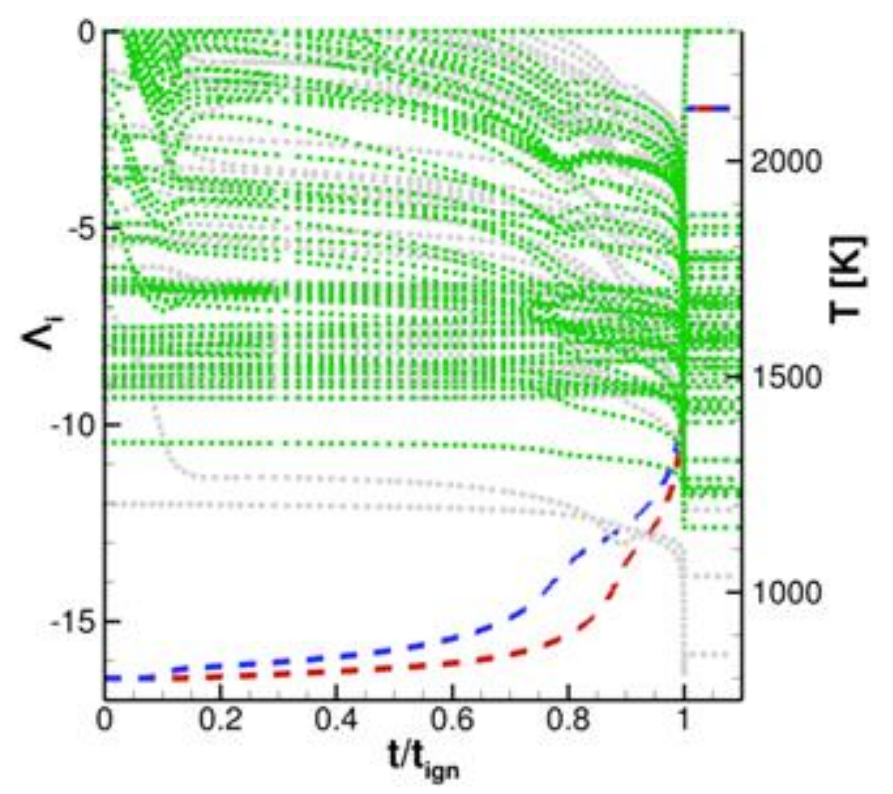

Figure 2. The smallest eigenvalues (largest norms) and temperature profiles using the original (grey and red colors) and the revised (green and blue colors) Arrhenius coefficients for the reactions in Table 4, during the autoignition of $30 \%$ iso-octane $/ 30 \%$ n-heptane $/ 20 \%$ toluene $/ 20 \%$ ethanol/air, $T(0)=800 \mathrm{~K}$, $p(0)=20$ atm, $\varphi=0.6$. In both cases, time has been scaled against the ignition delay time.

Table 4: The reactions identified by the TPI tool to generate the first two fastest timescales, along with their original and revised Arrhenius coefficients.

\begin{tabular}{|c|c|c|c|c|c|c|c|}
\hline \multirow[b]{2}{*}{ \#Rxn } & \multirow[b]{2}{*}{ Description } & \multicolumn{3}{|c|}{ Original values } & \multicolumn{3}{|c|}{ Revised values } \\
\hline & & $\mathbf{A}$ & b & $\mathbf{E a}$ & $\mathbf{A}$ & $\mathbf{b}$ & $\mathbf{E a}$ \\
\hline $3 f$ & $\mathrm{C}_{6} \mathrm{H}_{5} \mathrm{CH}_{2}+\mathrm{OH} \rightarrow \mathrm{C}_{6} \mathrm{H}_{5} \mathrm{CHO}+\mathrm{H}_{2}$ & $2.11 \mathrm{E}+19$ & 1.0 & 0.0 & $3.0 \mathrm{E}+14$ & 0.0 & 0.0 \\
\hline $4 \mathrm{f}$ & $\mathrm{C}_{6} \mathrm{H}_{5} \mathrm{CH}_{2}+\mathrm{HO}_{2} \rightarrow \mathrm{C}_{6} \mathrm{H}_{5} \mathrm{CHO}+\mathrm{H}_{2} \mathrm{O}$ & $2.11 \mathrm{E}+19$ & 0.0 & 0.0 & $3.0 \mathrm{E}+14$ & 0.0 & 0.0 \\
\hline $40 \mathrm{f}$ & $\mathrm{C}_{8} \mathrm{H}_{16} \mathrm{OOH}+\mathrm{O}_{2} \rightarrow \mathrm{C}_{8} \mathrm{H}_{16} \mathrm{OOH}-\mathrm{O}_{2}$ & $8.00 \mathrm{E}+14$ & 0.0 & 0.0 & $3.0 \mathrm{E}+14$ & 0.0 & 0.0 \\
\hline $38 \mathrm{f}$ & $\mathrm{C}_{8} \mathrm{H}_{17} \mathrm{O}_{2} \rightarrow \mathrm{C}_{8} \mathrm{H}_{16} \mathrm{OOH}$ & $2.86 \mathrm{E}+11$ & 1.23 & 22,000 & $2.86 \mathrm{E}+11$ & 1.23 & 22,000 \\
\hline $38 b$ & $\mathrm{C}_{8} \mathrm{H}_{17} \mathrm{O}_{2} \leftarrow \mathrm{C}_{8} \mathrm{H}_{16} \mathrm{OOH}$ & - & - & - & $1.37 \mathrm{E}+08$ & 1.28 & 6,835 \\
\hline
\end{tabular}

In order to demonstrate further the success of this refining process, the produced model was compared to other models available in the literature. While a fair comparison would require all mechanisms to have the same number of species. by comparing the current model with larger and smaller in size models we aim to demonstrate the success of the approach followed. Figure 3 shows the stiffness performance of the current model after its revision against three TPRF models of 
increasing number of complexity in terms of the included species and reactions: Liu's model [3], Sarathy's model [15] and Wang's model [4]. It is seen that the fastest of the chemical timescale (i.e., $\Lambda_{1}$ ) of the current model is considerably slower compared to Sarathy's and Wang's models (the larger ones) and slightly faster compared to Liu's model (the smaller one). Therefore, the present approach was able to reduce significantly the potential computational cost of the reaction source calculations using explicit solvers, making the introduced model ideal for usage in direct numerical simulations (DNS). This suggests that the computational cost of the current mechanism would be lower compared to Sarathy's and Wang's models, with the usage of an explicit solver.
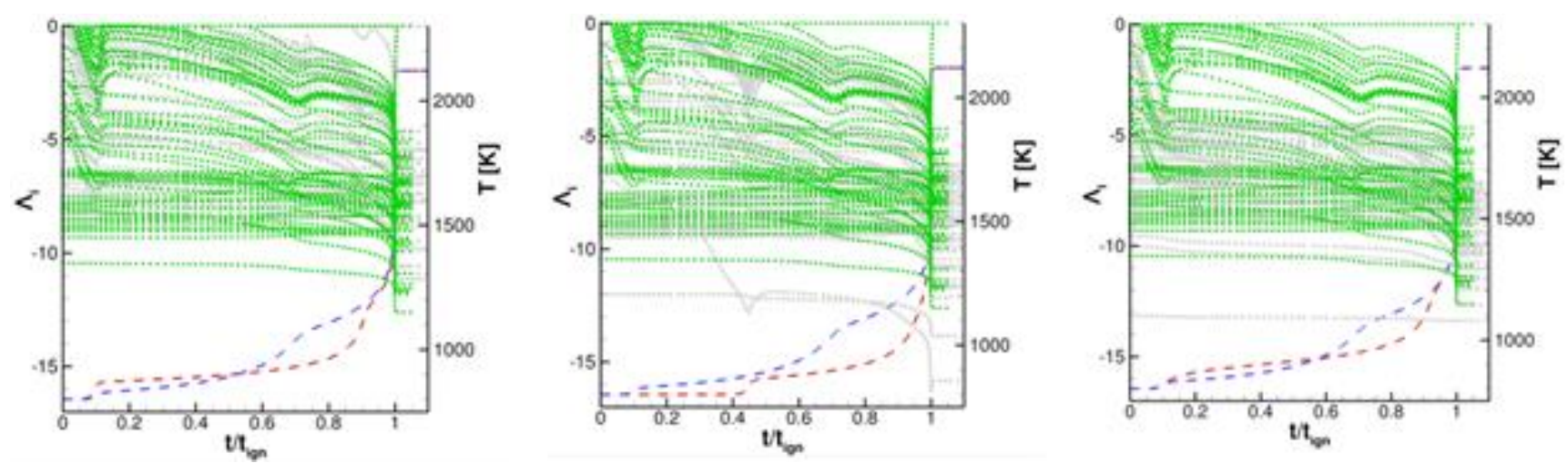

Figure 3. The smallest eigenvalues (largest norms) and temperature profiles using the produced revised (green and blue colors) model and three other models (grey and red color) available in the literature; Liu's model [3] on the left, Sarathy's model [15] in the middle and Wang's model [4] on the right. In all cases, a homogeneous batch reactor was used with $40 \%$ iso-octane/40\%n-heptane/20\%toluene/air, $T(0)=800 \mathrm{~K}, p(0)=20 \mathrm{~atm}, \varphi=0.6$. Time has been scaled against the respective ignition delay times.

\subsection{Ignition delay times (IDTs) validations}

It is evident that the feasibility of a highly reduced kinetic model largely relies on the validations against the experimental data. To this end, comprehensive literature reviews have been done for the IDT measurements of relevant fuels, for pure component (iso-octane, n-heptane and toluene), ethanol 
related mixture, gasoline surrogates and real gasolines oxidation, as shown in Table S2-S4 in the Supplementary Material. Among these, a comprehensive data matrix was selected for validations:

- Pure component (iso-octane, $\mathrm{n}$-heptane, toluene and ethanol) [17, 48-51]

- PRF surrogate mixtures (PRF60, 70, 80, 84, 91 and 95) [52, 53]

- $\quad$ TPRFs surrogate mixtures (TPRF70, 80, 91 and 97.5) [54]

- PRF- and TPRF-ethanol surrogate mixtures $[55,56]$

- Haltermann straight-run naphtha (HSRN) [57]

- A blend of low- and high-octane for gasoline compression ignition (GCI) engines (GCI Blend) [58]

- Haltermann gasoline [14]

- Coryton gasoline [14]

The selected data matrix covers a wide range of engine operating conditions:

- Research octane number (RON) from low to high $(0-118)$

- Fuel concentration or equivalence ratio from lean to rich $(0.5-2.0)$

- Pressures from low to high $(10-60 \mathrm{~atm})$

- Temperatures from low to high $(700-1300 \mathrm{~K})$

Correspondingly, the representative validation results were presented as following:

- Figure 4 Figure 9 show the validation results for the IDTs of PRF70, 91 and 95 surrogate mixtures oxidation $[52,53]$.

- Figure 10Figure 15 show the validation results for the IDTs of TPRF70, 91 and 97.5 surrogate mixtures oxidation [54].

- Figure 16Figure 17 show the validation results for the IDTs of PRF- and TPRF-Ethanol surrogate mixtures oxidation respectively $[55,56]$.

- Figure 18Figure 21 show the show the validation results for the IDTs of HSRN oxidation using both PRF60 and TPRF60 surrogates [57]. 
- Figure 22Figure 23 show the show the validation results for the IDTs of GCI Blend oxidation using PRF77 surrogate [58].

- Figure 24Figure 25 show the show the validation results for the IDTs of Haltermann Gasoline oxidation using TPRF-Ethanol surrogate [14].

- Figure 26Figure 27 show the show the validation results for the IDTs of Coryton Gasoline oxidation using TPRF-Ethanol surrogate [14].

Because of the length limitation of the paper, the rest of validation results were presented in Figure S1-S12 in the Supplementary Material.

In these figures, the reactants' compositions were presented in the caption of each figure, and the results generated from current model were compared with the ones predicted by Liu et al. [3] and Wang et al. [4]. Symbols are experimental data. Note that this study focuses on the validations of IDT measured from shock tubes, which are all solid symbols. Different line shapes correspond to different models' predictions, and different colors correspond to different pressures or equivalence ratios.

Overall, good agreements were observed for the entire validation matrix, the proposed model can accurately reproduce the IDT data both at high temperature regime and negative temperature coefficient (NTC) regime. However, Wang's model predicts too fast IDT (greater than a factor of two) when simulating the TPRF mixtures, and both Liu and Wang's models are absent in ethanol submechanism for the validations of PRF-ethanol and TPRF-ethanol surrogates. 


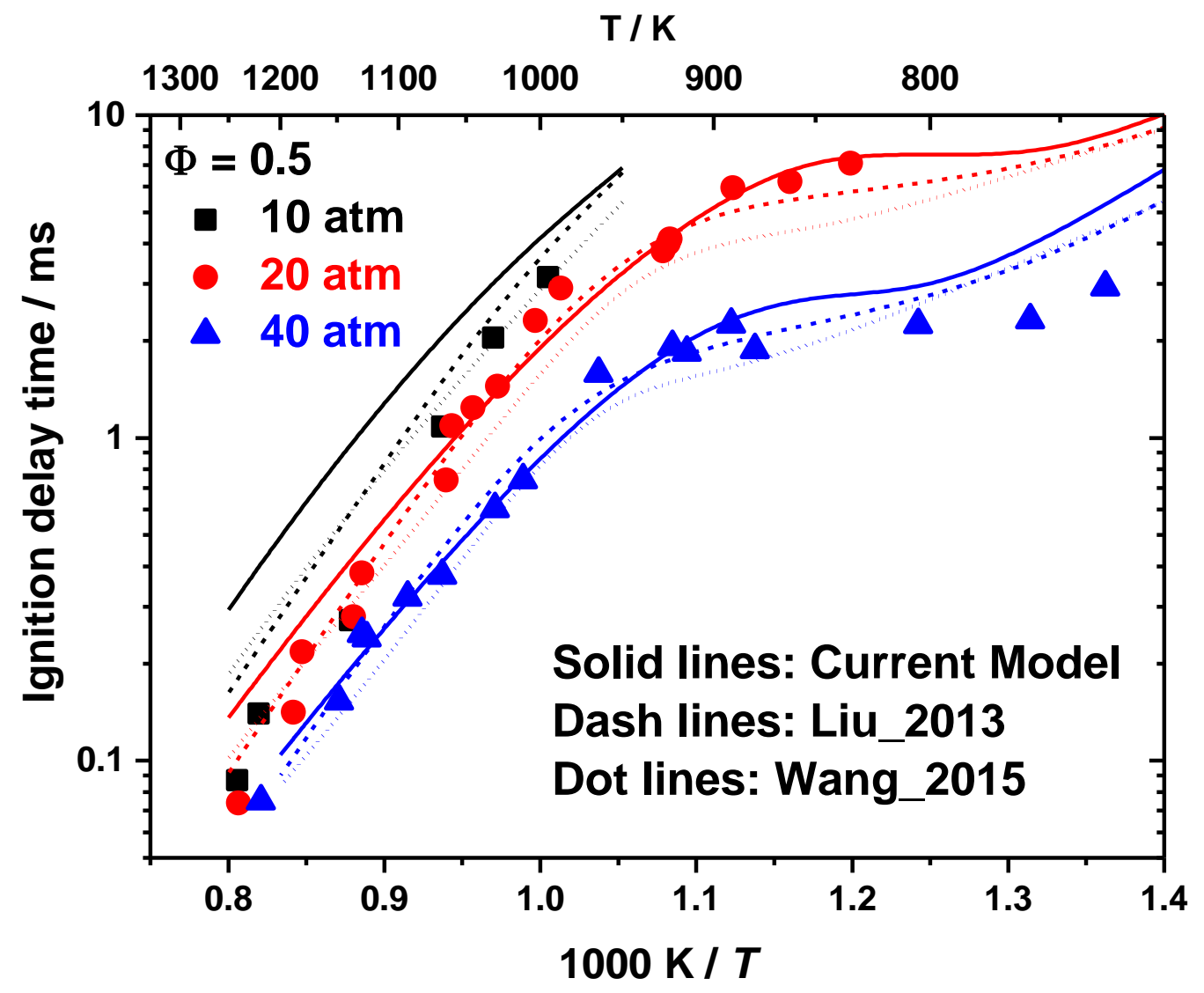

Figure 4. IDTs validation of PRF70 oxidation at $\varphi=0.5$. Reactants' composition: $0.59 \% \mathrm{IC}_{8} \mathrm{H}_{18}$, $0.28 \% \mathrm{NC}_{7} \mathrm{H}_{16}, 20.82 \% \mathrm{O}_{2}$ and $78.32 \% \mathrm{~N}_{2}$

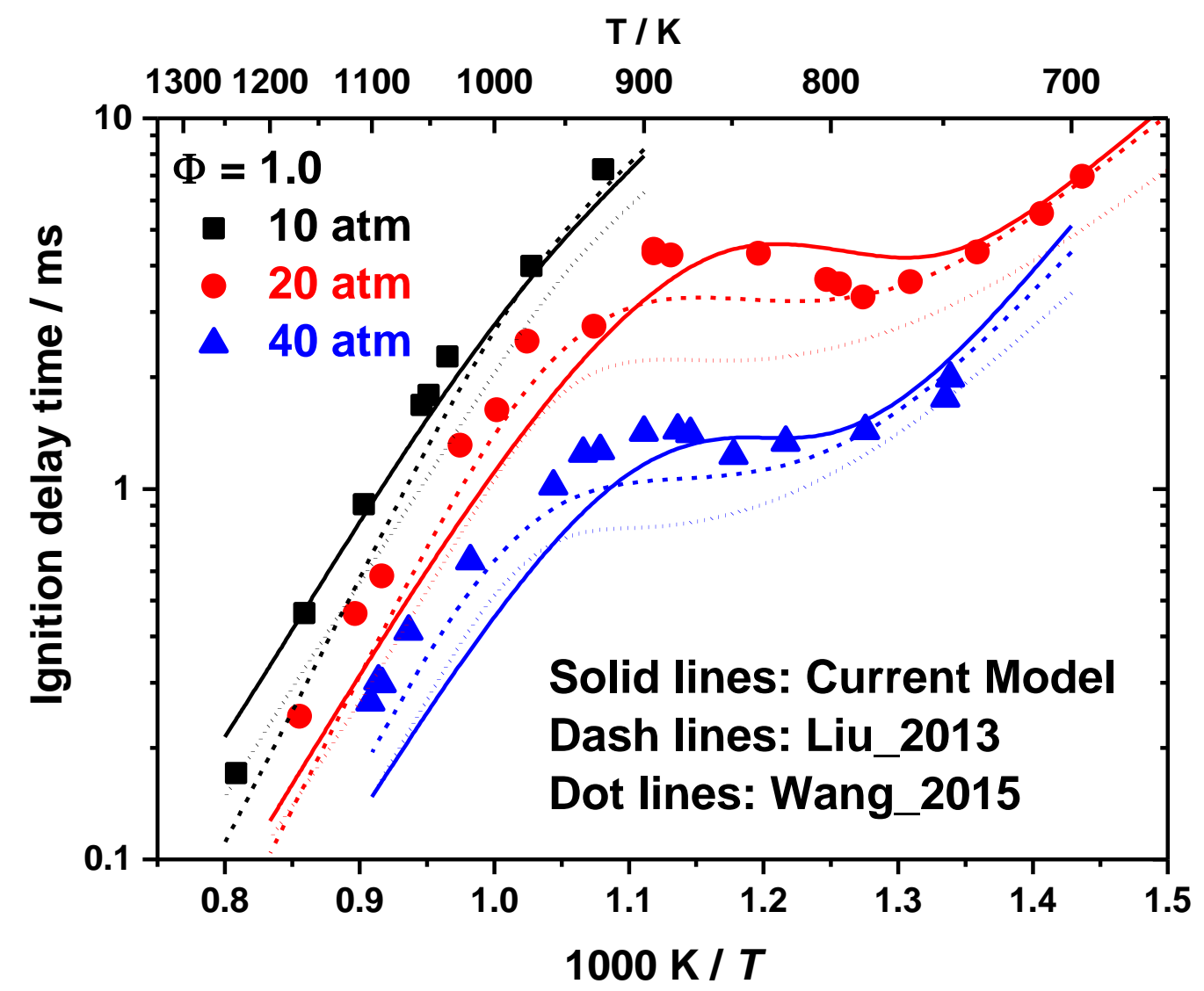

Figure 5. IDTs validation of PRF70 oxidation at $\varphi=1.0$. Reactants' composition: $1.16 \% \mathrm{IC}_{8} \mathrm{H}_{18}$, $0.56 \% \mathrm{NC}_{7} \mathrm{H}_{16}, 20.64 \% \mathrm{O}_{2}$ and $77.64 \% \mathrm{~N}_{2}$ 


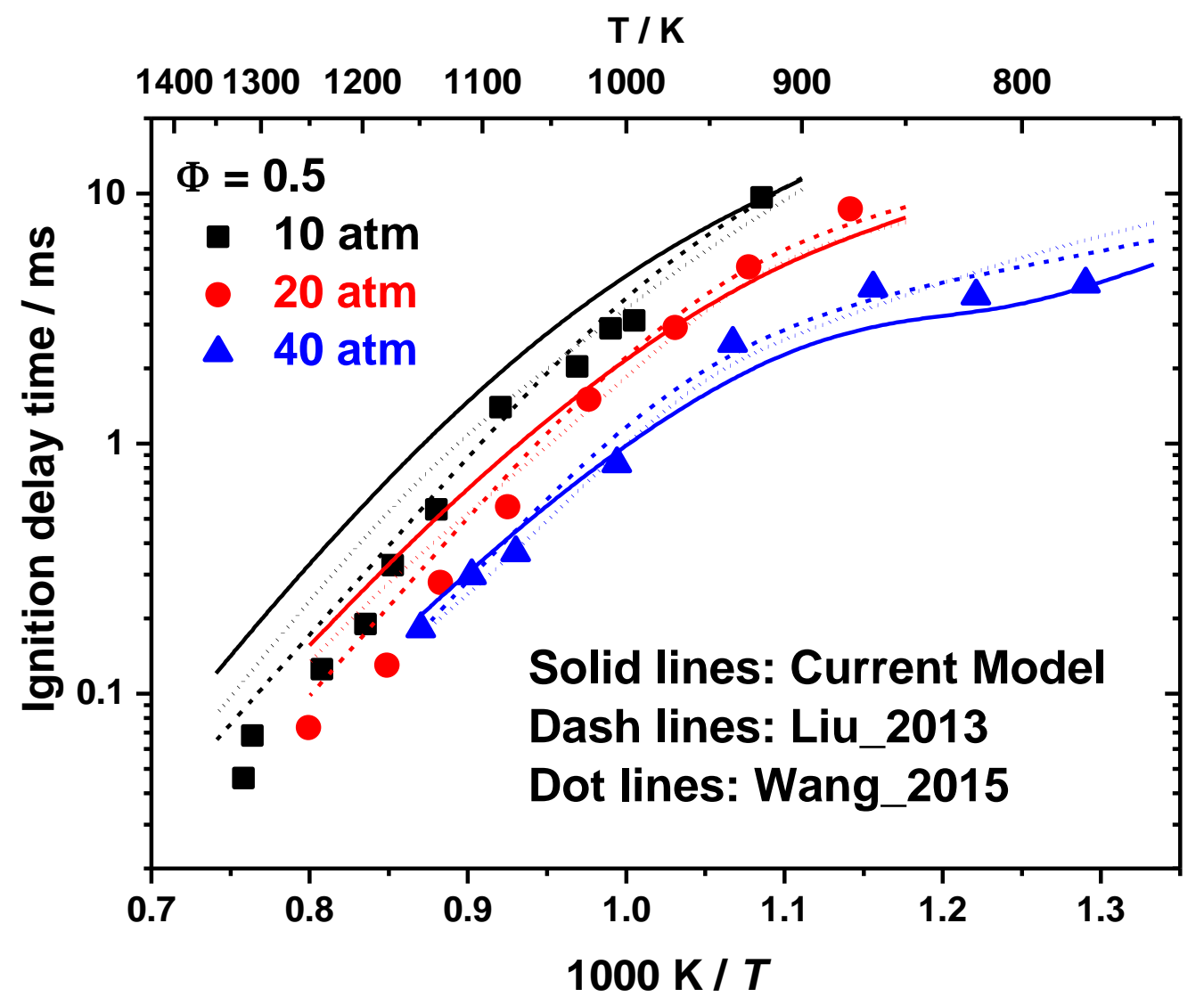

Figure 6. IDTs validation of PRF91 oxidation at $\varphi=0.5$. Reactants' composition: $0.76 \% \mathrm{IC}_{8} \mathrm{H}_{18}$, $0.08 \% \mathrm{NC}_{7} \mathrm{H}_{16}, 20.82 \% \mathrm{O}_{2}$ and $78.33 \% \mathrm{~N}_{2}$

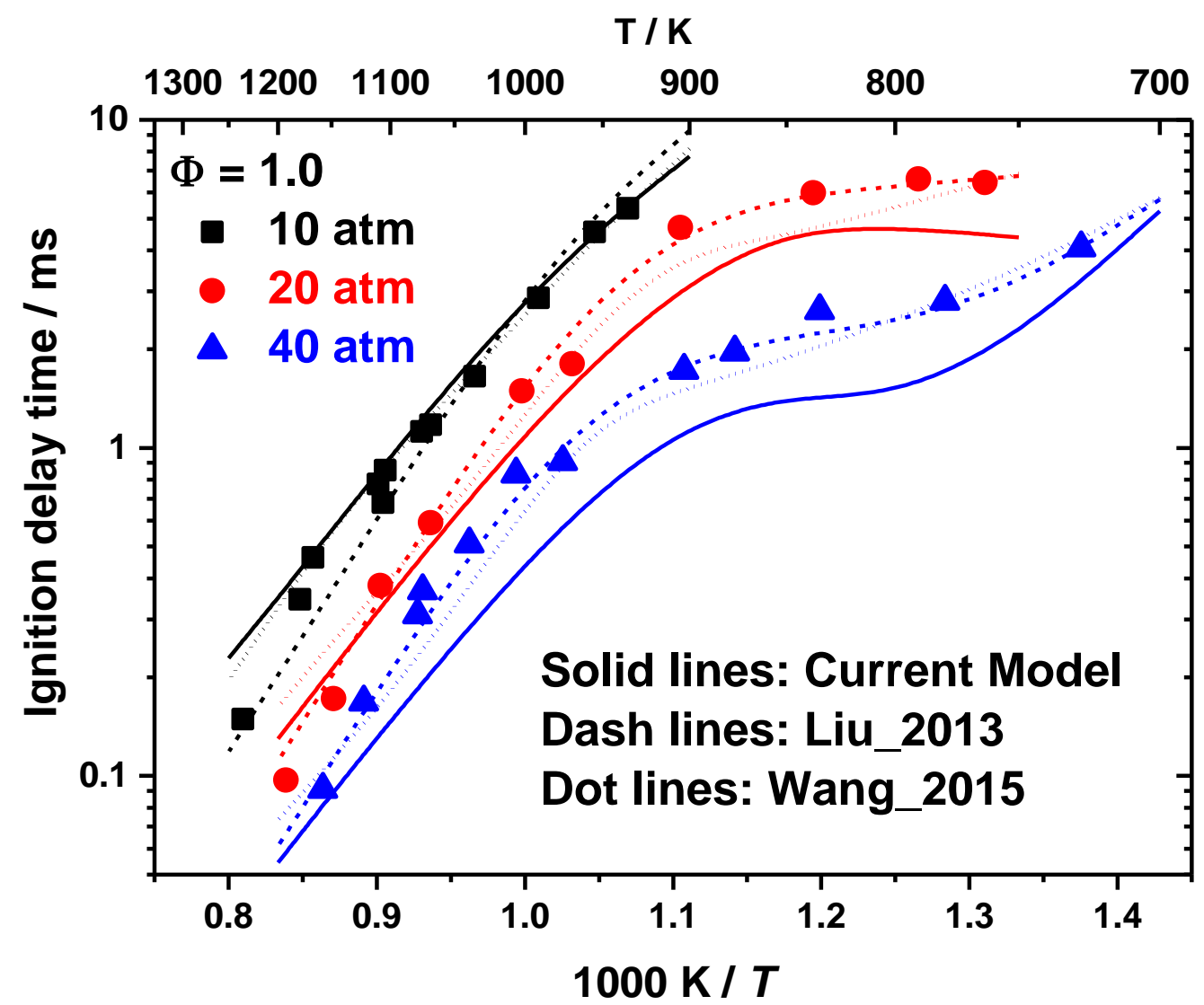

Figure 7. IDTs validation of PRF91 oxidation at $\varphi=1.0$. Reactants' composition: $1.51 \% \mathrm{IC}_{8} \mathrm{H}_{18}$, $0.17 \% \mathrm{NC}_{7} \mathrm{H}_{16}, 20.65 \% \mathrm{O}_{2}$ and $77.68 \% \mathrm{~N}_{2}$ 


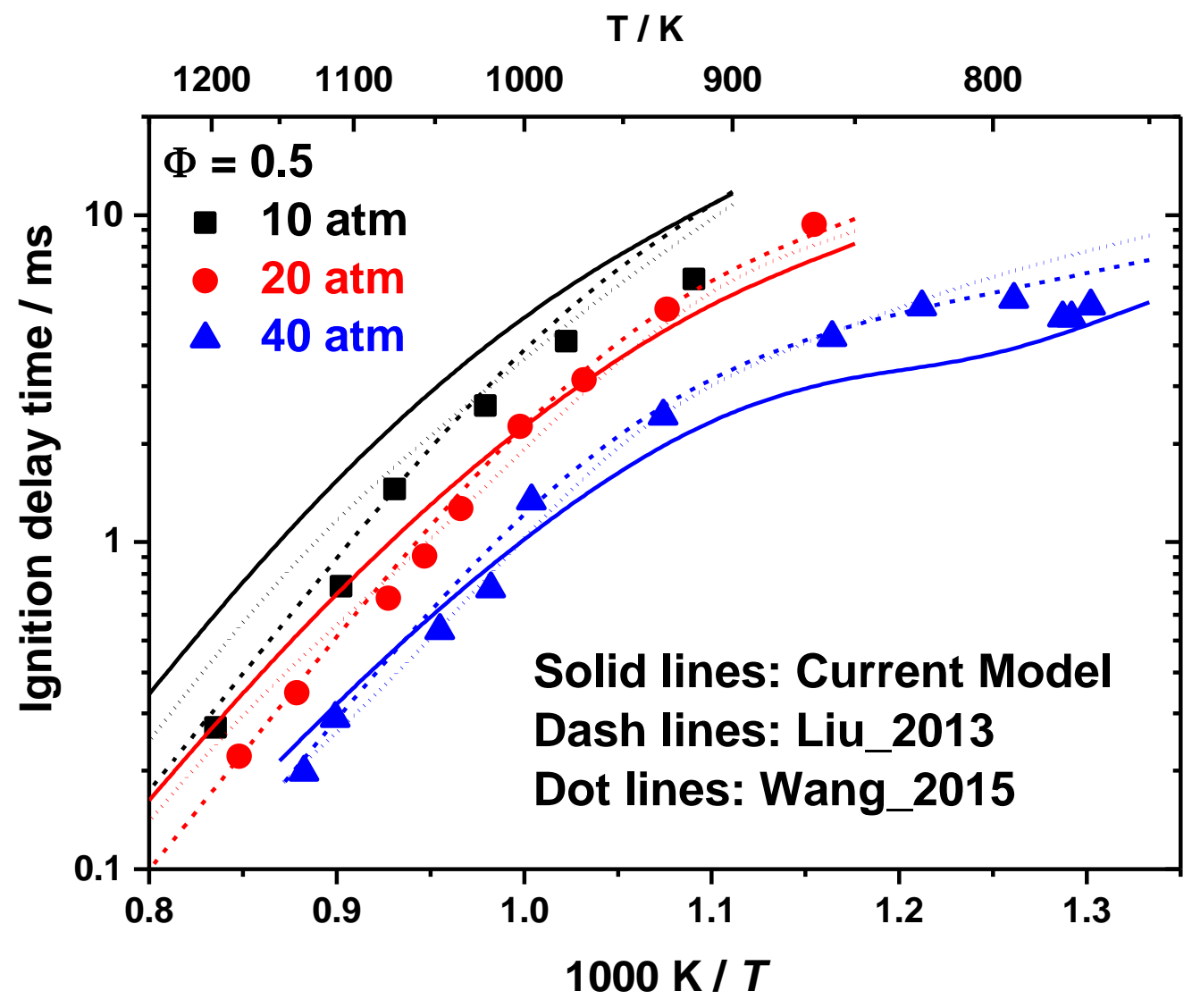

Figure 8. IDTs validation of PRF95 oxidation at $\varphi=0.5$. Reactants' composition: $0.79 \% \mathrm{IC}_{8} \mathrm{H}_{18}$, $0.05 \% \mathrm{NC}_{7} \mathrm{H}_{16}, 20.82 \% \mathrm{O}_{2}$ and $78.34 \% \mathrm{~N}_{2}$

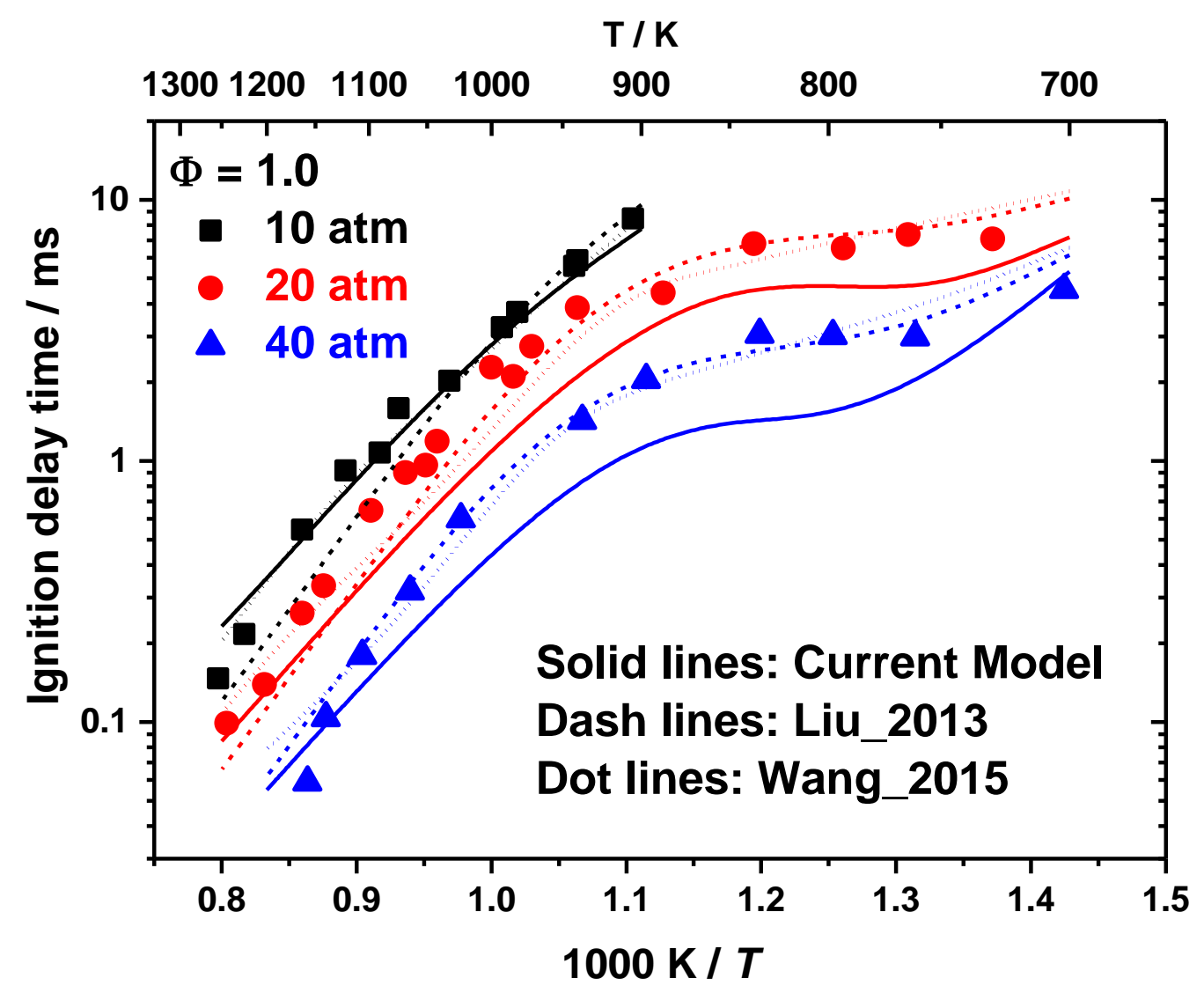

Figure 9. IDTs validation of PRF95 oxidation at $\varphi=1.0$. Reactants' composition: $1.57 \% \mathrm{IC}_{8} \mathrm{H}_{18}$, $0.09 \% \mathrm{NC}_{7} \mathrm{H}_{16}, 20.65 \% \mathrm{O}_{2}$ and $77.69 \% \mathrm{~N}_{2}$ 


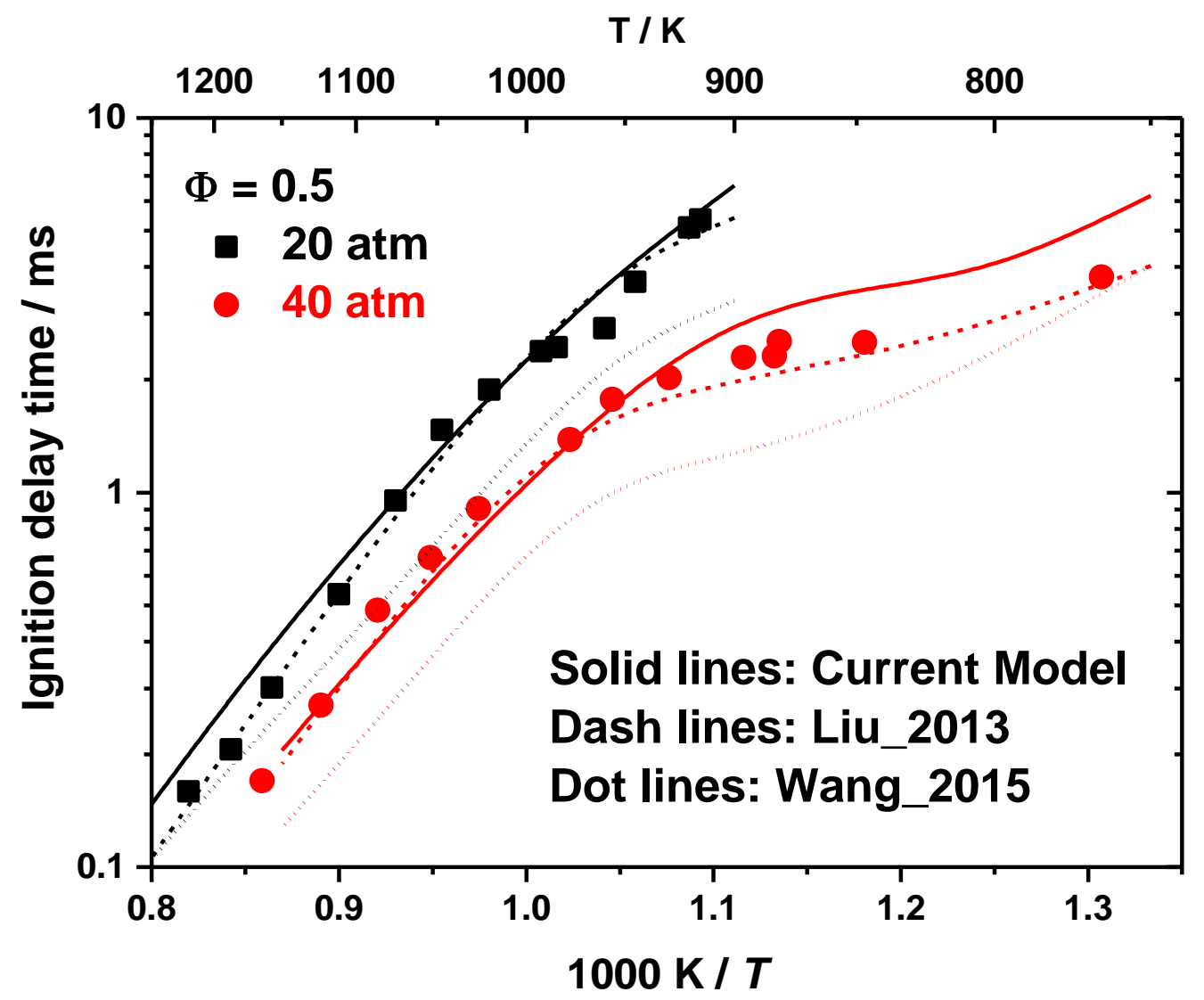

Figure 10. IDTs validation of TPRF70 oxidation at $\varphi=0.5$. Reactants' composition: $0.35 \% \mathrm{IC}_{8} \mathrm{H}_{18}$, $0.33 \% \mathrm{NC}_{7} \mathrm{H}_{16}, 0.27 \% \mathrm{C}_{6} \mathrm{H}_{5} \mathrm{CH}_{3}, 20.80 \% \mathrm{O}_{2}$ and $78.25 \% \mathrm{~N}_{2}$

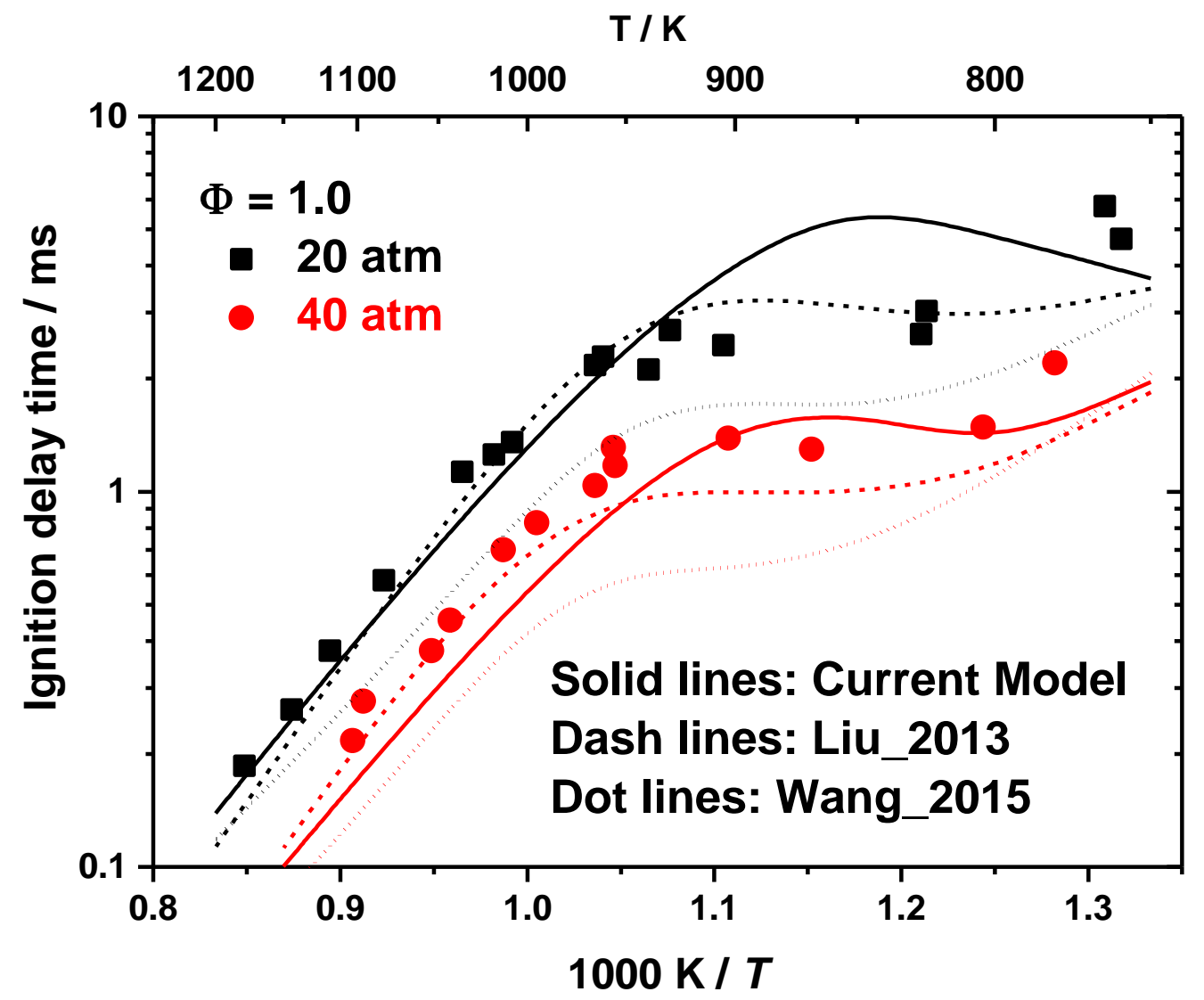

Figure 11. IDTs validation of TPRF70 oxidation at $\varphi=1.0$. Reactants' composition: $0.69 \% \mathrm{IC}_{8} \mathrm{H}_{18}$, $0.66 \% \mathrm{NC}_{7} \mathrm{H}_{16}, 0.54 \% \mathrm{C}_{6} \mathrm{H}_{5} \mathrm{CH}_{3}, 20.61 \% \mathrm{O}_{2}$ and $77.52 \% \mathrm{~N}_{2}$ 


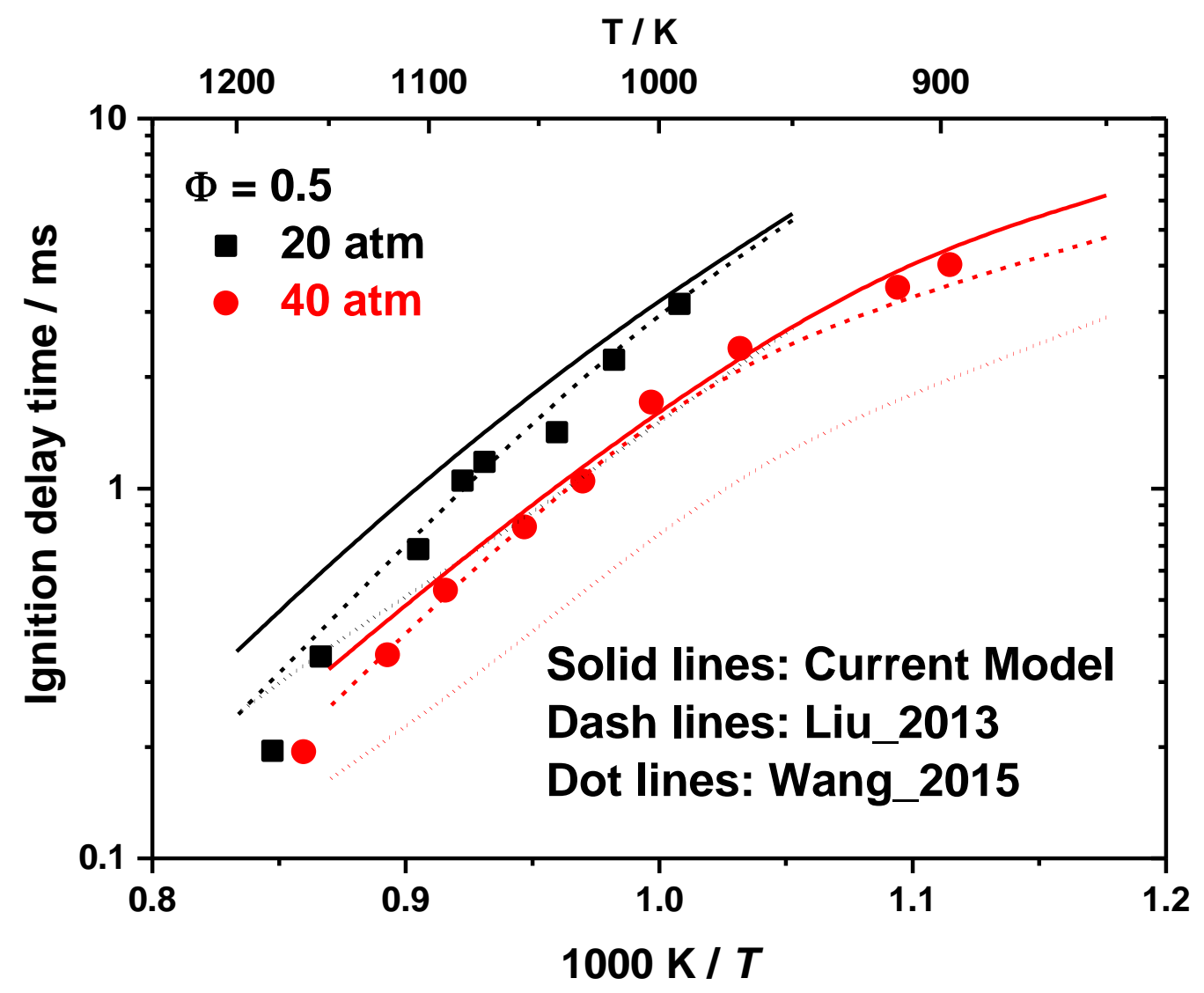

Figure 12. IDTs validation of TPRF91 oxidation at $\varphi=0.5$. Reactants' composition: $0.29 \% \mathrm{IC}_{8} \mathrm{H}_{18}$, $0.17 \% \mathrm{NC}_{7} \mathrm{H}_{16}, 0.54 \% \mathrm{C}_{6} \mathrm{H}_{5} \mathrm{CH}_{3}, 20.79 \% \mathrm{O}_{2}$ and $78.21 \% \mathrm{~N}_{2}$

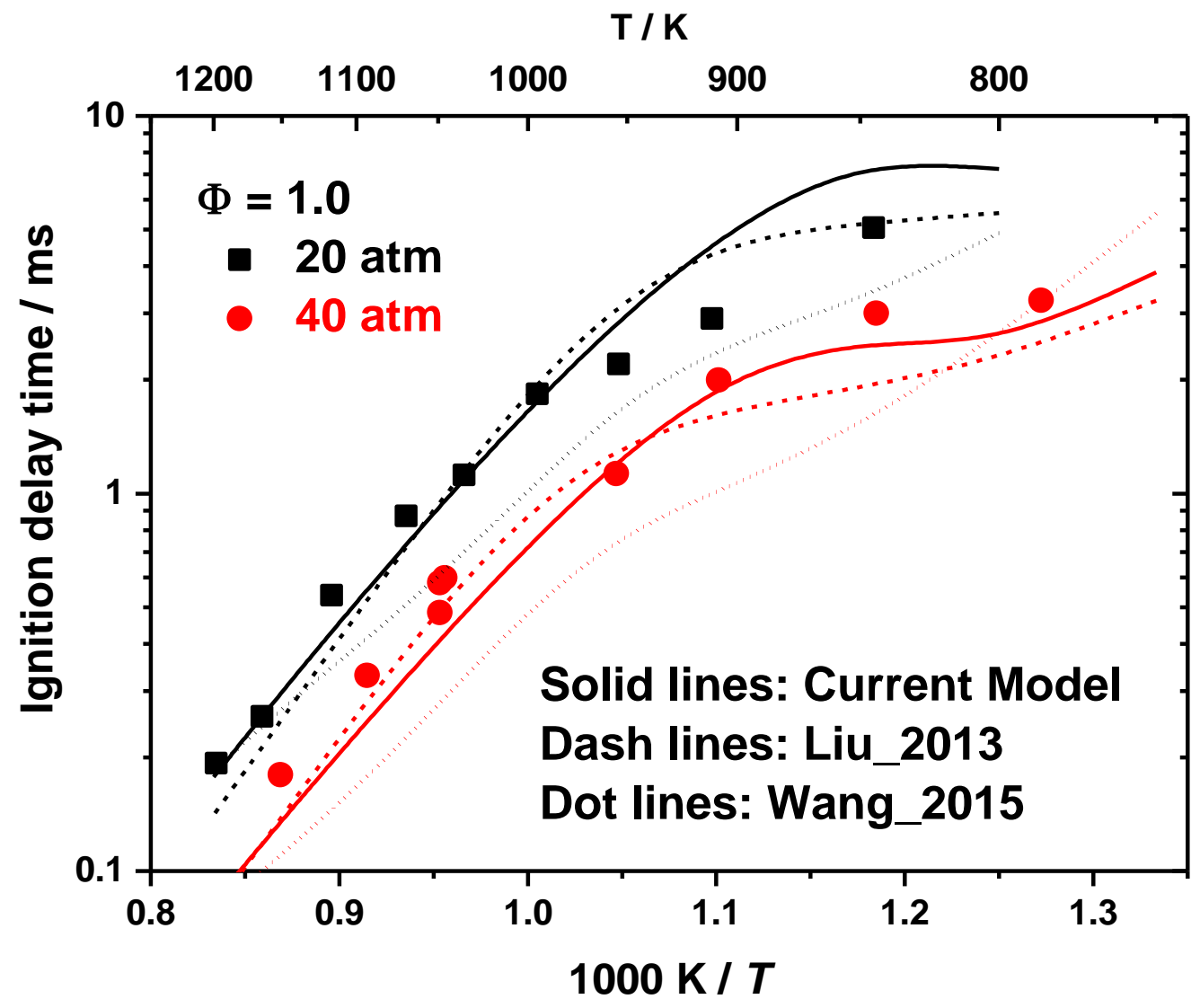

Figure 13. IDTs validation of TPRF91 oxidation at $\varphi=1.0$. Reactants' composition: $0.57 \% \mathrm{IC}_{8} \mathrm{H}_{18}$, $0.34 \% \mathrm{NC}_{7} \mathrm{H}_{16}, 1.08 \% \mathrm{C}_{6} \mathrm{H}_{5} \mathrm{CH}_{3}, 20.58 \% \mathrm{O}_{2}$ and $77.43 \% \mathrm{~N}_{2}$ 


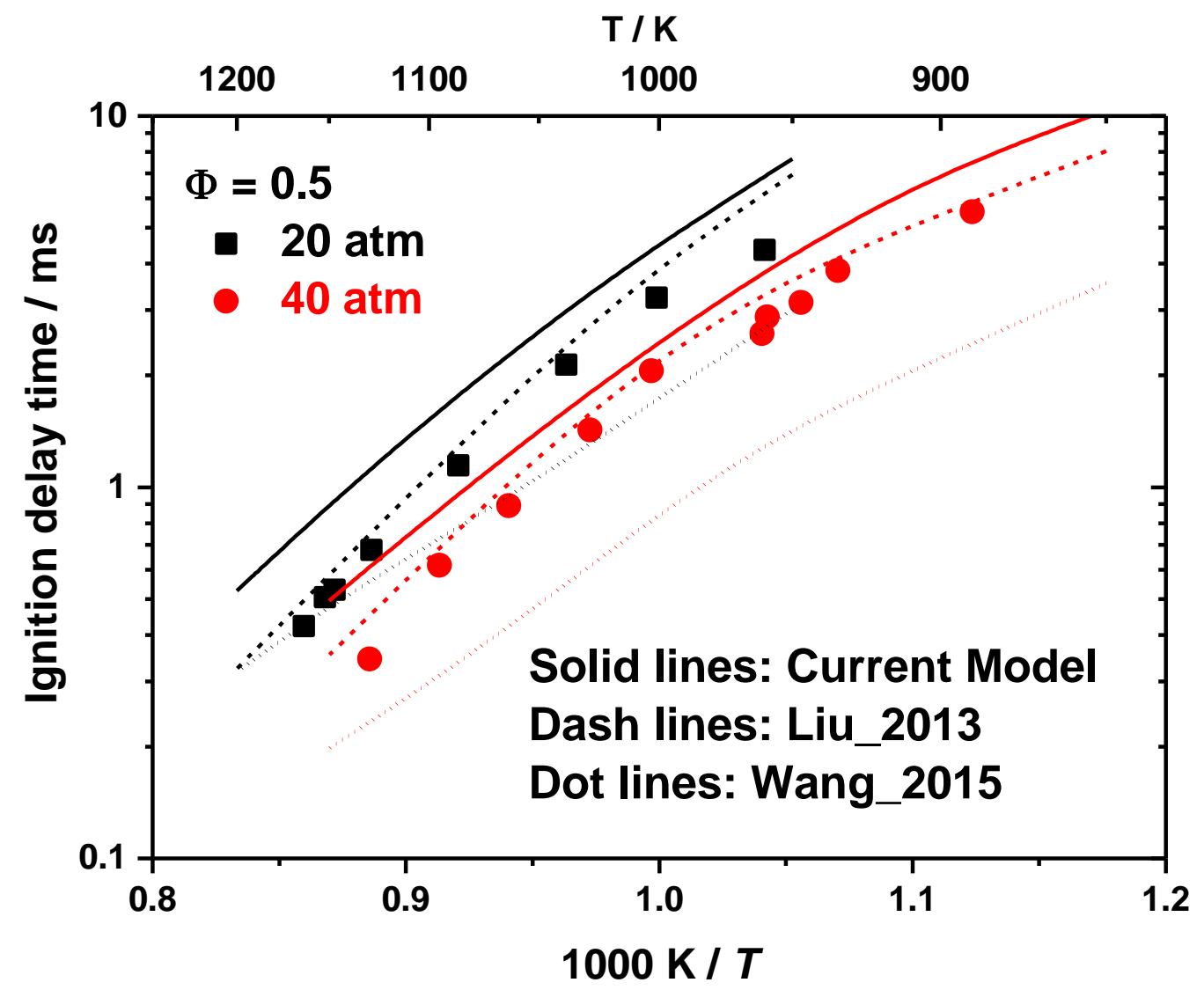

Figure 14. IDTs validation of TPRF97.5 oxidation at $\varphi=0.5$. Reactants' composition: $0.09 \% \mathrm{IC}_{8} \mathrm{H}_{18}$, $0.15 \% \mathrm{NC}_{7} \mathrm{H}_{16}, 0.84 \% \mathrm{C}_{6} \mathrm{H}_{5} \mathrm{CH}_{3}, 20.77 \% \mathrm{O}_{2}$ and $78.14 \% \mathrm{~N}_{2}$

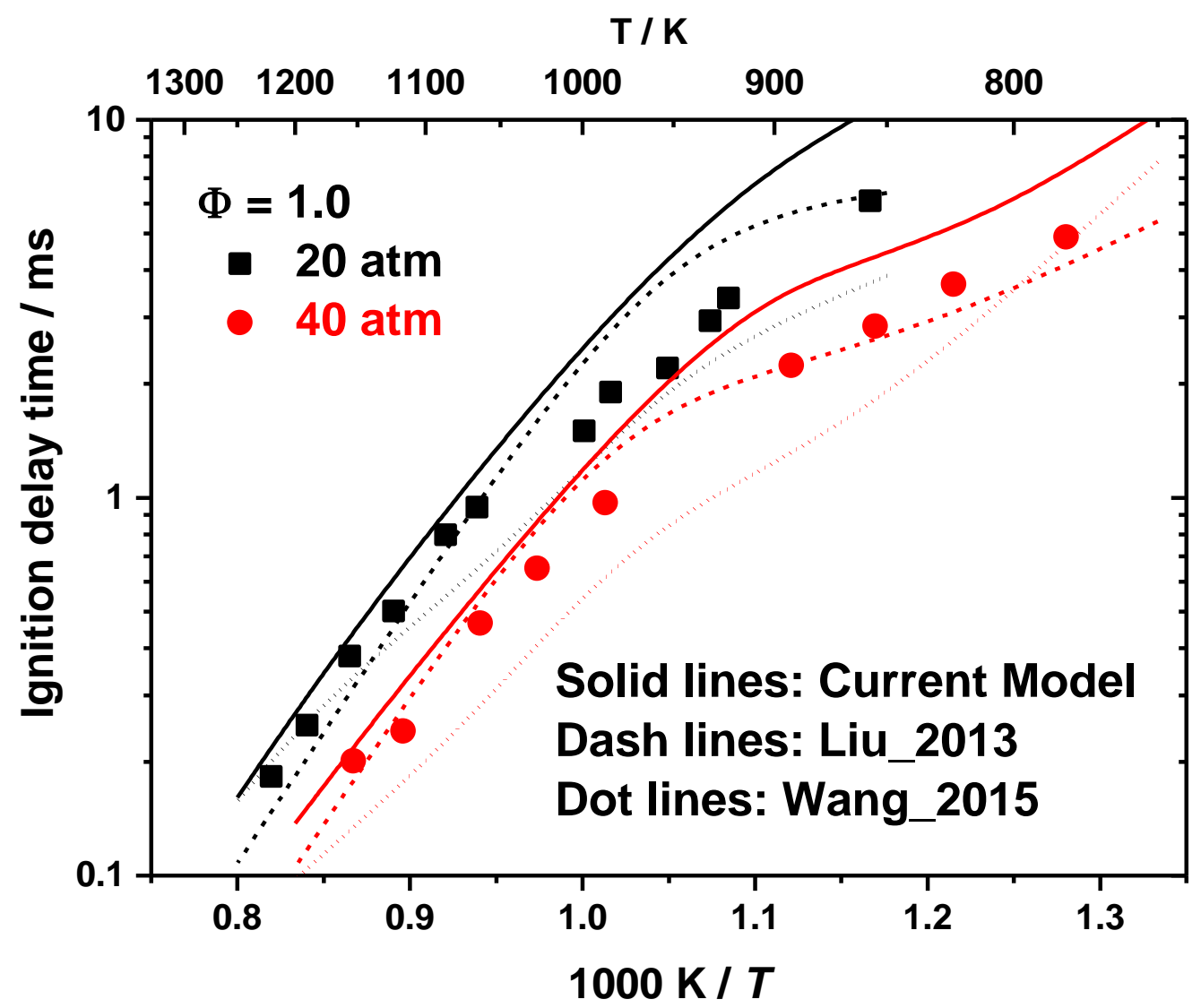

Figure 15. IDTs validation of TPRF97.5 oxidation at $\varphi=1.0$. Reactants' composition: $0.17 \% \mathrm{IC}_{8} \mathrm{H}_{18}$, $0.31 \% \mathrm{NC}_{7} \mathrm{H}_{16}, 1.67 \% \mathrm{C}_{6} \mathrm{H}_{5} \mathrm{CH}_{3}, 20.55 \% \mathrm{O}_{2}$ and $77.30 \% \mathrm{~N}_{2}$ 


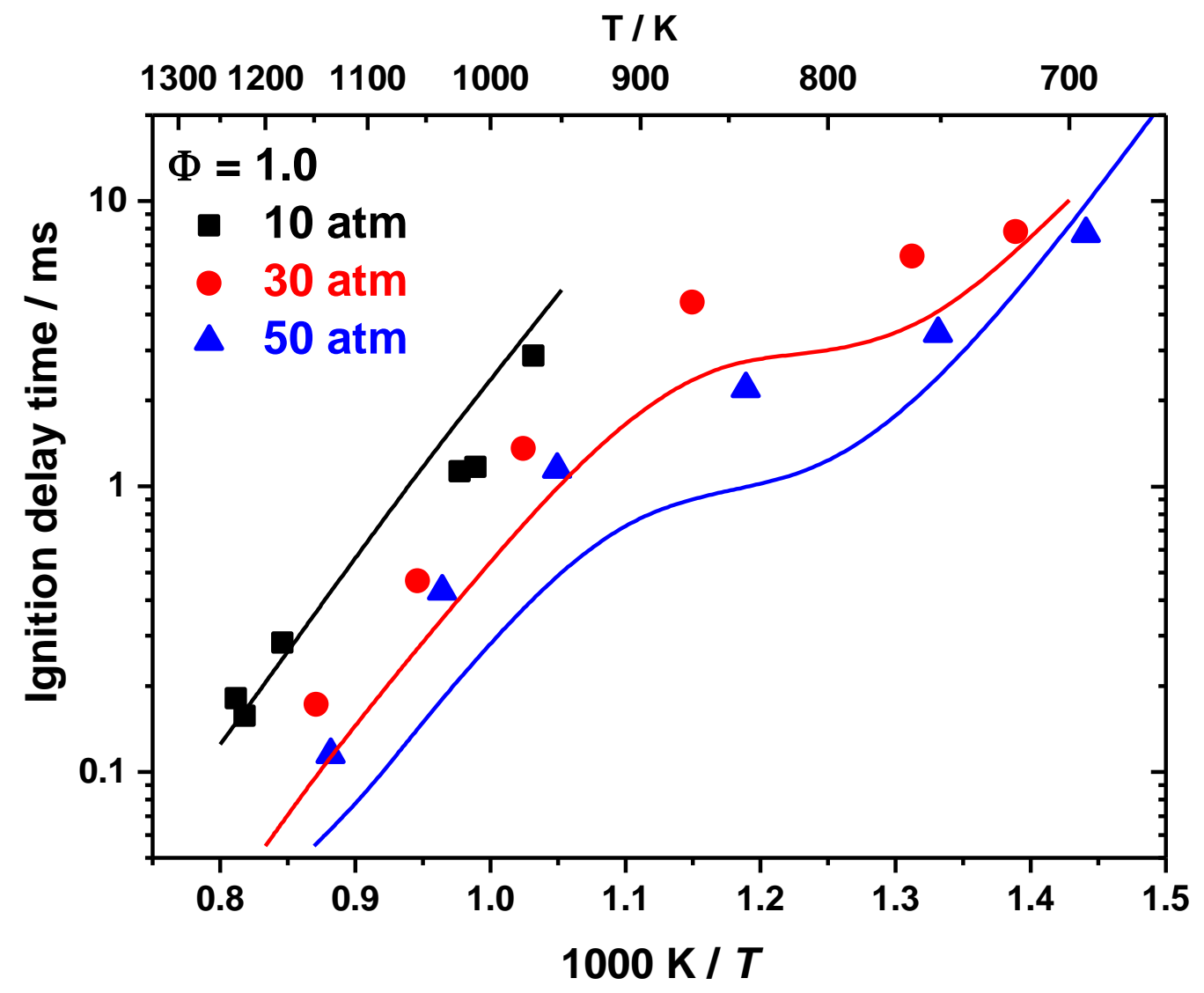

Figure 16. IDTs validation of PRF-Ethanol oxidation at $\varphi=1.0$. Reactants' composition: $1.09 \%$ $\mathrm{IC}_{8} \mathrm{H}_{18}, 0.35 \% \mathrm{NC}_{7} \mathrm{H}_{16}, 0.99 \% \mathrm{C}_{2} \mathrm{H}_{5} \mathrm{OH}, 20.49 \% \mathrm{O}_{2}$ and $77.08 \% \mathrm{~N}_{2}$

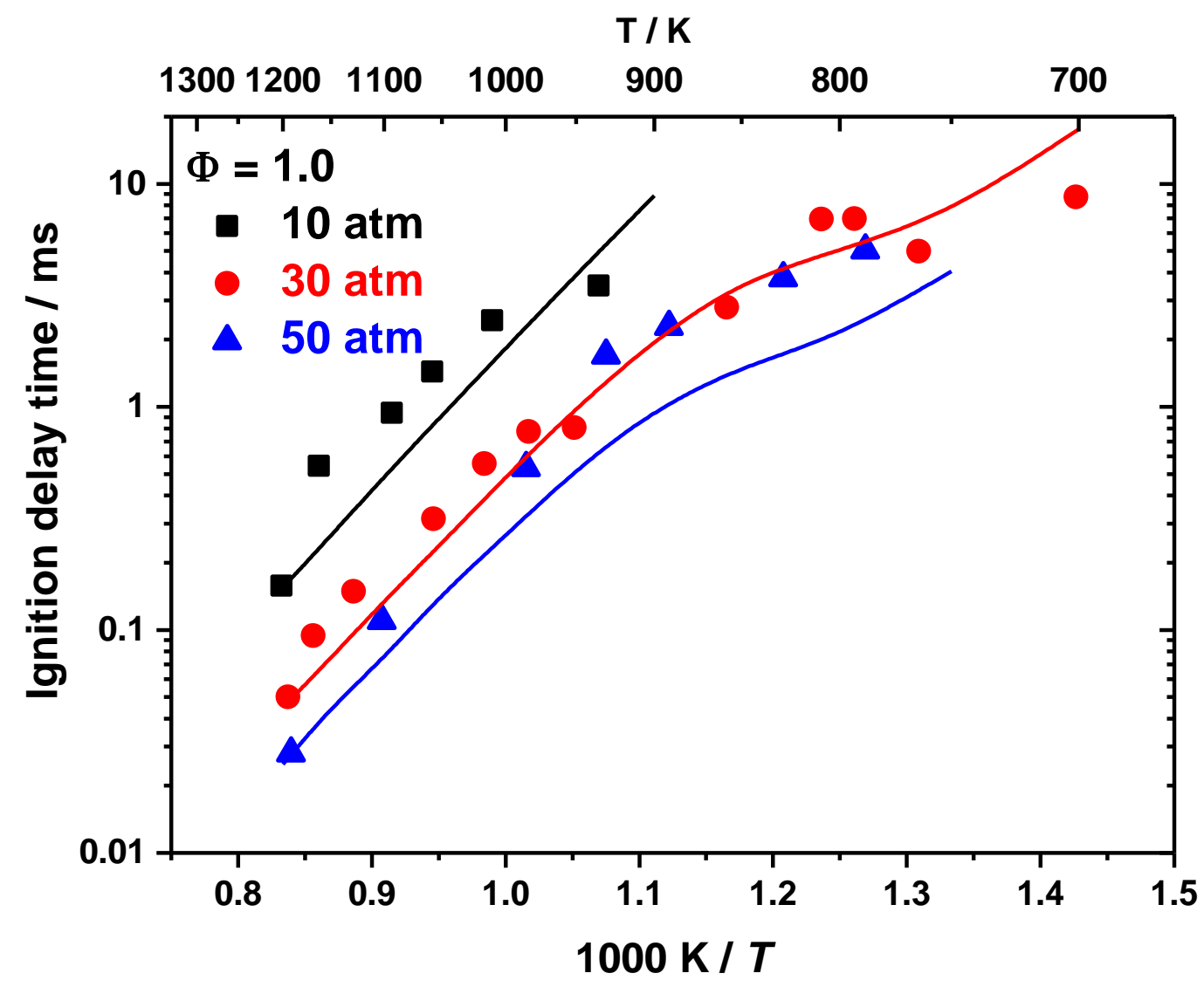

Figure 17. IDTs validation of TPRF-Ethanol oxidation at $\varphi=1.0$. Reactants' composition: 0.69\% $\mathrm{IC}_{8} \mathrm{H}_{18}, 0.21 \% \mathrm{NC}_{7} \mathrm{H}_{16}, 0.34 \% \mathrm{C}_{6} \mathrm{H}_{5} \mathrm{CH}_{3}, 2.08 \% \mathrm{C}_{2} \mathrm{H}_{5} \mathrm{OH}, 20.30 \% \mathrm{O}_{2}$ and $76.37 \% \mathrm{~N}_{2}$ 
T / K

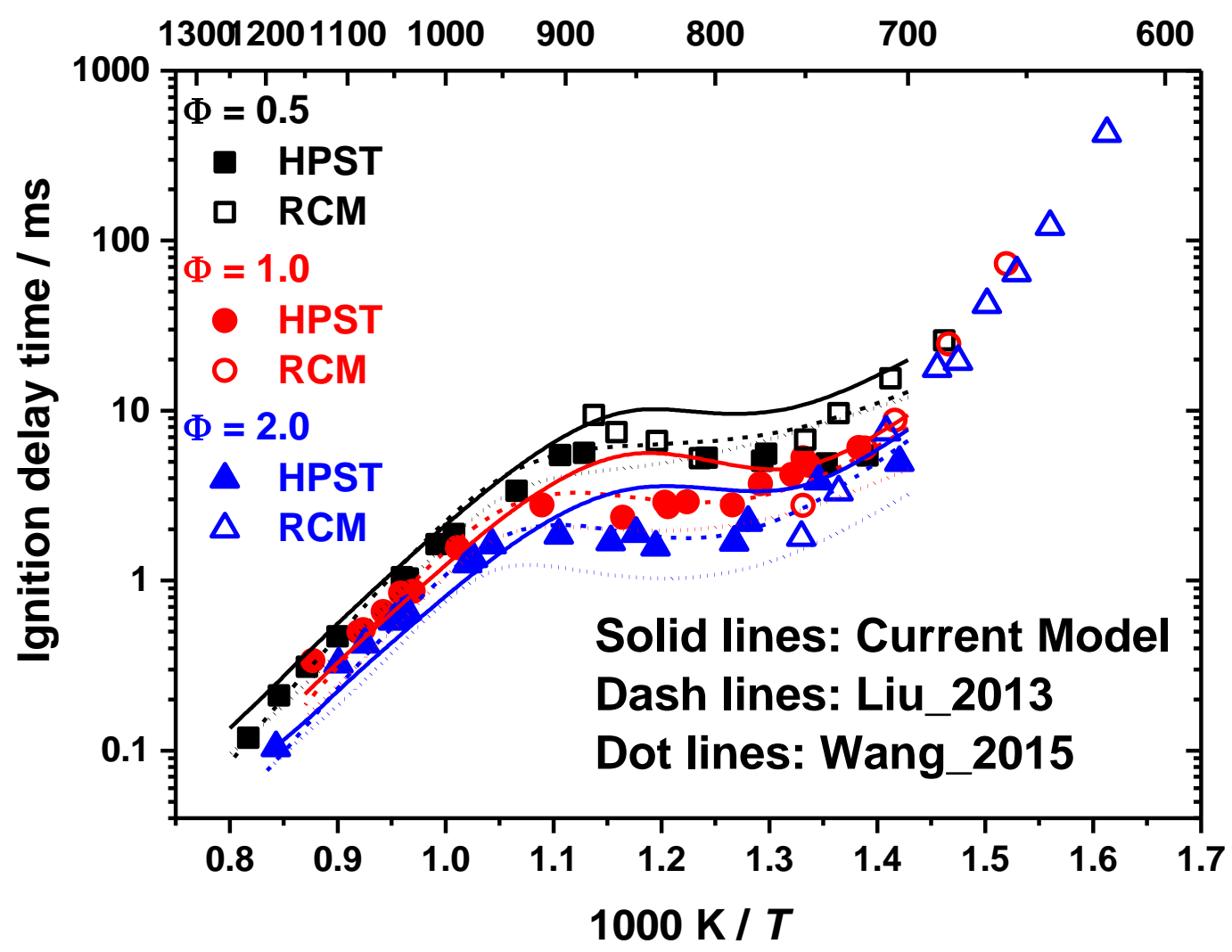

Figure 18. IDTs validation of HSRN oxidation at $p=20$ atm using PRF60 surrogate.

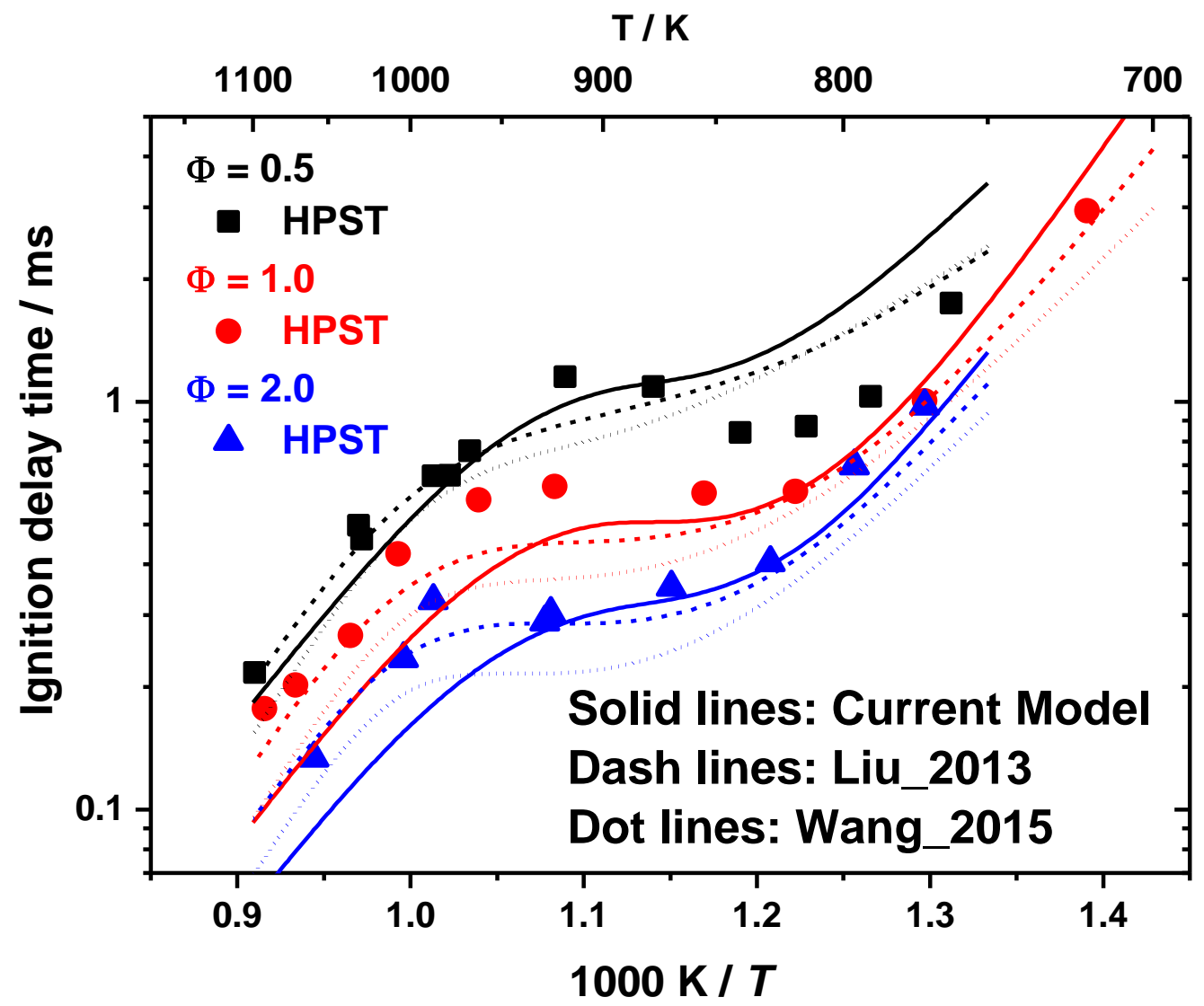

Figure 19. IDTs validation of HSRN oxidation at $p=60$ atm using PRF60 surrogate. 
T / K

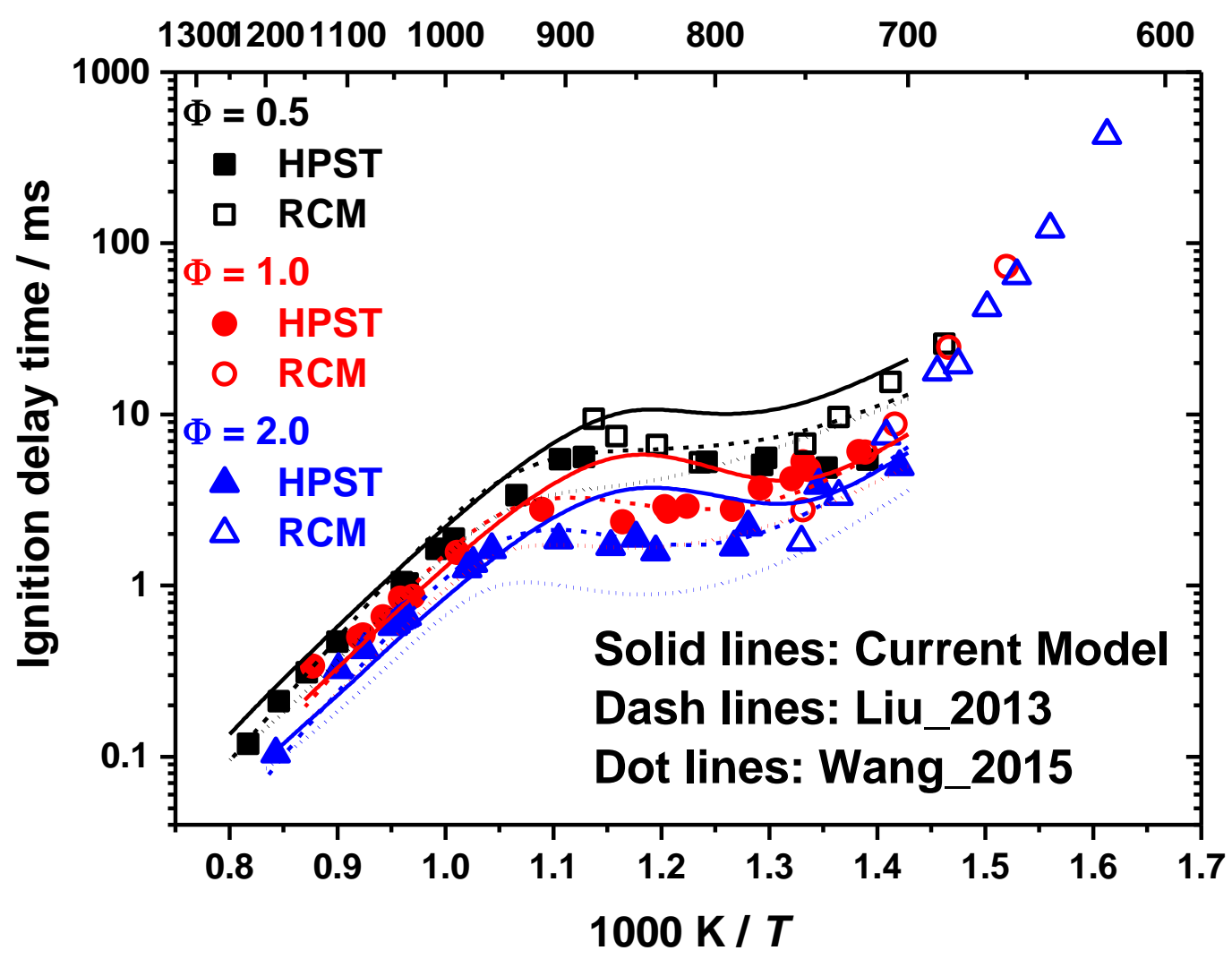

Figure 20. IDTs validation of HSRN oxidation at $p=20$ atm using TPRF60 surrogate.

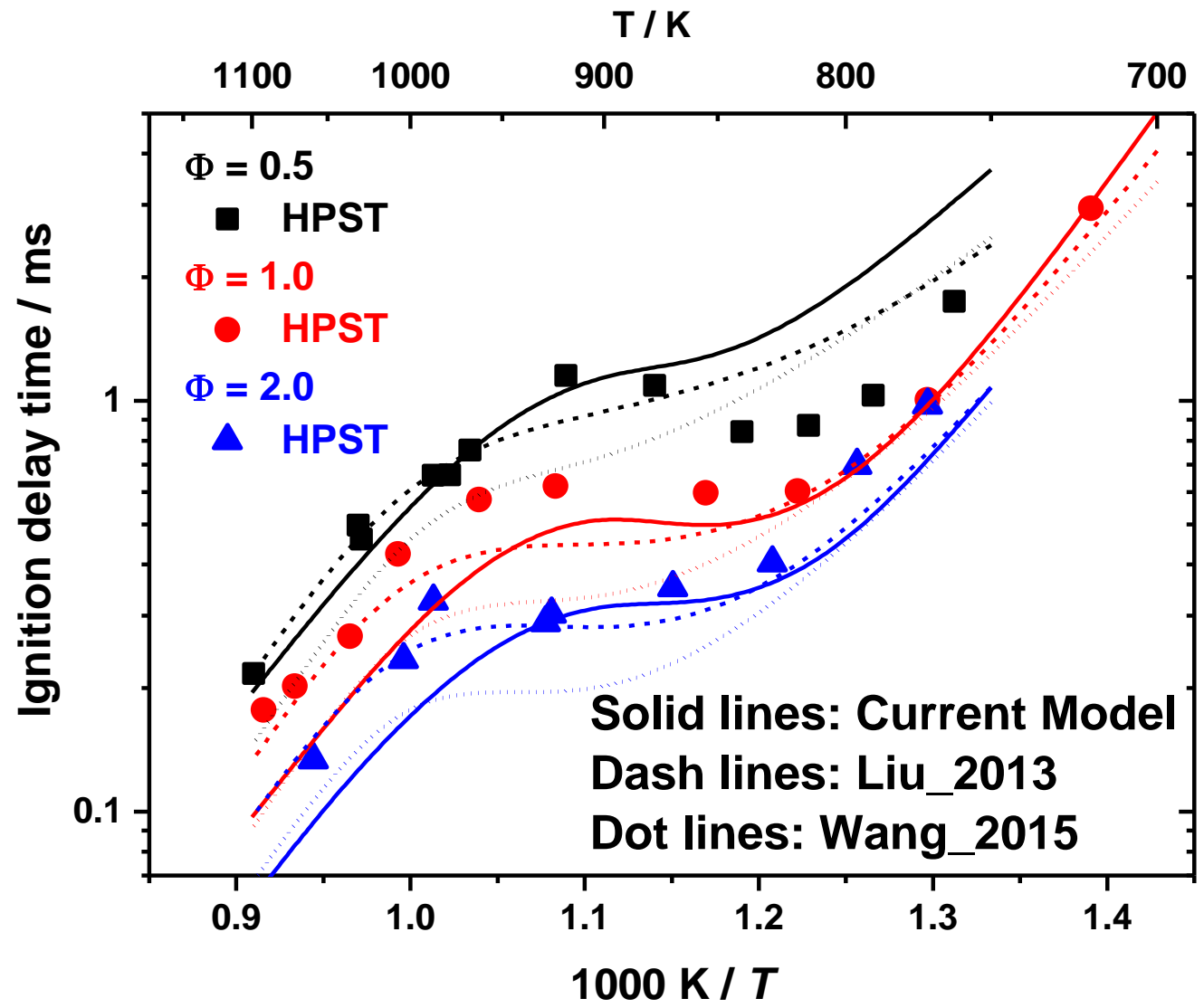

Figure 21. IDTs validation of HSRN oxidation at $p=60$ atm using TPRF60 surrogate. 


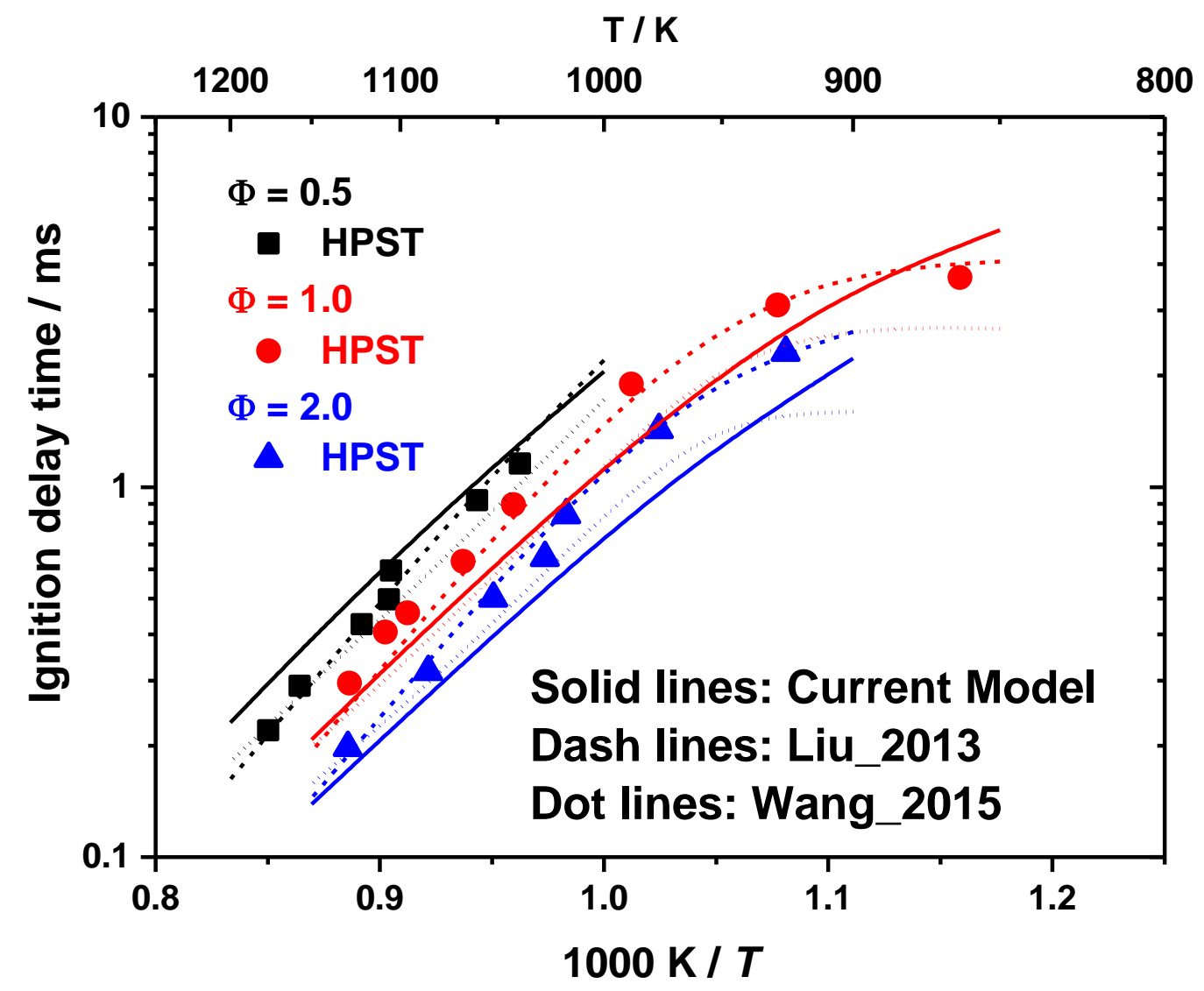

Figure 22. IDTs validation of GCI blend oxidation at $p=20$ atm using PRF77 surrogate.

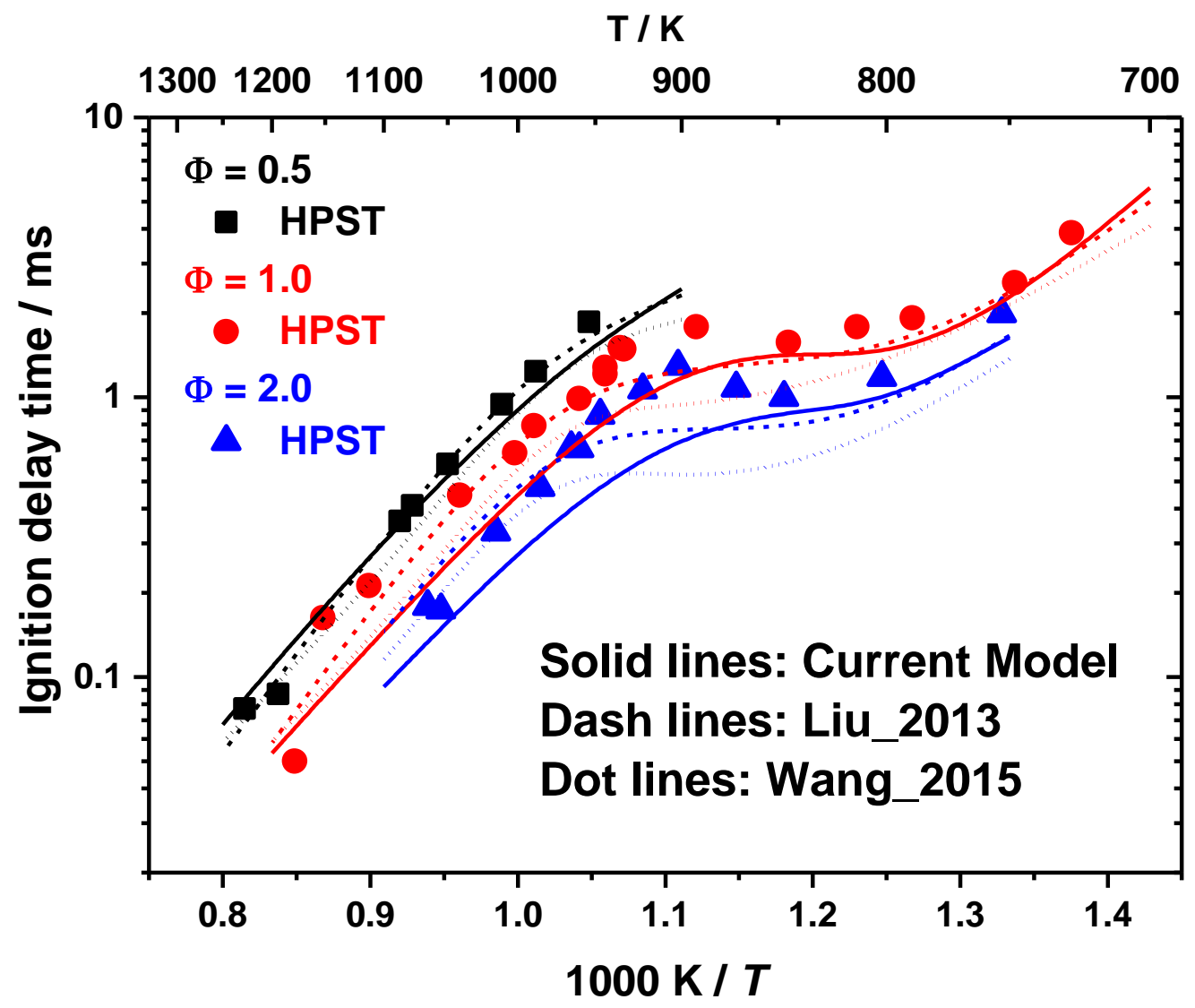

Figure 23. IDTs validation of GCI blend oxidation at $p=40$ atm using PRF77 surrogate. 


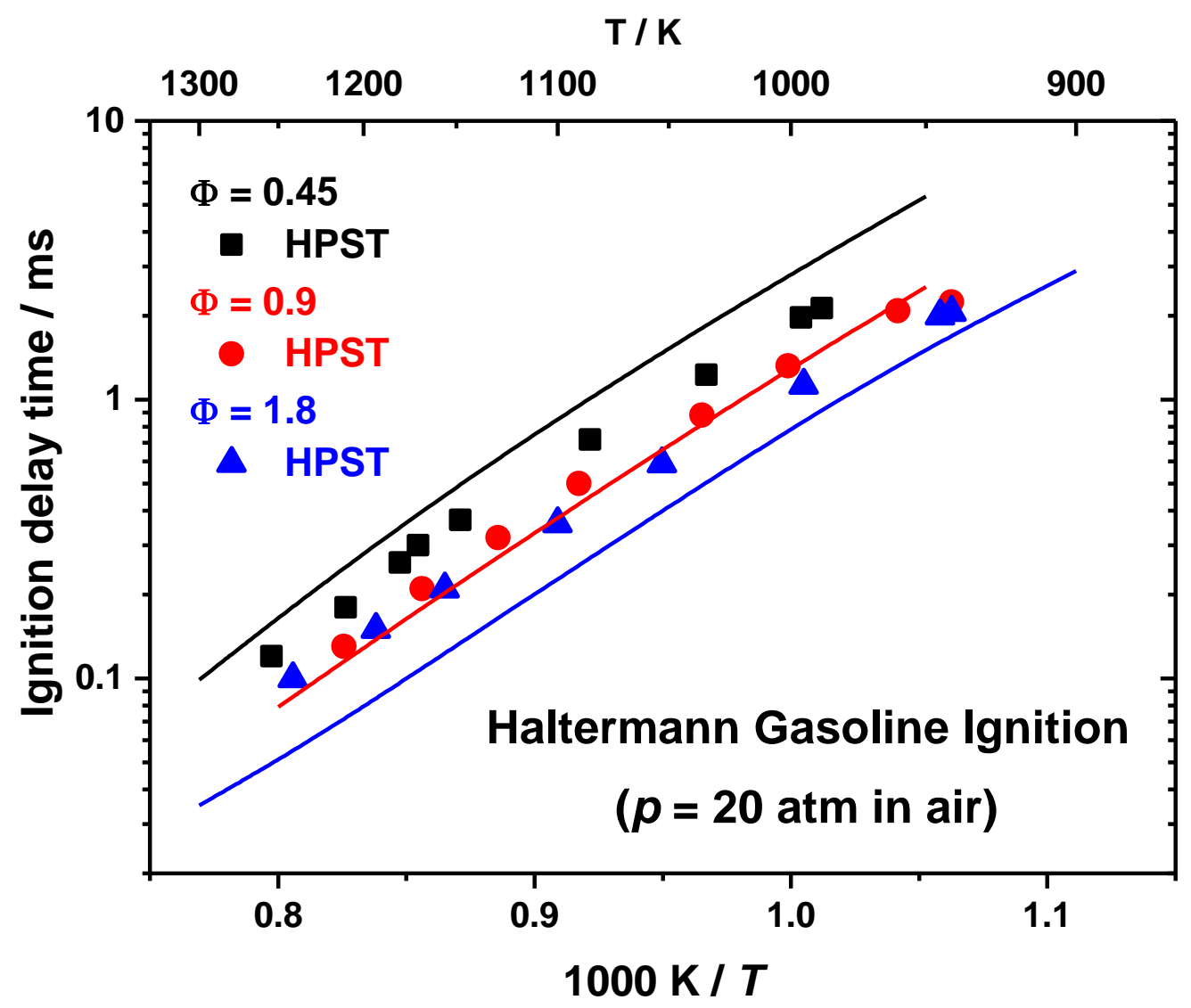

Figure 24. IDTs validation of Haltermann gasoline oxidation at $p=20 \mathrm{~atm}$ using TPRF-E surrogate.

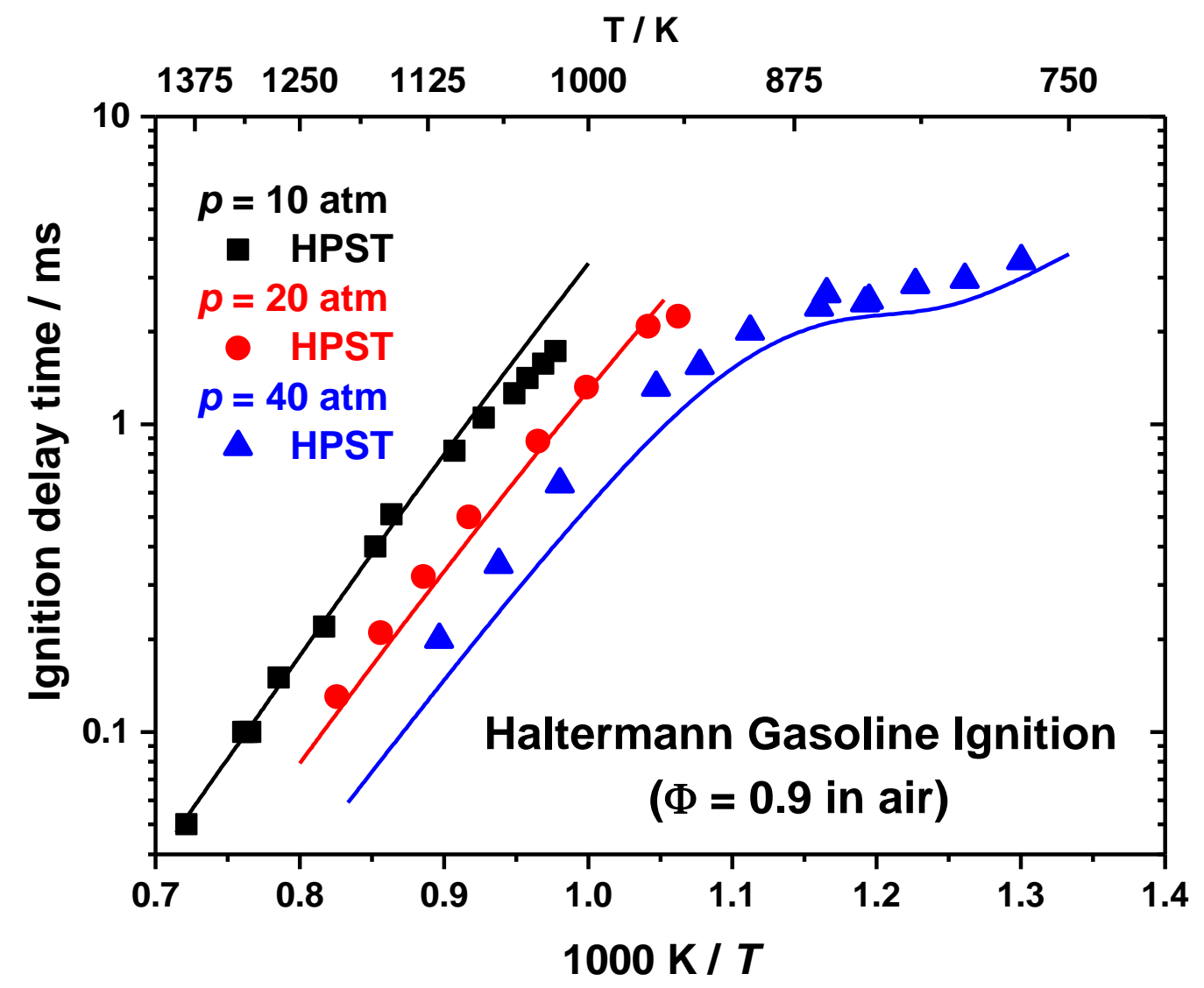

Figure 25. IDTs validation of Haltermann gasoline oxidation at $\varphi=0.9$ using TPRF-E surrogate. 


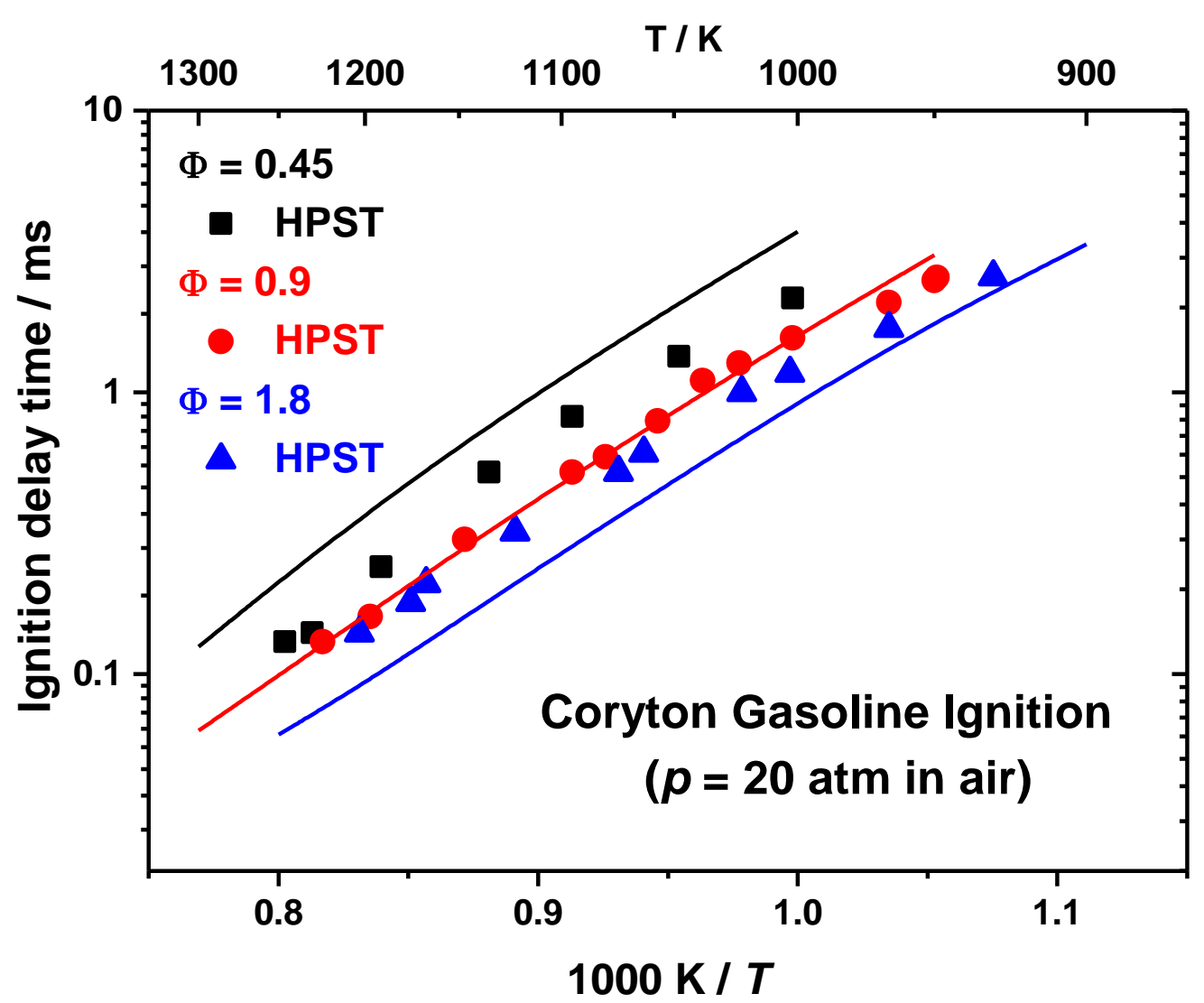

Figure 26. IDTs validation of Coryton gasoline oxidation at $p=20$ atm using TPRF-E surrogate.

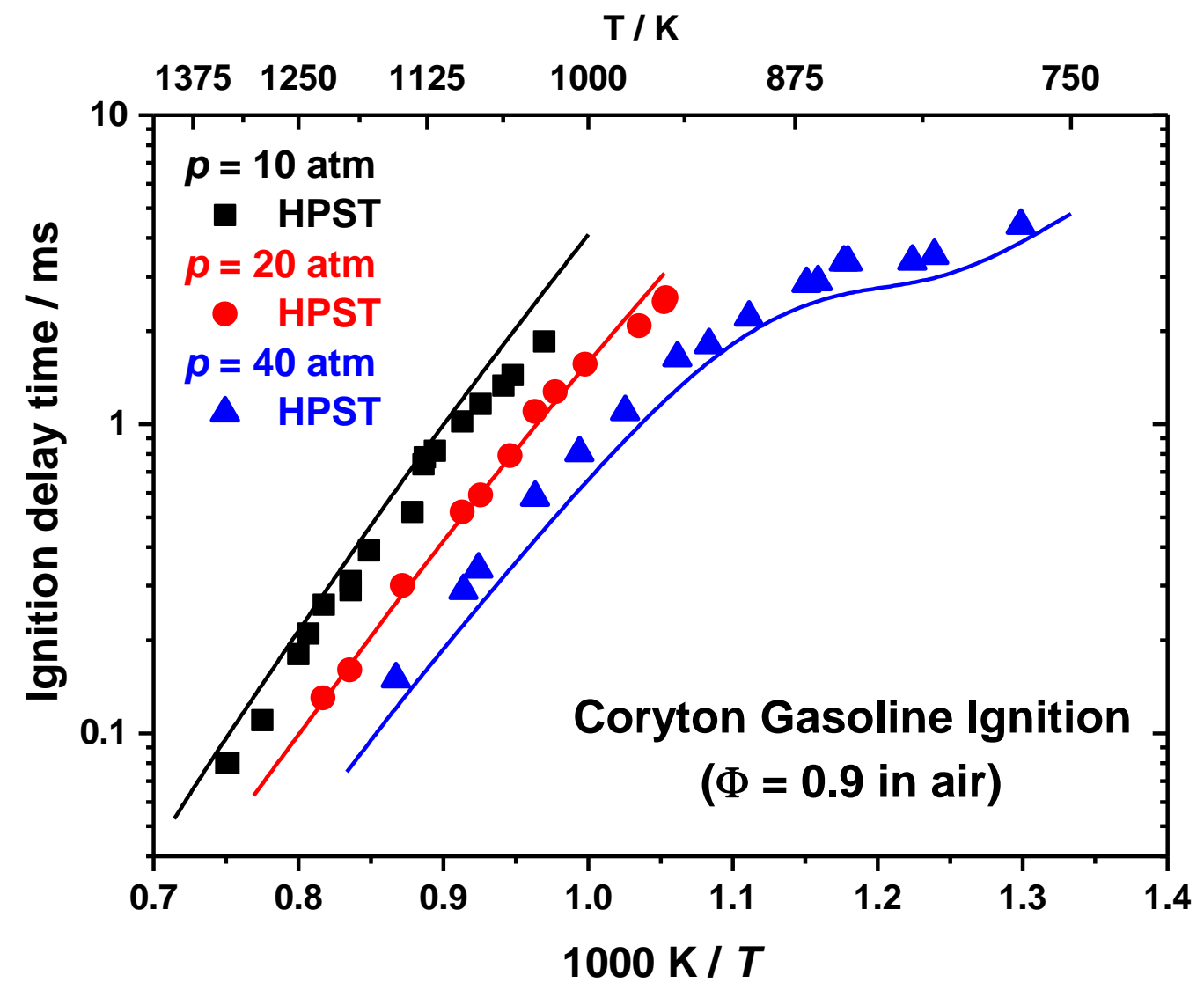

Figure 27. IDTs validation of Coryton gasoline oxidation at $\varphi=0.9$ using TPRF-E surrogate. 


\subsection{Flame speeds (FSs) validations}

Similar to the IDTs validations, comprehensive literature reviews were also carried out for the FSs measurements of relevant fuels. A comprehensive literature review has been done for pure component (iso-octane, n-heptane, toluene and ethanol), gasoline surrogates and real gasolines oxidation, shown in Table S5-S6 in the Supplementary Material. Among these, a comprehensive data matrix was selected for validations:

- $\quad$ iso-Octane [59-66]

- n-Heptane [59-65, 67, 68]

- Toluene [59, 60, 69]

- Ethanol $[63,70,71]$

- iso-Octane and ethanol mixture [63]

- $\quad$-Heptane and ethanol mixture [63]

- $\quad$ PRFs (PRF50, 80, 87, 90 and 95) [61, 63, 65]

- PRF and ethanol mixture [63]

The selected data matrix covers wide range of conditions:

- Research octane number (RON) from low to high $(0-118)$

- Fuel concentration or equivalence ratio from lean to rich $(0.6-1.7)$

- Initial pressures from low to high $(0.5-25 \mathrm{~atm})$

- Unburn gas temperatures from low to high $(298-470 \mathrm{~K})$

Correspondingly, the validation results for the iso-octane/n-heptane/toluene/ethanol mixtures were presented as following:

- Figure 28 shows the validation results for the FSs of iso-octane and ethanol mixture [63].

- Figure 29 shows the validation results for the FSs of n-heptane and ethanol mixture [63].

- Figure 30Figure 32 show the validation results for the FSs of PRFs (PRF50, 80, 87, 90 and 95) $[61,63,65]$ 
- Figure 33 shows the validation results for the FSs of PRF and ethanol mixture [63].

Because of the length limitation of the paper, the validation results for the pure iso-octane, nheptane, toluene and ethanol component were presented in Figure S13-S24 in the Supplementary Material.

In these figures, the results generated from current model were again compared with the ones predicted by two literature models from Liu et al. [3] and Wang et al. [4]. Symbols are experimental data, different line shapes correspond to different models' predictions, and different colors correspond to different experimental conditions: either different initial pressures or different unburn gas temperatures. Overall, good agreements were observed for the entire validation matrix, the proposed model was able to predict the FSs data across a range of equivalence ratios for different reactant mixtures. However, Liu's model performs too slow at fuel lean side and too fast at fuel rich side for almost all mixtures.

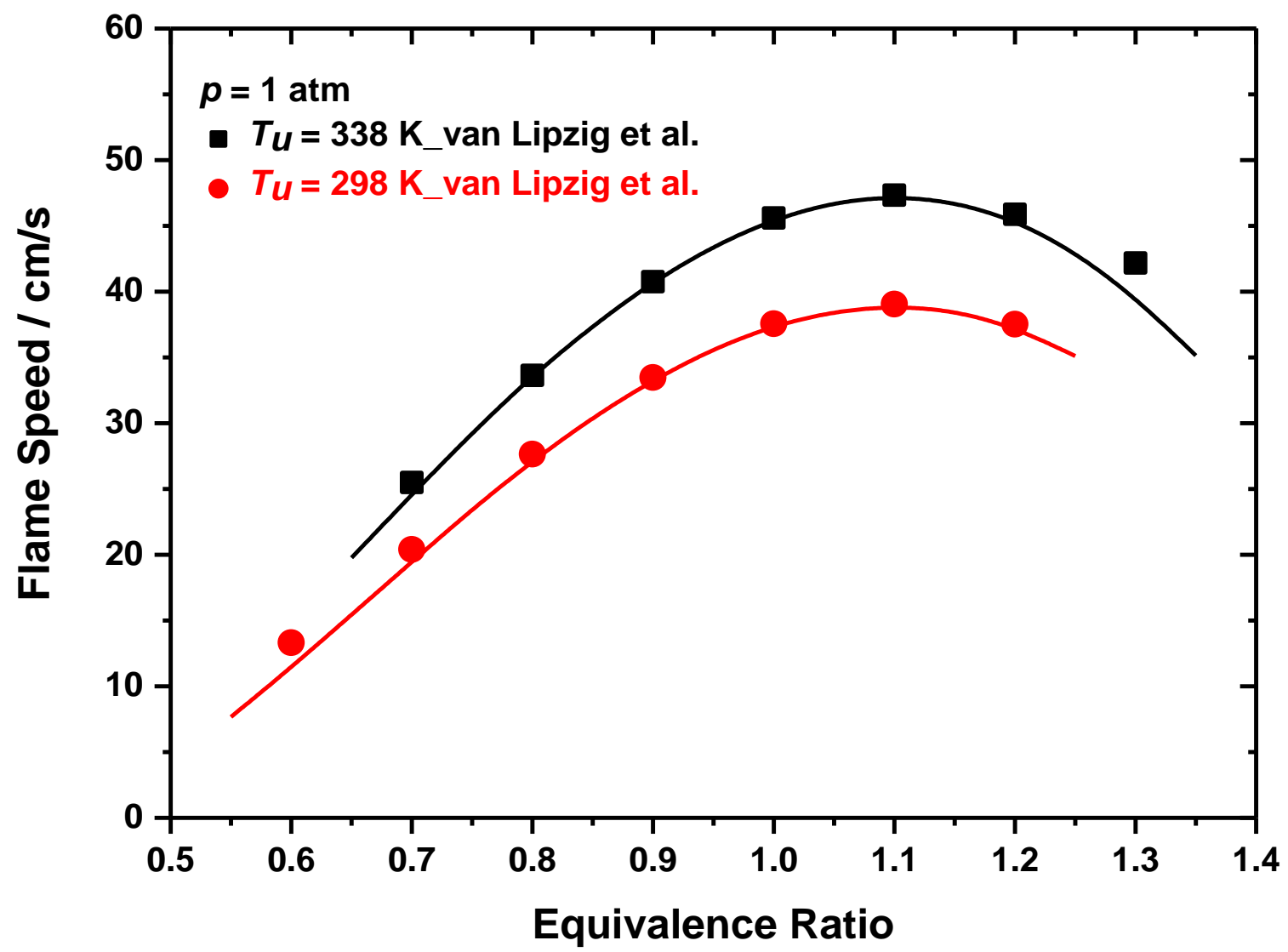

Figure 28. FSs validation of iso-octane and ethanol mixture oxidation at $p=1 \mathrm{~atm}$. 


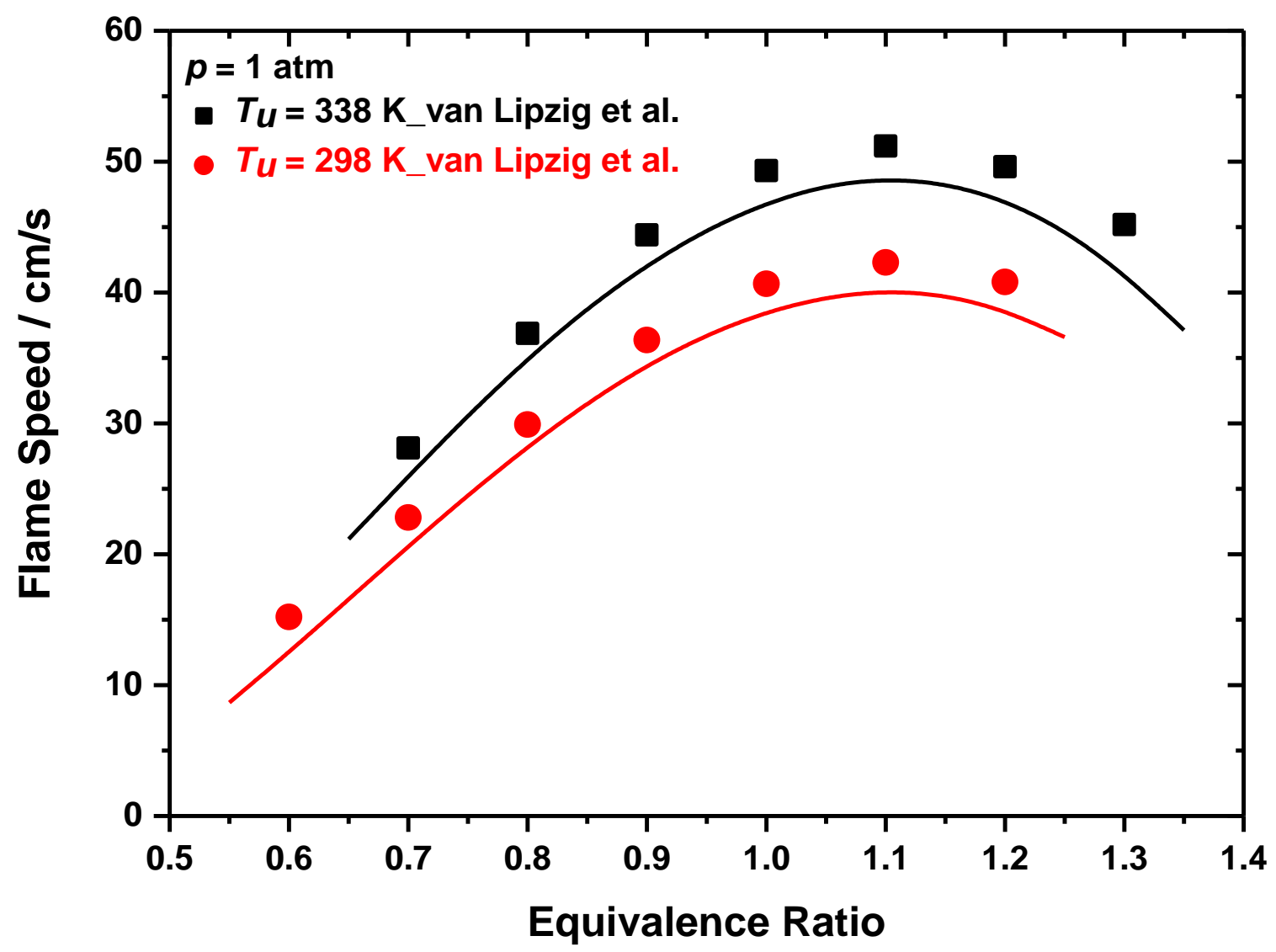

Figure 29. FSs validation of $\mathrm{n}$-heptane and ethanol mixture oxidation at $p=1 \mathrm{~atm}$.

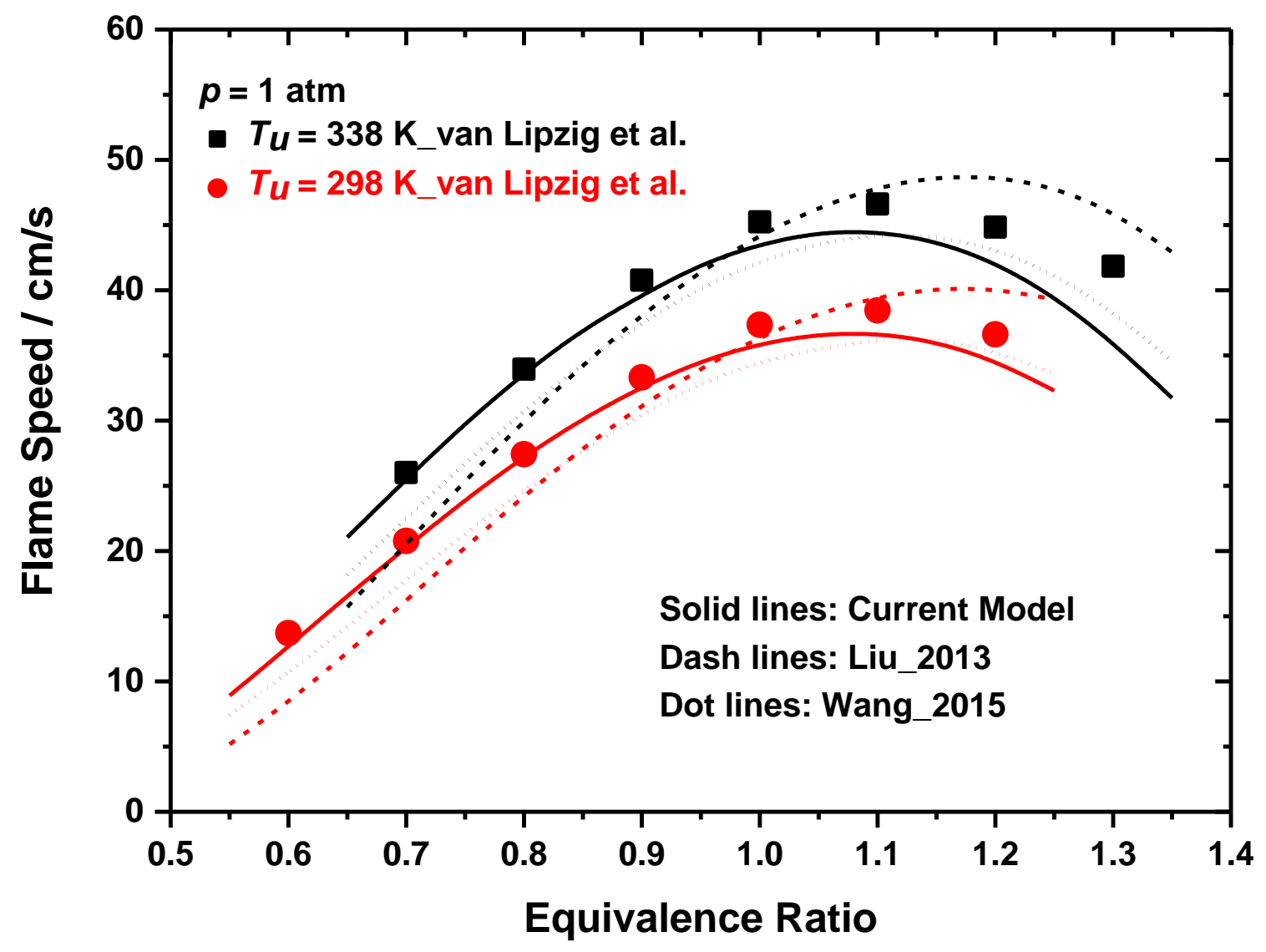

Figure 30. FSs validation of PRF50 oxidation at $p=1 \mathrm{~atm}$. 


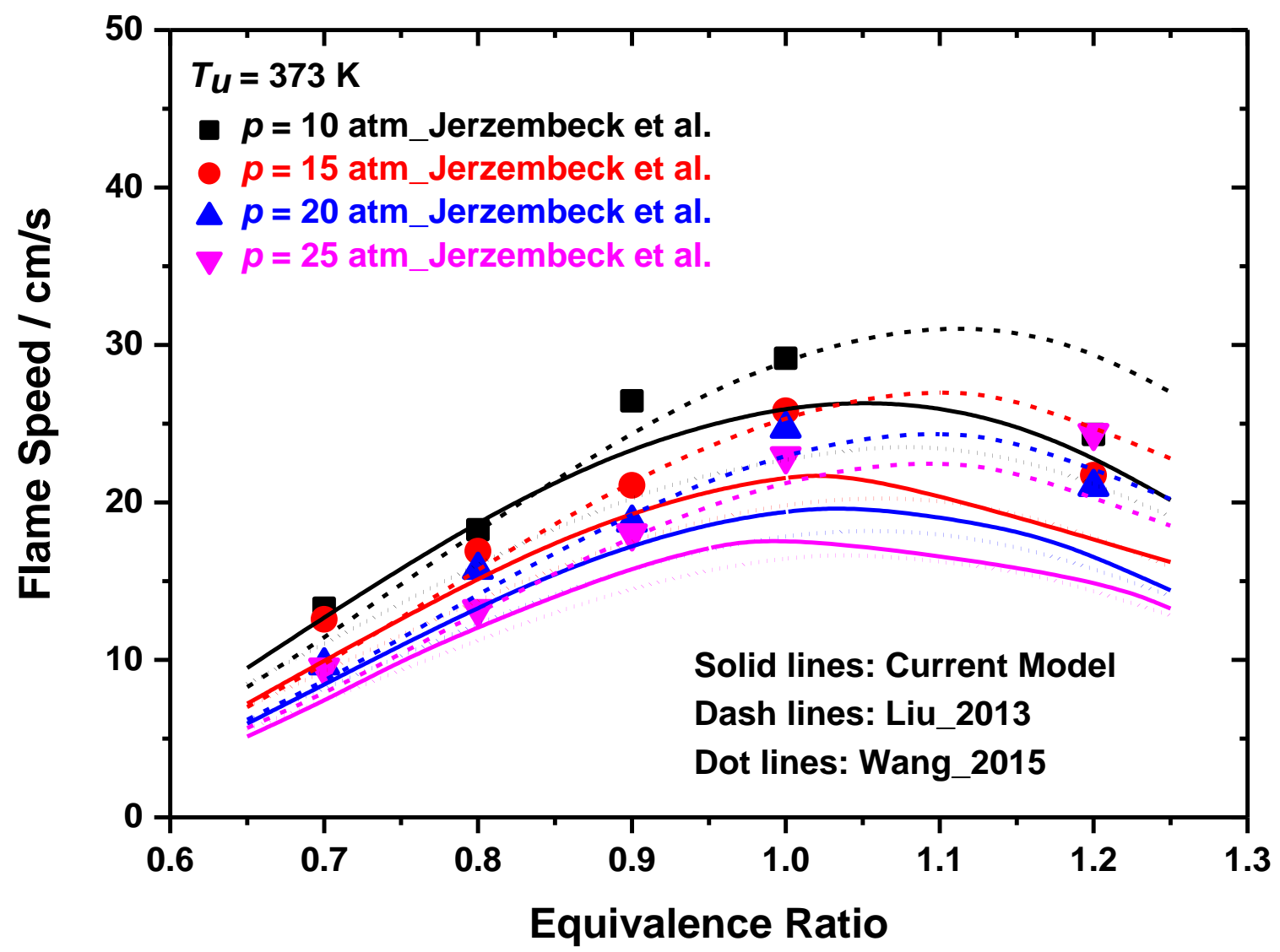

Figure 31. FSs validation of PRF87 oxidation at $T_{u}=373 \mathrm{~K}$.

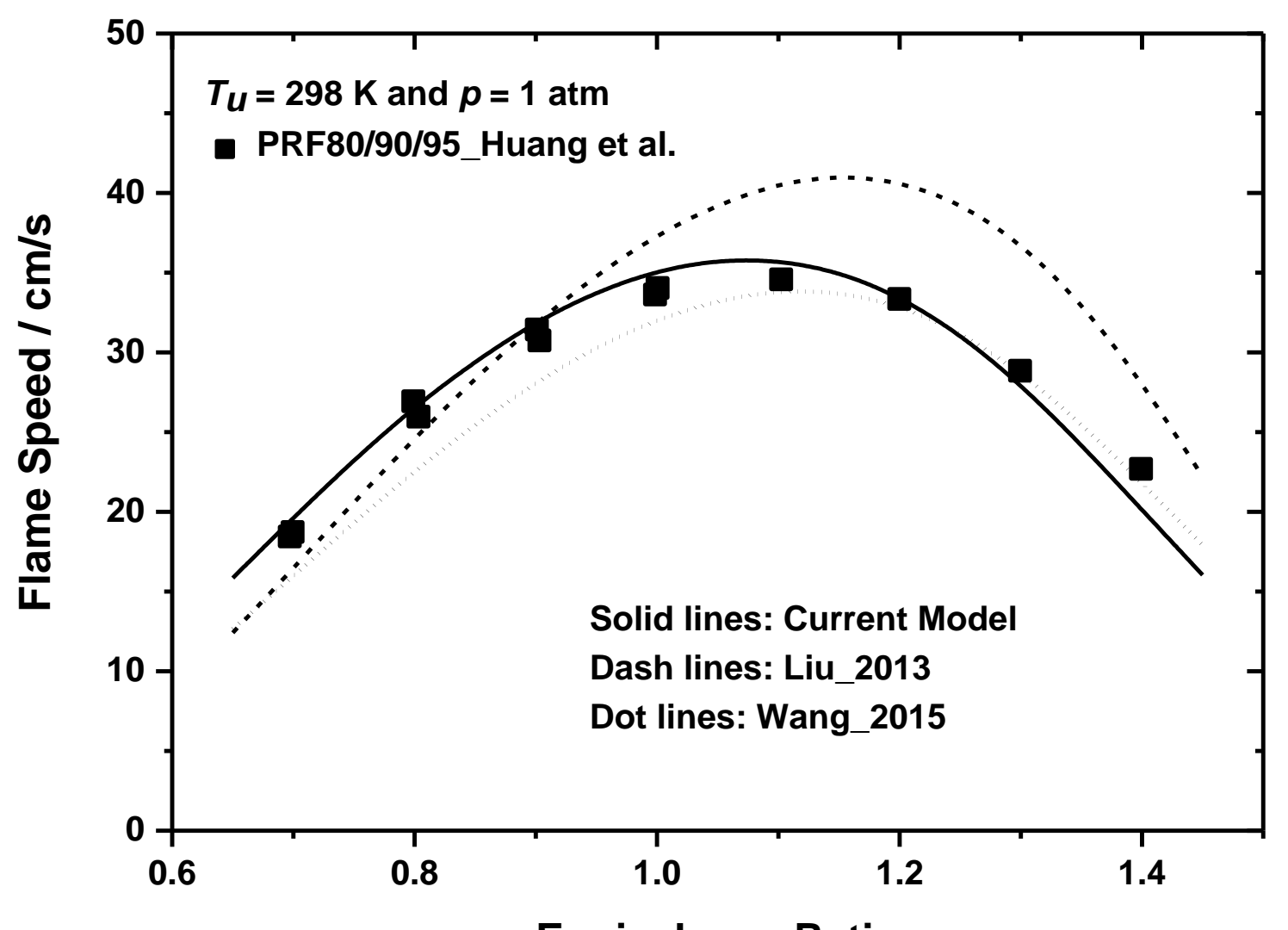

Equivalence Ratio

Figure 32. FSs validation of PRF80, 90 and 95 oxidation at $T_{u}=298 \mathrm{~K}$ and $p=1 \mathrm{~atm}$. 


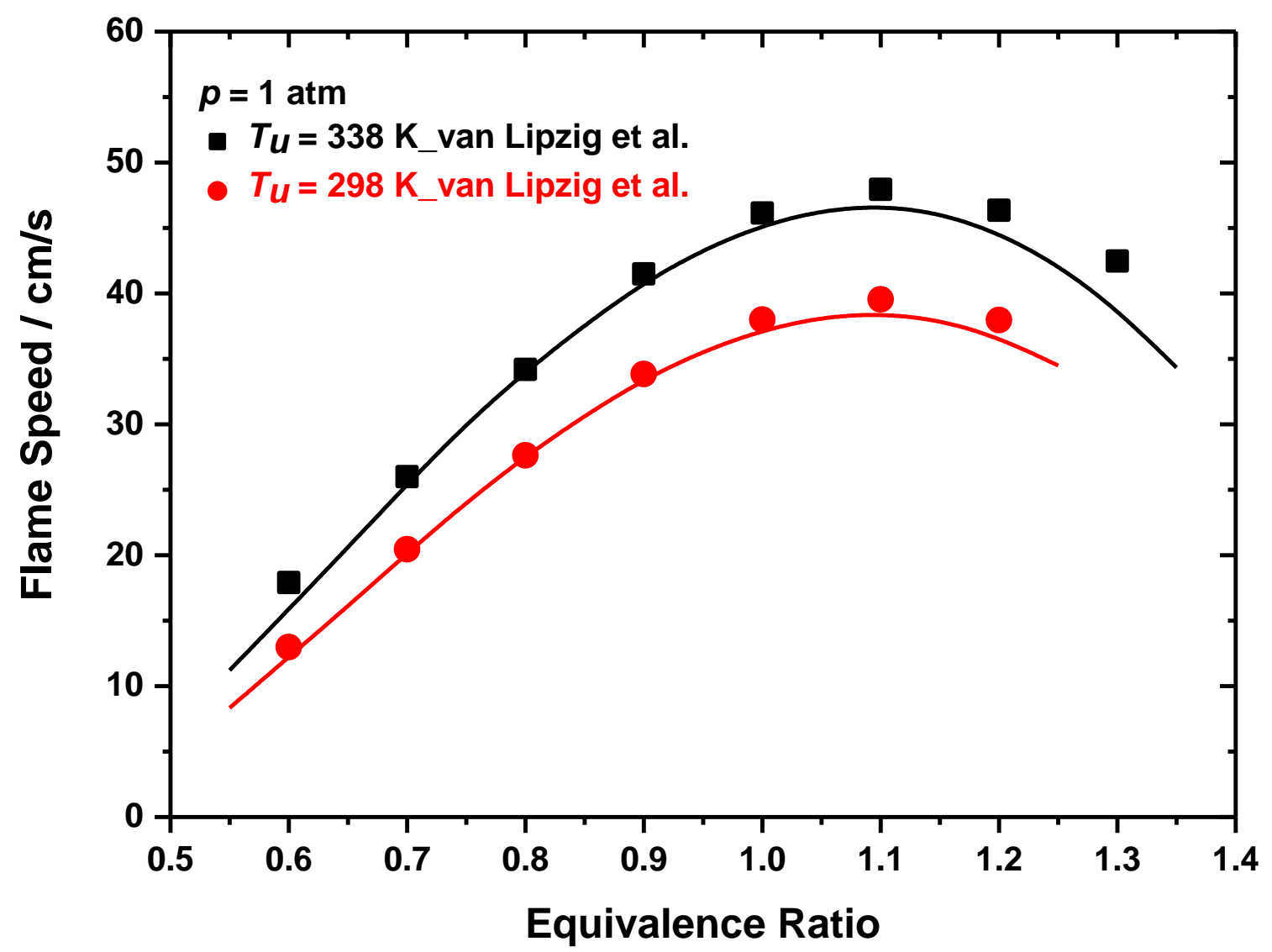

Figure 33. FSs validation of PRF and ethanol mixture oxidation at $p=1 \mathrm{~atm}$.

\subsection{Sensitivity, rate of production (ROP) and flux analyses}

Sensitivity, rate of production (ROP) and flux analyses were carried out in order to show the reasonably detailed chemistry in this highly reduced model. Key reactions responsible for IDT targets and fuel consumption pathways were identified. Analyses in this section and the IDT and FS validations in next two sections were performed using ANSYS Chemkin 19.1 software package [72]. A TPRF-ethanol mixture $\left(0.78 \% \mathrm{IC}_{8} \mathrm{H}_{18}, 0.28 \% \mathrm{NC}_{7} \mathrm{H}_{16}, 0.53 \% \mathrm{C}_{6} \mathrm{H}_{5} \mathrm{CH}_{3}, 0.35 \% \mathrm{C}_{2} \mathrm{H}_{5} \mathrm{OH}, 20.60 \%\right.$ $\mathrm{O}_{2}$ and $77.48 \% \mathrm{~N}_{2}$ ) used as a Haltermann gasoline surrogate [14] was selected as a representative reactant for the sensitivity, ROP and flux analyses in this section, and simulations were performed in a constant-volume batch reactor.

The sensitivity coefficient of the basic sensitivity analyses for IDT targets were defined as: 


$$
S=\frac{\ln \left(\tau_{+} / \tau_{-}\right)}{\ln \left(k_{+} / k_{-}\right)}=\frac{\ln \left(\tau_{+} / \tau_{-}\right)}{\ln (2.0 / 0.5)}
$$

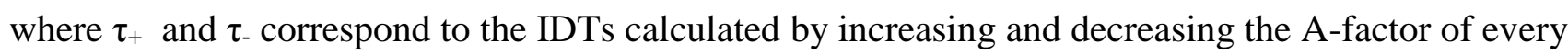
reaction rate by a factor of two respectively. A positive value of $S$ indicates an inhibiting reaction and vice versa.

Figure 34 shows the sensitivity analysis results at $\varphi=0.9$ in air and $p=40$ atm. The top-ten most relevant reactions that are sensitive to fuel and fuel radicals were highlighted at (a) $T=1200$ and (b) $T$ $=800 \mathrm{~K}$, respectively. The typical reaction classes, such as alkyl radicals $\left(\dot{\mathrm{C}}_{8} \mathrm{H}_{17}\right.$ and $\left.\mathrm{NC}_{7} \mathrm{H}_{15}\right)$ unimolecular decomposition, $\mathrm{H}$-atom abstraction from weekly-bonded allylic- and $\alpha$-sites $\left(\mathrm{C}_{6} \mathrm{H}_{5} \mathrm{CH}_{3}\right.$ $+\mathrm{O}_{2}$ and $\left.\mathrm{C}_{2} \mathrm{H}_{5} \mathrm{OH}+\mathrm{HO}_{2}\right)$, alkylperoxy radicals $\left(\mathrm{C}_{8} \mathrm{H}_{17} \dot{\mathrm{O}}_{2}\right.$ and $\left.\mathrm{NC}_{7} \mathrm{H}_{15} \mathrm{OO}\right)$ isomerization and concerted elimination, were identified as either promoting or inhibiting the reactivity.

Figure 35 shows the ROP analysis results at $\varphi=0.9$ in air and $p=40 \mathrm{~atm}$. The concentration profiles of four reactants $\left(\mathrm{IC}_{8} \mathrm{H}_{18}, \mathrm{NC}_{7} \mathrm{H}_{16}, \mathrm{C}_{6} \mathrm{H}_{5} \mathrm{CH}_{3}\right.$ and $\left.\mathrm{C}_{2} \mathrm{H}_{5} \mathrm{OH}\right)$ and pressure profiles were plotted in different colors at (a) $T=1200$ and (b) $T=800 \mathrm{~K}$, respectively. Flux analysis was performed at the time point of 0.035 and $0.7 \mathrm{~ms}$ respectively, where the four reactants were under rapid consumption process. The qualitative flux analysis results shown in Figure 36 demonstrates the reasonably detailed chemistry that has been included in this highly reduced model. Note that, the results have combined the reaction pathways at high-temperature $(T=1200 \mathrm{~K})$ and low-temperature $(T=800 \mathrm{~K})$ together, and for iso-octane and n-heptane oxidation, typical structures were presented for the lumped fuel radical $\left(\dot{\mathrm{C}}_{8} \mathrm{H}_{17}\right.$ and $\left.\mathrm{NC}_{7} \mathrm{H}_{15}\right)$ and the subsequent radical pools. 


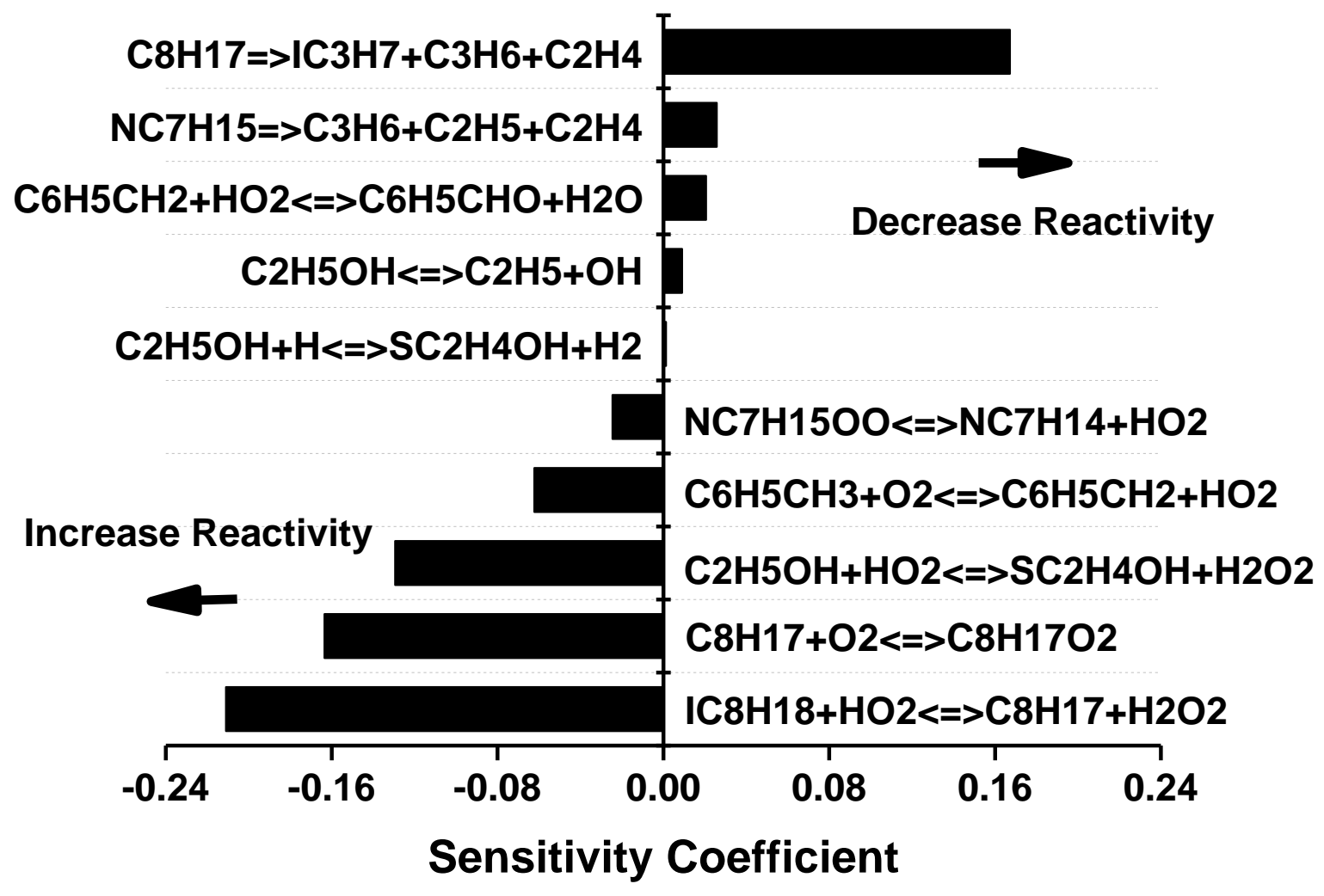

(a) $T=1200 \mathrm{~K}$

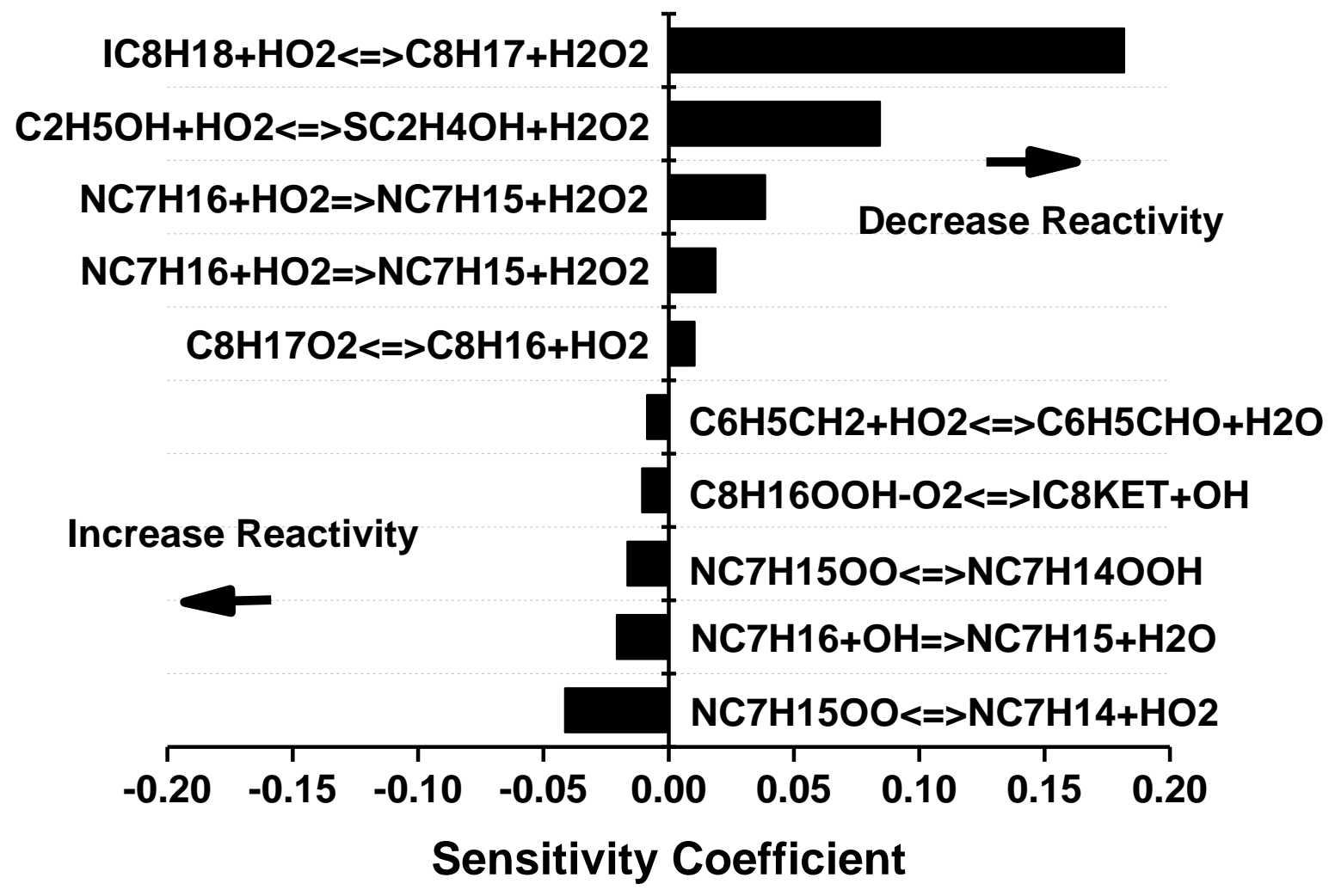

(b) $T=800 \mathrm{~K}$

Figure 34. Sensitivity analysis for a TPRF-Ethanol mixture used as a Haltermann Gasoline surrogate $\left(0.78 \% \mathrm{IC}_{8} \mathrm{H}_{18}, 0.28 \% \mathrm{NC}_{7} \mathrm{H}_{16}, 0.53 \% \mathrm{C}_{6} \mathrm{H}_{5} \mathrm{CH}_{3}, 0.35 \% \mathrm{C}_{2} \mathrm{H}_{5} \mathrm{OH}, 20.60 \% \mathrm{O}_{2}\right.$ and $\left.77.48 \% \mathrm{~N}_{2}\right), \varphi=$ 0.9 in 'air' and $p=40$ atm. 


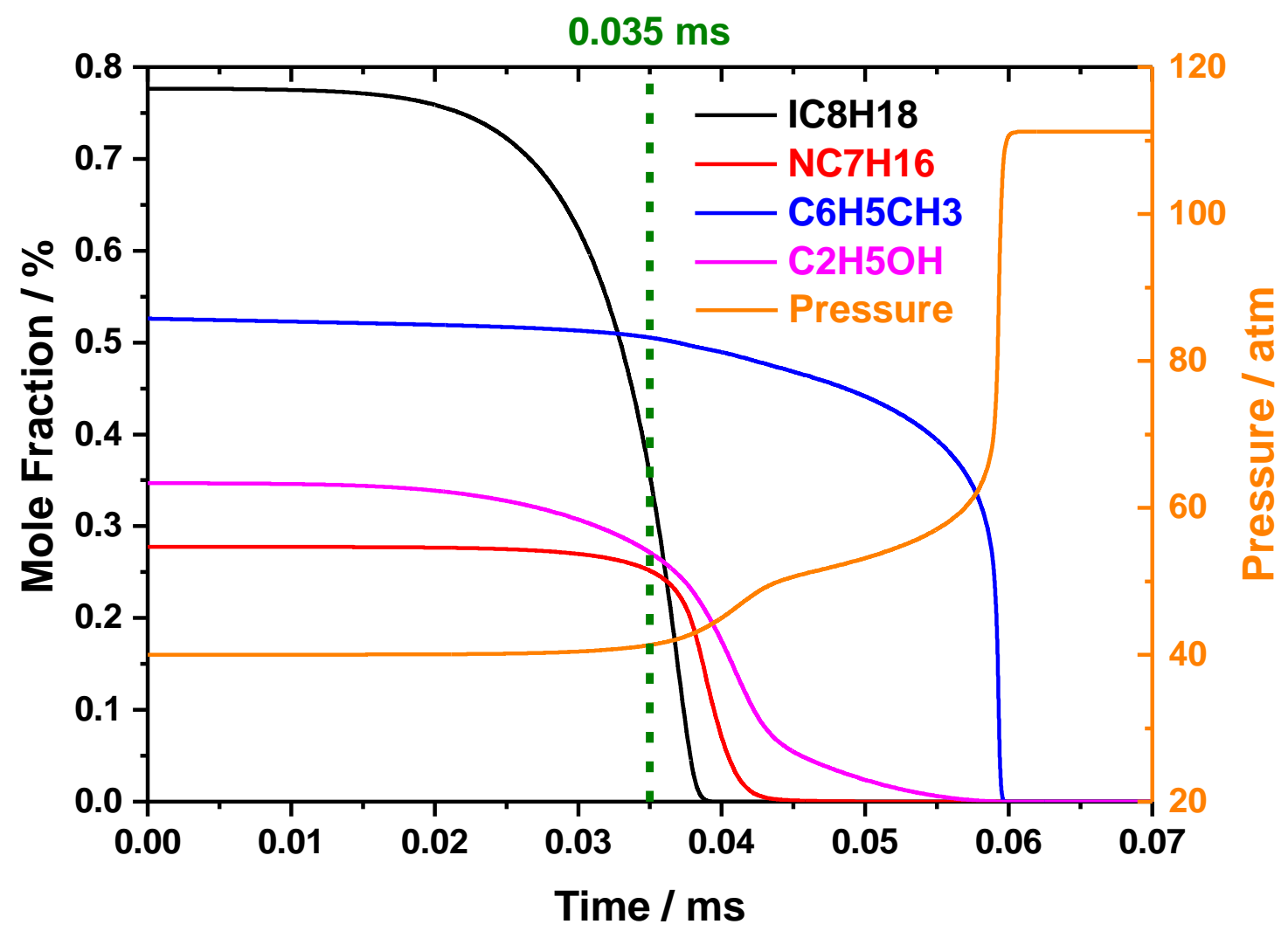

(a) $T=1200 \mathrm{~K}$

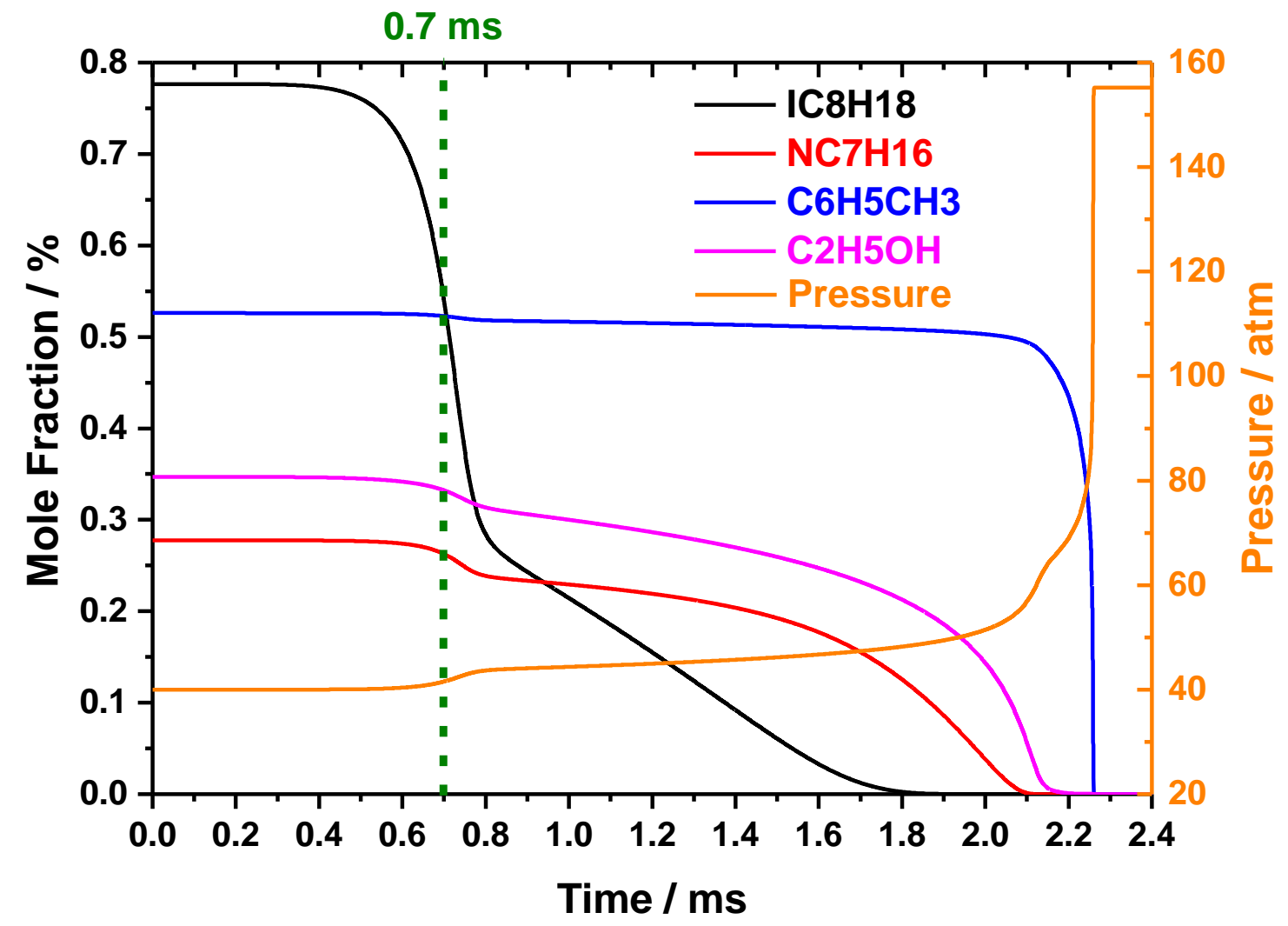

(b) $T=800 \mathrm{~K}$

Figure 35. ROP analysis for a TPRF-Ethanol mixture used as a Haltermann Gasoline surrogate $\left(0.78 \% \mathrm{IC}_{8} \mathrm{H}_{18}, 0.28 \% \mathrm{NC}_{7} \mathrm{H}_{16}, 0.53 \% \mathrm{C}_{6} \mathrm{H}_{5} \mathrm{CH}_{3}, 0.35 \% \mathrm{C}_{2} \mathrm{H}_{5} \mathrm{OH}, 20.60 \% \mathrm{O}_{2}\right.$ and $\left.77.48 \% \mathrm{~N}_{2}\right), \varphi=$ 0.9 in 'air' and $p=40$ atm. 
$\mathrm{IC}_{8} \mathrm{H}_{18}: \mathbf{0 . 7 8 \%}$<smiles>CC(C)CC(C)(C)C</smiles>

$\downarrow+\dot{o} H$<smiles>CCCC=C=CCCCCC(C)CC(C)(C)C</smiles>

$\downarrow+\mathrm{O}_{2}$<smiles>CCC(C)(C)C=C(C)C(C)(C)C=CC(C)(C)C([Ge]O)C(C)C</smiles><smiles>[Tl]</smiles><smiles>CC(C)C(OO)C(C)(C)C</smiles><smiles>[13CH3][13CH3]</smiles><smiles>CCC(C)(C)C(=O)C(C)(C)O</smiles>

$\mathrm{C}_{6} \mathrm{H}_{5} \mathrm{CH}_{3}: 0.53 \%$<smiles>C[14c]1[14cH][14cH][14cH][14c]([14CH2]c2ccccc2)[14cH]1</smiles>

$\downarrow+\dot{\mathrm{OH}}$ and $\mathrm{O}_{2}$<smiles>Cc1ccccc1</smiles>

$\downarrow+\mathrm{HO}_{2}$<smiles>O=Cc1ccccc1</smiles>

$\downarrow+\dot{\mathrm{OH}}$ and $\dot{\mathrm{H}}$<smiles>C=Cc1ccccc1</smiles><smiles>CO[14c]1[14cH][14cH][14cH][14cH][14cH]1</smiles>

$\mathrm{NC}_{7} \mathrm{H}_{16}: 0.28 \%$<smiles>CCCCCCC</smiles>

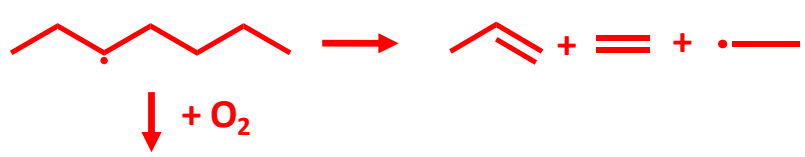

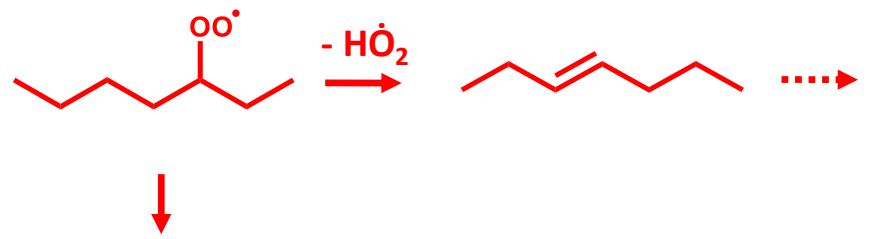<smiles>CCCCC(CC)OO</smiles>

Figure 36. Flux analysis for a TPRF-Ethanol mixture used as a Haltermann Gasoline surrogate $\left(0.78 \% \mathrm{IC}_{8} \mathrm{H}_{18}, 0.28 \% \mathrm{NC}_{7} \mathrm{H}_{16}, 0.53 \% \mathrm{C}_{6} \mathrm{H}_{5} \mathrm{CH}_{3}, 0.35 \% \mathrm{C}_{2} \mathrm{H}_{5} \mathrm{OH}, 20.60 \% \mathrm{O}_{2}\right.$ and $\left.77.48 \% \mathrm{~N}_{2}\right), \varphi=$ 0.9 in 'air' and $p=40 \mathrm{~atm}$. 


\subsection{Constant volume reacting spray related CFD simulations}

Before we illustrate the CFD simulation results of HSRN ignition in the setup described above, the IDT validation of this practical fuel and PRF60 mixture using both PRF and TPRF surrogates in a homogenous reactor (shock tube) has been carried out under the condition of $\varphi=1.0$ and $\mathrm{p}=60 \mathrm{~atm}$, as shown in Figure 37. Figure 38 shows the CFD simulation results for the IDTs of HSRN fuel. The experimental conditions used for validation are the ambient pressure of $6 \mathrm{MPa}$, ambient temperature of 800,900 and $1100 \mathrm{~K}$, injection pressure of $150 \mathrm{MPa}$ and $15 \%$ ambient oxygen. The ignition delay time is defined as the time until $1 \%$ of the cumulative heat release has occurred from the Start Of Injection (SOI). Both PRF and TPRF surrogates are considered for the current model and compared with that of Liu's model and Wang's model. It was found that the current model predicts ignition delay times closer to the experimental values compared to other models. When different surrogates are considered, TPRF surrogate predicts better compared with the PRF surrogate. This shows that the TPRF surrogate of the current model is performing well under heavy-duty engine conditions.

Figure 39 shows the comparisons between experimental and simulated Flame Lift-Off Length (FLOL) under the ambient temperature of $1100 \mathrm{~K}$, the ambient pressure of $6 \mathrm{MPa}$ and injection pressure of $150 \mathrm{MPa}$. The $\mathrm{OH}$ profiles are time averaged from 2 to $5 \mathrm{~ms}$ after the start of injection when combustion has stabilized. The $\mathrm{OH}$ boundaries are defined as $2 \%$ of the maximum $\mathrm{OH}$ mass fraction as per Engine Combustion Network (ECN) guidelines [73]. The simulated FLOL is defined as the distance from the injector nozzle to the first appearance of $\mathrm{OH}$ which forms a continuous $\mathrm{OH}$ profile. It can be seen that the experimental and simulated FLOL by both PRF and TPRF surrogates of the current model are very similar. FLOL is predominantly governed by the chemistry of fuel under high ambient temperatures and densities [74]. This shows that the current model is good enough to simulate HSRN combustion under diesel engine conditions. 


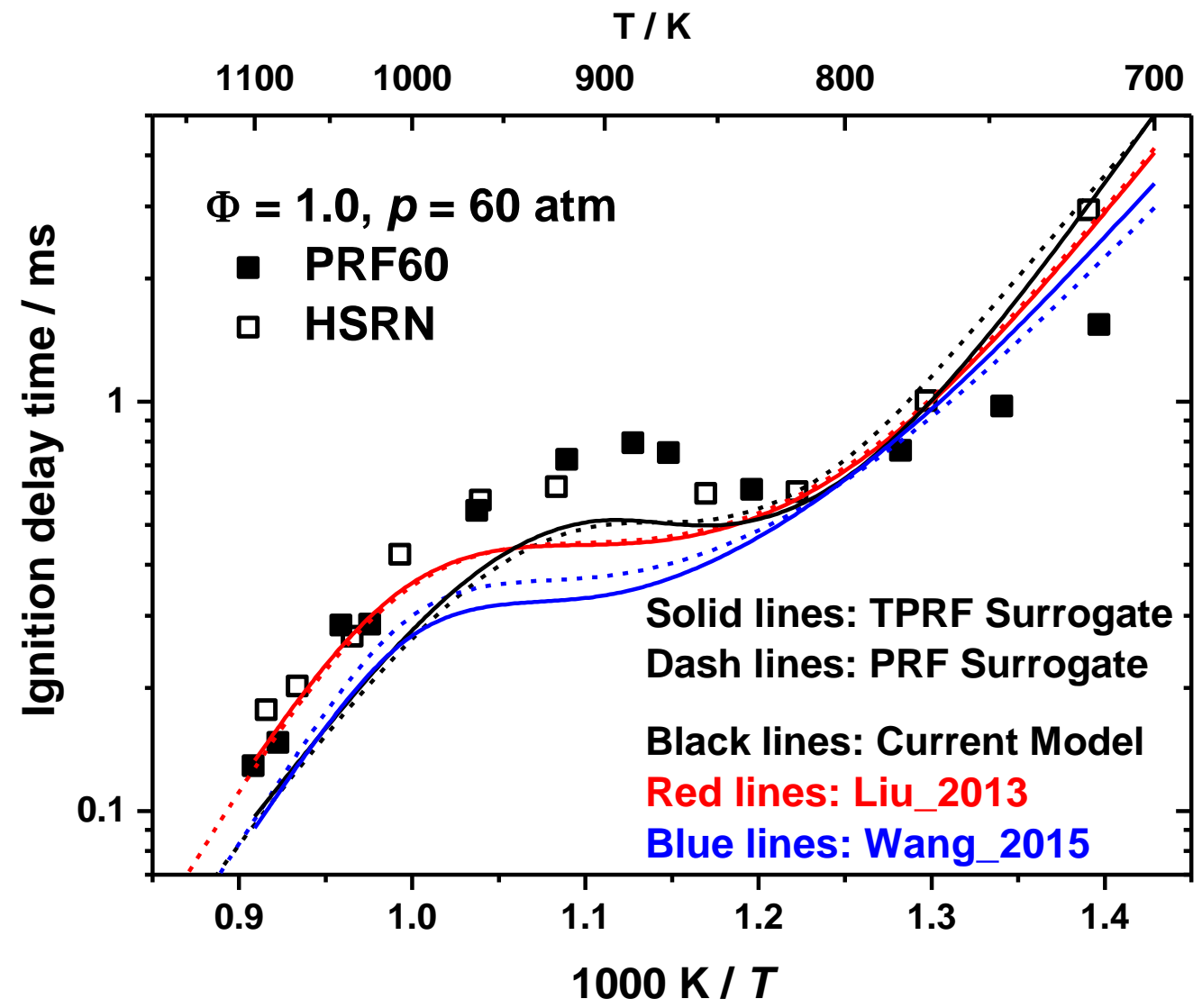

Figure 37. IDTs validation of both HSRN and PRF60 oxidation at $\varphi=1.0$ and $p=60$ atm, using both PRF and TPRF surrogates.

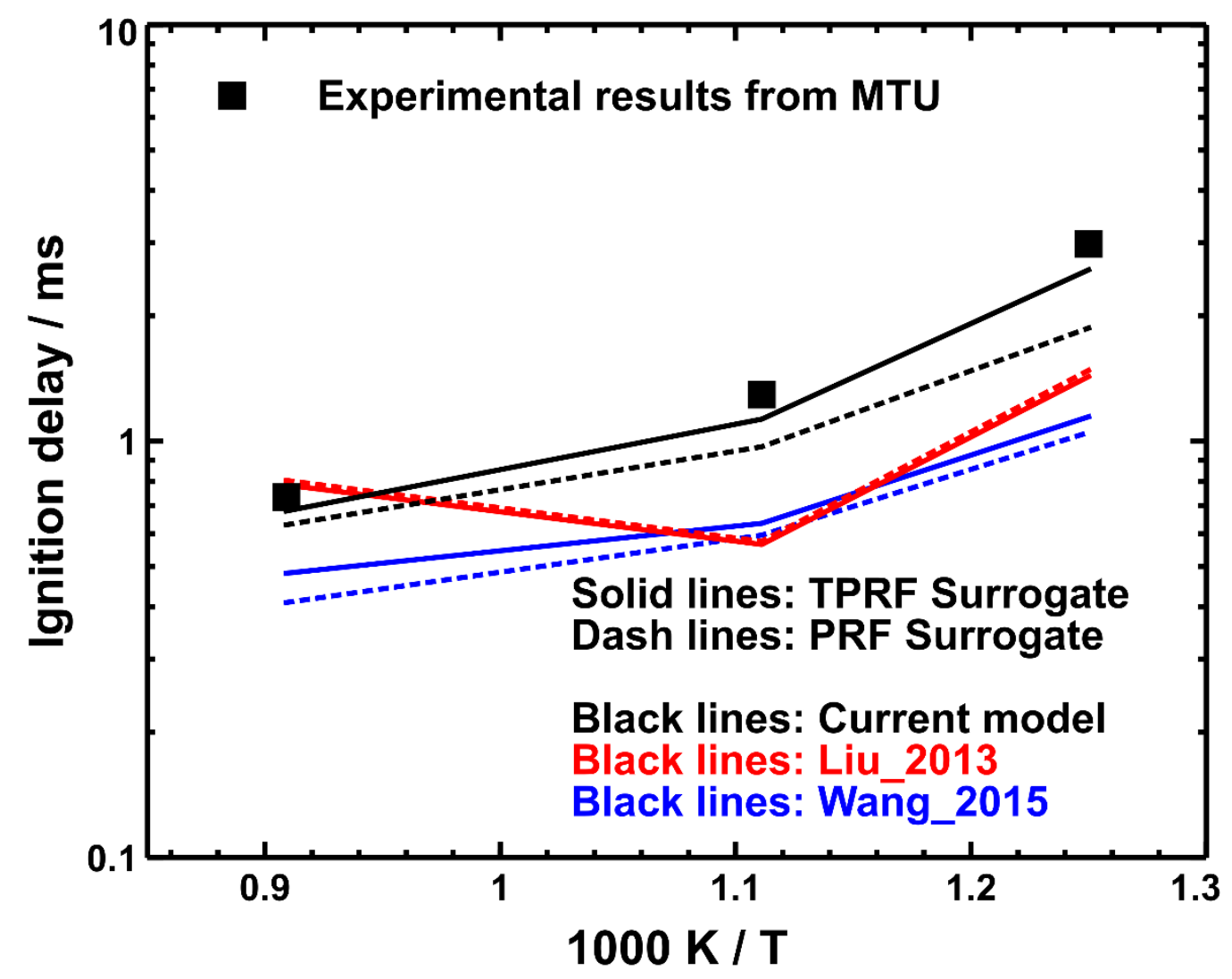

Figure 38. IDTs validation of HSRN at ambient pressure of 60 bar, using both PRF and TPRF surrogates through 3D CFD simulations. 


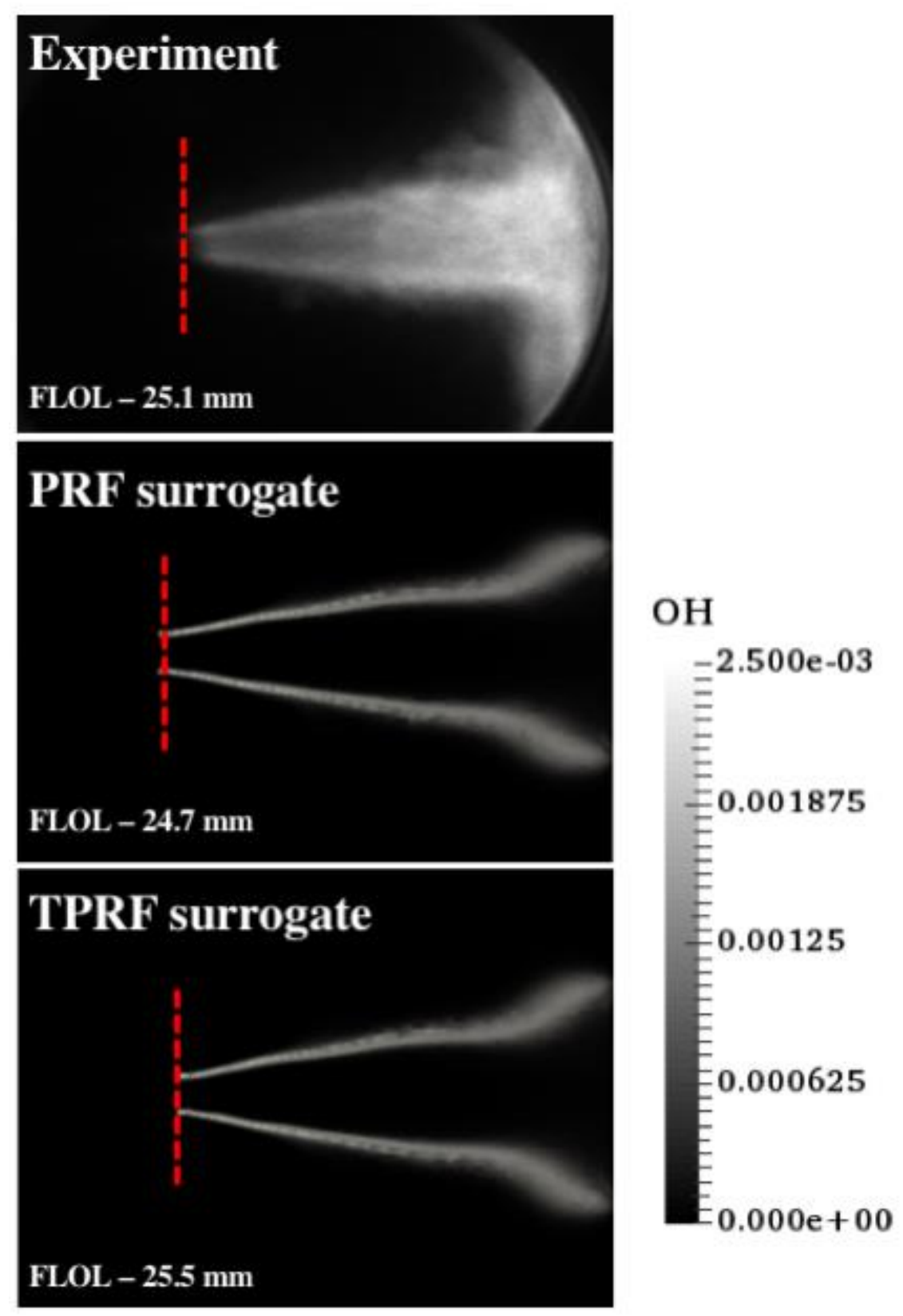

Figure 39. Flame lift of length validation of HSRN at ambient pressure of 60 bar using both PRF and TPRF surrogates through 3D CFD simulation.

\subsection{Engine related CFD simulations}

The accuracy of the presented reduced chemical kinetic model was further examined against engine experimental data. Closed-cycle simulations were performed here. The base mesh size used in this work was $4 \mathrm{~mm}$. The mesh was refined to $2 \mathrm{~mm}$ in a geometrical cylinder that contains the cylinder region. The cylinder region had additional embedding levels with the base grid size of $1 \mathrm{~mm}$. The mesh near the nozzle exit was further refined to $0.25 \mathrm{~mm}$ when during the injection process. In addition to 
these fixed embedding refinements, temperature and velocity AMR with an embedding level of 3 for each were implemented, resulting in the smallest grid size of $0.25 \mathrm{~mm}$ in the domain. This proved to produce grid independent solution for the simulated motored runs and hence the same mesh is utilized for the subsequent GCI cases. Similar grid was utilized by our group in recent works [43, 44, 75-77]. The current reduced TPRFE chemical kinetic models was used in this work. The prediction of NOx emissions was performed using the extended Zedovich thermal NOx model. The soot formation and oxidation were simulated through the two-step Hiroyasu-NSC (Nagle and Strickland-Constable) approach. Acetylene was considered as the inception species in the soot model.

This particular gasoline fuel was recently investigated by our group [14]. The ignition delay times of the gasoline fuel and its surrogates were measured using shock tubes and rapid compression machines. Three surrogates were developed for the RON91 gasoline. The first was ternary Toluene Primary Reference Fuel (TPRF), the second was quaternary TPRF plus ethanol (TPRFE) and the third was an eight-component surrogate. It was shown that the TPRFE successfully predicts the ignition delay times of the real gasoline at a wide range of conditions. As such, a TPRFE surrogate was formulated following the procedure in [78], yielding a mixture with 20 vol.\% n-heptane, 44.3 vol. $\%$ iso-octane, 27.5 vol.\% toluene and 8.2 vol.\% ethanol. The RON and MON of the TPRFE surrogate match those of the real fuel. In addition, the lower heating value of the TPRFE surrogate was changed to match the gasoline fuel and hence the same experimental fuel mass was used in the simulations.

The boundary and initial conditions listed in Table 3 are used in the engine simulations. For the closed-cycle simulations, the initial conditions at intake valve closing (IVC) were obtained from opencycle 3-D engine simulations. The measured (average of 300 cycles) and calculated in-cylinder pressure and heat release rate (HRR) profiles are presented in Figure 40. As can be seen from Figure 40, the onset of ignition is well captured by the current model but the peak pressure is under predicted. This is partly due to the fact that the experimental pressure profile is the average of 300 cycles. However, the agreement between the measured and calculated combustion phasing is very promising considering the difficulty in resolving the chemical kinetics leading to ignition at these engine 
operating conditions. The onset and magnitude of the heat release rate are also successfully predicted using the current model where low-temperature heat release prior to main combustion is observed from the calculations. This low-temperature heat release needs to be resolved correctly in order to successfully capture the ignition process which occurs at temperatures between $950 \mathrm{~K}$ to $1000 \mathrm{~K}$ at these engine conditions (not shown here).

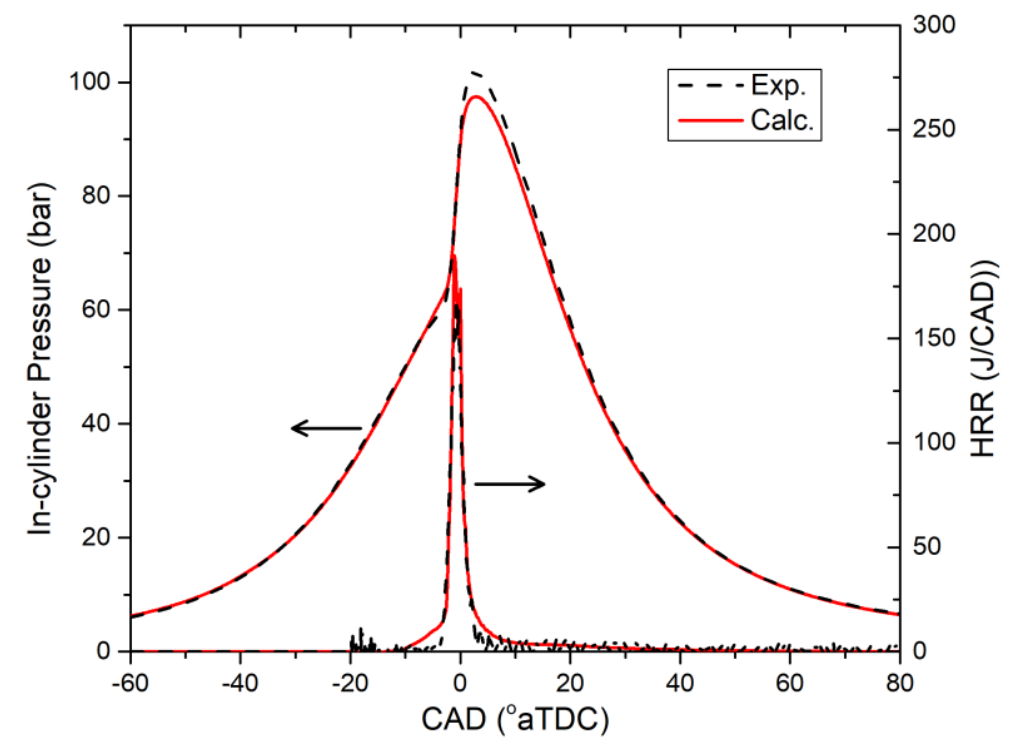

Figure 40. Measured and calculated in-cylinder pressures and temperatures.

\section{Conclusions}

This work presented a new reduced kinetic mechanism for four-component (toluene/n-heptane/isooctane/ethanol) gasoline surrogate fuels for efficient CFD applications. Stiffness analysis were performed using the computational singular perturbation (CSP) approach, and the results were compared to three literature models, demonstrating the successful stiffness removal of the mechanism. Sensitivity, rate of production (ROP) and flux analyses were also performed to demonstrate accurate predictability with such a highly reduced mechanism.

The mechanism was validated against wide range of IDT and FS data based on comprehensive literature reviews. Overall, good agreements were observed across the entire RON, equivalence ratio, 
pressure and temperature range. Specifically, the proposed model was found to have better performance on IDT validation compared with Wang's model, and on FS validation compared with Liu's model.

In addition, the mechanism was coupled with the computational fluid dynamic (CFD) models to simulate the experimental data of constant volume reacting spray of a low-octane gasoline (Haltermann straight-run naphtha), and in-cylinder pressures and temperatures of a high-octane gasoline (Haltermann gasoline) combustion in a heavy-duty compression ignition engine. The combined mechanism was shown to qualitatively predict the experimentally obtained data with an improved performance for PRF, TPRF, and TPRFE surrogate. A further improved multi-component surrogate model will be developed in future work.

\section{Acknowledgements}

The authors acknowledge the support from KAUST and Saudi Aramco under the FUELCOM project.

\section{Reference}

[1] T. Lu, C.K. Law, A directed relation graph method for mechanism reduction, Proceedings of the Combustion Institute 30 (2005) 1333-1341.

[2] T. Lu, M. Plomer, Z. Luo, S. Sarathy, W. Pitz, S. Som, D. Longman, Directed relation graph with expert knowledge for skeletal mechanism reduction, Lawrence Livermore National Lab.(LLNL), Livermore, CA (United States), 2011. [3] Y.-D. Liu, M. Jia, M.-Z. Xie, B. Pang, Development of a New Skeletal Chemical Kinetic Model of Toluene Reference Fuel with Application to Gasoline Surrogate Fuels for Computational Fluid Dynamics Engine Simulation, Energy \& Fuels 27 (2013) 4899-4909.

[4] H. Wang, M. Yao, Z. Yue, M. Jia, R.D. Reitz, A reduced toluene reference fuel chemical kinetic mechanism for combustion and polycyclic-aromatic hydrocarbon predictions, Combustion and Flame 162 (2015) 2390-2404.

[5] G. Kalghatgi, Is it really the end of internal combustion engines and petroleum in transport?, Applied Energy 225 (2018) 965-974.

[6] G. Kalghatgi, H. Levinsky, M. Colket, Future transportation fuels, Progress in Energy and Combustion Science 69 (2018) 103-105.

[7] S.M. Sarathy, A. Farooq, G.T. Kalghatgi, Recent progress in gasoline surrogate fuels, Progress in Energy and Combustion Science 65 (2018) 67-108.

[8] G. Kalghatgi, H. Babiker, J. Badra, A Simple Method to Predict Knock Using Toluene, N-Heptane and Iso-Octane Blends (TPRF) as Gasoline Surrogates, SAE International Journal of Engines 8 (2015) 505-519.

[9] N. Morgan, A. Smallbone, A. Bhave, M. Kraft, R. Cracknell, G. Kalghatgi, Mapping surrogate gasoline compositions into RON/MON space, Combustion and Flame 157 (2010) 1122-1131.

[10] A. Ahmed, G. Goteng, V.S.B. Shankar, K. Al-Qurashi, W.L. Roberts, S.M. Sarathy, A computational methodology for formulating gasoline surrogate fuels with accurate physical and chemical kinetic properties, Fuel 143 (2015) 290-300. 
[11] A.G. Abdul Jameel, N. Naser, G. Issayev, J. Touitou, M.K. Ghosh, A.-H. Emwas, A. Farooq, S. Dooley, S.M. Sarathy, A minimalist functional group (MFG) approach for surrogate fuel formulation, Combustion and Flame 192 (2018) 250-271.

[12] S.M. Sarathy, P. Oßwald, N. Hansen, K. Kohse-Höinghaus, Alcohol combustion chemistry, Progress in Energy and Combustion Science 44 (2014) 40-102.

[13] B. Zhang, S.M. Sarathy, Lifecycle optimized ethanol-gasoline blends for turbocharged engines, Applied Energy 181 (2016) 38-53.

[14] C. Lee, A. Ahmed, E.F. Nasir, J. Badra, G. Kalghatgi, S.M. Sarathy, H. Curran, A. Farooq, Autoignition characteristics of oxygenated gasolines, Combustion and Flame 186 (2017) 114-128.

[15] M. Sarathy, N. Atef, A. Alfazazi, J. Badra, Y. Zhang, T. Tzanetakis, Y. Pei, Reduced Gasoline Surrogate (Toluene/n-Heptane/iso-Octane) Chemical Kinetic Model for Compression Ignition Simulations, SAE International, 2018

[16] A. Alfazazi, U. Niemann, H. Selim, R.J. Cattolica, S.M. Sarathy, Effects of Substitution on Counterflow Ignition and Extinction of C3 and C4 Alcohols, Energy \& Fuels 30 (2016) 6091-6097.

[17] N. Atef, G. Kukkadapu, S.Y. Mohamed, M.A. Rashidi, C. Banyon, M. Mehl, K.A. Heufer, E.F. Nasir, A. Alfazazi, A.K. Das, C.K. Westbrook, W.J. Pitz, T. Lu, A. Farooq, C.-J. Sung, H.J. Curran, S.M. Sarathy, A comprehensive iso-octane combustion model with improved thermochemistry and chemical kinetics, Combustion and Flame 178 (2017) 111-134.

[18] M.J. Al Rashidi, J.C. Mármol, C. Banyon, M.B. Sajid, M. Mehl, W.J. Pitz, S. Mohamed, A. Alfazazi, T. Lu, H.J. Curran, A. Farooq, S.M. Sarathy, Cyclopentane combustion. Part II. Ignition delay measurements and mechanism validation, Combustion and Flame 183 (2017) 372-385.

[19] S.H. Lam, D.A. Goussis, Understanding complex chemical kinetics with computational singular perturbation, Symposium (International) on Combustion 22 (1989) 931-941.

[20] A. Massias, D. Diamantis, E. Mastorakos, D.A. Goussis, An algorithm for the construction of global reduced mechanisms with CSP data, Combustion and Flame 117 (1999) 685-708.

[21] P. Koniavitis, S. Rigopoulos, W.P. Jones, Reduction of a detailed chemical mechanism for a kerosene surrogate via RCCE-CSP, Combustion and Flame 194 (2018) 85-106.

[22] J. Prager, H.N. Najm, M. Valorani, D.A. Goussis, Skeletal mechanism generation with CSP and validation for premixed n-heptane flames, Proceedings of the Combustion Institute 32 (2009) 509-517.

[23] E.-A. Tingas, D.J. Diamantis, D.A. Goussis, Issues arising in the construction of QSSA mechanisms: the case of reduced n-heptane/air models for premixed flames, Combustion Theory and Modelling 22 (2018) 1049-1083.

[24] E.A. Tingas, D.C. Kyritsis, D.A. Goussis, Autoignition dynamics of DME/air and EtOH/air homogeneous mixtures, Combustion and Flame 162 (2015) 3263-3276.

[25] D.M. Manias, E.A. Tingas, C.E. Frouzakis, K. Boulouchos, D.A. Goussis, The mechanism by which $\mathrm{CH} 2 \mathrm{O}$ and $\mathrm{H} 2 \mathrm{O} 2$ additives affect the autoignition of CH4/air mixtures, Combustion and Flame 164 (2016) 111-125.

[26] M. Jaasim, E.-A. Tingas, F.E. Hernández Pérez, H.G. Im, Computational singular perturbation analysis of superknock in SI engines, Fuel 225 (2018) 184-191.

[27] E.A. Tingas, D.M. Manias, S. Mani Sarathy, D.A. Goussis, CH4/air homogeneous autoignition: A comparison of two chemical kinetics mechanisms, Fuel 223 (2018) 74-85.

[28] E.A. Tingas, H.G. Im, D.C. Kyritsis, D.A. Goussis, The use of CO2 as an additive for ignition delay and pollutant control in CH4/air autoignition, Fuel 211 (2018) 898-905.

[29] E.-A. Tingas, Z. Wang, S. Mani Sarathy, H.G. Im, D.A. Goussis, Chemical kinetic insights into the ignition dynamics of n-hexane, Combustion and Flame 188 (2018) 28-40.

[30] E.-A. Tingas, D.C. Kyritsis, D.A. Goussis, Comparative investigation of homogeneous autoignition of DME/air and EtOH/air mixtures at low initial temperatures, Combustion Theory and Modelling 21 (2017) 93-119.

[31] S.M. Sarathy, E.-A. Tingas, E.F. Nasir, A. Detogni, Z. Wang, A. Farooq, H. Im, Three-stage heat release in nheptane auto-ignition, Proceedings of the Combustion Institute, doi:https://doi.org/10.1016/j.proci.2018.07.075(2018).

[32] E.A. Tingas, D.C. Kyritsis, D.A. Goussis, Algorithmic determination of the mechanism through which H2Odilution affects autoignition dynamics and NO formation in CH4/air mixtures, Fuel 183 (2016) 90-98.

[33] E.A. Tingas, D.C. Kyritsis, D.A. Goussis, Ignition delay control of DME/air and EtOH/air homogeneous autoignition with the use of various additives, Fuel 169 (2016) 15-24.

[34] J. Prager, H.N. Najm, M. Valorani, D.A. Goussis, Structure of n-heptane/air triple flames in partially-premixed mixing layers, Combustion and Flame 158 (2011) 2128-2144.

[35] M. Valorani, H.N. Najm, D.A. Goussis, CSP analysis of a transient flame-vortex interaction: time scales and manifolds, Combustion and Flame 134 (2003) 35-53.

[36] W. Song, E.-A. Tingas, H.G. Im, A computational analysis of methanol autoignition enhancement by dimethyl ether addition in a counterflow mixing layer, Combustion and Flame 195 (2018) 84-98. 
[37] D.M. Manias, E.-A. Tingas, F.E. Hernández Pérez, R. Malpica Galassi, P. Paolo Ciottoli, M. Valorani, H.G. Im, Investigation of the turbulent flame structure and topology at different Karlovitz numbers using the tangential stretching rate index, Combustion and Flame 200 (2019) 155-167.

[38]

D. Manias, A.-E. Tingas, F.E. Hernandez Perez, H.G. Im, R.M. Galassi, P.P. Ciottoli, M. Valorani. Analysis of Hydrogen/Air Turbulent Premixed Flames at Different Karlovitz Numbers Using Computational Singular Perturbation. In: editor^editors. 2018 AIAA Aerospace Sciences Meeting; 2018. p. 0364.

[39] J. Zhang, M. Tang, T. Menucci, H. Schmidt, S.-Y. Lee, J. Naber, T. Tzanetakis, Experimental Investigation of Spray Characteristics of High Reactivity Gasoline and Diesel Fuel Using a Heavy-Duty Injector, Part II: NonReacting, Vaporizing Spray, ILASS-Americas 29th Annual Conference on Liquid Atomization and Spray Systems, (2017).

[40] M. Tang, J. Zhang, T. Menucci, H. Schmidt, J. Naber, S.-Y. Lee, T. Tzanetakis, Experimental Spray Ignition and Soot Forming Characteristics of High Reactivity Gasoline and Diesel Fuel in a Heavy-Duty Single-Hole Injector, 10th U.S. National Combustion Meeting, (2017).

[41] B. Mohan, M.J. Mubarak Ali, A. Ahmed, F. Hernandez Perez, J. Sim, W. Roberts, M. Sarathy, H. Im, Numerical Simulations of High Reactivity Gasoline Fuel Sprays under Vaporizing and Reactive Conditions, SAE International, 2018.

[42] Y. Pei, R. Torelli, T. Tzanetakis, Y. Zhang, M. Traver, D.J. Cleary, S. Som, Modeling the Fuel Spray of a High Reactivity Gasoline Under Heavy-Duty Diesel Engine Conditions, doi:10.1115/ICEF2017-3530(2017) V002T006A002.

[43] J. Badra, R. Bakor, A. AlRamadan, M. Almansour, J. Sim, A. Ahmed, Y. Viollet, J. Chang, Standardized Gasoline Compression Ignition Fuels Matrix, SAE International, 2018.

[44] J.A. Badra, J. Sim, Y. Viollet, Y. Zhang, N. Engineer, J. Chang, CFD Guided Gasoline Compression Ignition Engine Calibration, doi:10.1115/ICEF2017-3583(2017) V002T006A012.

[45] K. Richards, P. Senecal, E. Pomraning, CONVERGE (Version 2.2. 0) Manual, Convergent Science, Inc., Madison, WI, (2014).

[46] R.D. Reitz, R. Diwakar, Structure of High-Pressure Fuel Sprays, SAE International, 1987.

[47] D. Duke, A. L. Kastengren, K. Matusik, A. Swantek, C. F. Powell, R. Payri, D. Vaquerizo, L. Itani, G. Bruneaux, Ronald O. Grover, Jr., S. Parrish, L. Markle, D. Schmidt, J. Manin, S. A. Skeen, L. M. Pickett, Internal and Near Nozzle Measurements of Engine Combustion Network "Spray G" Gasoline Direct Injectors, 2017.

[48] K. Zhang, C. Banyon, J. Bugler, H.J. Curran, A. Rodriguez, O. Herbinet, F. Battin-Leclerc, C. B'Chir, K.A. Heufer, An updated experimental and kinetic modeling study of n-heptane oxidation, Combustion and Flame 172 (2016) 116-135.

[49] Y. Zhang, K.P. Somers, M. Mehl, W.J. Pitz, R.F. Cracknell, H.J. Curran, Probing the antagonistic effect of toluene as a component in surrogate fuel models at low temperatures and high pressures. A case study of toluene/dimethyl ether mixtures, Proceedings of the Combustion Institute 36 (2017) 413-421.

[50] L.R. Cancino, M. Fikri, A.A.M. Oliveira, C. Schulz, Measurement and Chemical Kinetics Modeling of ShockInduced Ignition of Ethanol-Air Mixtures, Energy \& Fuels 24 (2010) 2830-2840.

[51] Y. Zhang, H. El-Merhubi, B. Lefort, L. Le Moyne, H.J. Curran, A. Kéromnès, Probing the low-temperature chemistry of ethanol via the addition of dimethyl ether, Combustion and Flame 190 (2018) 74-86.

[52] M. AlAbbad, T. Javed, F. Khaled, J. Badra, A. Farooq, Ignition delay time measurements of primary reference fuel blends, Combustion and Flame 178 (2017) 205-216.

[53] S.M. Sarathy, G. Kukkadapu, M. Mehl, W. Wang, T. Javed, S. Park, M.A. Oehlschlaeger, A. Farooq, W.J. Pitz, C.-J. Sung, Ignition of alkane-rich FACE gasoline fuels and their surrogate mixtures, Proceedings of the Combustion Institute 35 (2015) 249-257.

[54] T. Javed, C. Lee, M. AlAbbad, K. Djebbi, M. Beshir, J. Badra, H. Curran, A. Farooq, Ignition studies of nheptane/iso-octane/toluene blends, Combustion and Flame 171 (2016) 223-233.

[55] L.R. Cancino, M. Fikri, A.A.M. Oliveira, C. Schulz, Ignition delay times of ethanol-containing multi-component gasoline surrogates: Shock-tube experiments and detailed modeling, Fuel 90 (2011) 1238-1244.

[56] L.R. Cancino, M. Fikri, A.A.M. Oliveira, C. Schulz, Autoignition of gasoline surrogate mixtures at intermediate temperatures and high pressures: Experimental and numerical approaches, Proceedings of the Combustion Institute 32 (2009) 501-508.

[57] M. Alabbad, G. Issayev, J. Badra, A.K. Voice, B.R. Giri, K. Djebbi, A. Ahmed, S.M. Sarathy, A. Farooq, Autoignition of straight-run naphtha: A promising fuel for advanced compression ignition engines, Combustion and Flame 189 (2018) 337-346.

[58] M. AlAbbad, J. Badra, K. Djebbi, A. Farooq, Ignition delay measurements of a low-octane gasoline blend, designed for gasoline compression ignition (GCI) engines, Proceedings of the Combustion Institute, doi:https://doi.org/10.1016/j.proci.2018.05.097(2018).

[59] K. Kumar, J.E. Freeh, C.J. Sung, Y. Huang, Laminar Flame Speeds of Preheated iso-Octane/O2/N2 and nHeptane/O2/N2 Mixtures, Journal of Propulsion and Power 23 (2007) 428-436. 
[60] S.G. Davis, C.K. Law, Determination of and Fuel Structure Effects on Laminar Flame Speeds of C1 to C8 Hydrocarbons, Combustion Science and Technology 140 (1998) 427-449.

[61] Y. Huang, C.J. Sung, J.A. Eng, Laminar flame speeds of primary reference fuels and reformer gas mixtures, Combustion and Flame 139 (2004) 239-251.

[62] A.P. Kelley, A.J. Smallbone, D.L. Zhu, C.K. Law, Laminar flame speeds of C5 to C8n-alkanes at elevated pressures: Experimental determination, fuel similarity, and stretch sensitivity, Proceedings of the Combustion Institute 33 (2011) 963-970.

[63] J.P.J. van Lipzig, E.J.K. Nilsson, L.P.H. de Goey, A.A. Konnov, Laminar burning velocities of n-heptane, isooctane, ethanol and their binary and tertiary mixtures, Fuel 90 (2011) 2773-2781.

[64] D. Bradley, R.A. Hicks, M. Lawes, C.G.W. Sheppard, R. Woolley, The Measurement of Laminar Burning Velocities and Markstein Numbers for Iso-octane-Air and Iso-octane-n-Heptane-Air Mixtures at Elevated Temperatures and Pressures in an Explosion Bomb, Combustion and Flame 115 (1998) 126-144.

[65] S. Jerzembeck, N. Peters, P. Pepiot-Desjardins, H. Pitsch, Laminar burning velocities at high pressure for primary reference fuels and gasoline: Experimental and numerical investigation, Combustion and Flame 156 (2009) $292-301$.

[66] F. Halter, T. Tahtouh, C. Mounaïm-Rousselle, Nonlinear effects of stretch on the flame front propagation, Combustion and Flame 157 (2010) 1825-1832.

[67] C. Ji, E. Dames, Y.L. Wang, H. Wang, F.N. Egolfopoulos, Propagation and extinction of premixed C5-C12nalkane flames, Combustion and Flame 157 (2010) 277-287.

[68] A.J. Smallbone, W. Liu, C.K. Law, X.Q. You, H. Wang, Experimental and modeling study of laminar flame speed and non-premixed counterflow ignition of n-heptane, Proceedings of the Combustion Institute 32 (2009) 12451252.

[69] T. Hirasawa, C.J. Sung, A. Joshi, Z. Yang, H. Wang, C.K. Law, Determination of laminar flame speeds using digital particle image velocimetry: Binary Fuel blends of ethylene, n-Butane, and toluene, Proceedings of the Combustion Institute 29 (2002) 1427-1434.

[70] E. Varea, V. Modica, A. Vandel, B. Renou, Measurement of laminar burning velocity and Markstein length relative to fresh gases using a new postprocessing procedure: Application to laminar spherical flames for methane, ethanol and isooctane/air mixtures, Combustion and Flame 159 (2012) 577-590.

[71] P.S. Veloo, Y.L. Wang, F.N. Egolfopoulos, C.K. Westbrook, A comparative experimental and computational study of methanol, ethanol, and n-butanol flames, Combustion and Flame 157 (2010) 1989-2004.

[72] ANSYS Chemkin 19.1, (2018).

[73] ECN4 TOPIC 5 - COMBUSTION SUBMISSION GUIDELINES, Engine Combustion Network 4th Workshop, ECN4: Kyoto Japan, September 5-6, 2015, after the JSAE/SAE 2015 International Powertrains, Fuels \& Lubricants Meeting, (2015).

[74] A.J. Donkerbroek, M.D. Boot, C.C.M. Luijten, N.J. Dam, J.J. ter Meulen, Flame lift-off length and soot production of oxygenated fuels in relation with ignition delay in a DI heavy-duty diesel engine, Combustion and Flame 158 (2011) 525-538.

[75] J. Badra, A. Elwardany, J. Sim, Y. Viollet, H. Im, J. Chang, Effects of In-Cylinder Mixing on Low Octane Gasoline Compression Ignition Combustion, SAE International, 2016.

[76] J.A. Badra, J. Sim, A. Elwardany, M. Jaasim, Y. Viollet, J. Chang, A. Amer, H.G. Im, Numerical Simulations of Hollow-Cone Injection and Gasoline Compression Ignition Combustion With Naphtha Fuels, Journal of Energy Resources Technology 138 (2016) 052202-052202-052211.

[77] J. Badra, Y. Viollet, A. Elwardany, H.G. Im, J. Chang, Physical and chemical effects of low octane gasoline fuels on compression ignition combustion, Applied Energy 183 (2016) 1197-1208.

[78] J. Badra, A.S. AlRamadan, S.M. Sarathy, Optimization of the octane response of gasoline/ethanol blends, Applied Energy 203 (2017) 778-793. 